\section{Resúmenes de los Trabajos Libres del LXXIII Congreso de Neumología y Cirugía de Tórax (Querétaro, Qro., 2014)*}

\section{ORALES}

\section{4}

Fisiología pulmonar en
pacientes obesos con
trastornos respiratorios del
dormir

Bautista HD, Díaz R, Septién S.

Hospital General de México

Descripción: La obesidad es un problema de salud pública a nivel mundial y altamente prevalente en nuestro país, afectando a más del 50\% de la población adulta. Puede alterar de forma significativa la fisiología y mecánica pulmonar. La apnea obstructiva del sueño se asocia a la obesidad, y en etapas avanzadas a alteraciones en el intercambio gaseoso. El objetivo es describir las alteraciones

\footnotetext{
* La transcripción de los resúmenes es responsabilidad de los propios autores y de acuerdo con las indicaciones y numeración otorgada por el Comité Científico de la Sociedad Mexicana de Neumología y Cirugía de Tórax.
}

en la fisiología pulmonar de los pacientes enviados a la Clínica de Sueño de nuestra institución. Material y métodos: Estudio observacional, descriptivo, transversal. Se incluyeron a todos los pacientes referidos a la Clínica de sueño en el período 20102013. Se utilizó estadística descriptiva. Los resultados se presentan en medias y desviación estándar. La asociación entre variables cuantitativas se estudió mediante coeficiente de correlación de Pearson. Se utilizó el programa SPSS 22.0. Resultados: Se incluyeron en el estudio a 303 pacientes. Se realizaron pletismografía a 111 pacientes, espirometría a 280 pacientes, gasometría a 68 pacientes y oximetría de pulso a 275 pacientes. Se observó correlación positiva con $\mathrm{r}=0.39(\mathrm{p}<0.01)$ entre el índice de masa corporal (IMC) y la capacidad residual funcional (CRF). No hubo correlación significativa entre el IMC con la capacidad vital, capacidad pulmonar total, volumen exhalado forzado en el primer segundo ni la capacidad vital forzada. Se observaron correlaciones significativas entre el índice de apnea-hipopnea y la saturación por oximetría de pulso ( $\mathrm{SO}_{2} \mathrm{Ox}$ ), la saturación de oxígeno mínima durante la polisomnografía $\left(\mathrm{SO}_{2} \mathrm{~min}\right)$ y la capacidad vital forzada como porcentaje del predicho $(\mathrm{p}<0.01)$. $\mathrm{La} \mathrm{SO}_{2}$ ox se correlacionó con la $\mathrm{SO}_{2}$ min y la presión parcial de $\mathrm{CO}_{2}(\mathrm{p}<0.01)$. Conclusiones: No se observó influencia de la obesidad sobre la mecánica ventilatoria. La gravedad de la apnea de sueño tiene impacto importante en el intercambio gaseoso de los pacientes.

\section{7}

La espirometría

\section{Galván CRM}

INER Ismael Cosío Villegas

Antecedentes: La espirometría forzada constituye el estándar de oro en la eva- luación de los pacientes con asma, y con la cual se diagnostica el patrón funcional obstructivo. Una de las desventajas de esta maniobra es que es dependiente del esfuerzo del paciente. Una variante es la espirometría lenta, la cual ha demostrado ser útil en la evaluación de pacientes poco cooperadores. Material y métodos: Estudio transversal. Se incluyeron niños procedentes de la consulta externa de Neumología Pediátrica con diagnóstico de asma en diferentes grados de control. Posterior a obtener el consentimiento informado por parte de los padres, se registraron los datos generales, peso, talla y el cuestionario de control de asma (ACT) modificado para niños. Se les realizó espirometría lenta y forzada (Easy One Pro) antes y después de broncodilatador de acuerdo a las recomendaciones ATS/ ERS 2005. Resultados: Se incluyeron un total de 32 pacientes con asma, de éstos $27(84.3 \%)$ eran del sexo masculino, 25 (78.1\%) presentaban un mal control por cuestionario ACT. Los índices $\mathrm{FEV}_{1}$ / FVC y $\mathrm{FEV}_{1} / \mathrm{SVC}$ fueron menores al límite inferior de la normalidad en 27 pacientes (84.3\%); asimismo, el índice IC/SVC mostró obstrucción a partir del límite inferior de la normalidad en 24 (75\%) pacientes. No hubo diferencias significativas entre la FVC y la SVC ni antes ni después del broncodilatador, en el análisis de correlación y concordancia entre ambos parámetros se obtuvo una $\mathrm{r}=0.97$ ( $\mathrm{p}<0.0001)$ y un coeficiente de correlación de concordancia, $\mathrm{CCC}=0.97$, media de las diferencias 0.019 L (+0.179 DE) y límites de acuerdo de -0.331 a 0.369 L. Se realizó una regresión para obtener $\mathrm{FEV}_{1}$ a partir de IC y obtener la siguiente fórmula: $\mathrm{FEV}_{1}=-0.2762107+(\mathrm{IC} * 1.222129)$, con r2 $=0.86$. Conclusiones: La función pulmonar fue semejante independientemente del cuestionario ACT. El FEV ${ }_{1}$ puede ser estimado a partir de parámetros obtenidos en la espirometría lenta. 
08

Efecto de una

concentración baja de oxígeno sobre la viabilidad de las células epiteliales A549 y fibroblastos de pulmón. Resultados preliminares

\section{Aquino GA, González Á, Sommer C, Delgado T, Gutiérrez G.}

INER Ismael Cosío Villegas

Introducción: La hipoxia, como condición estresante, puede comprometer la viabilidad celular, induciendo apoptosis, senescencia, citotoxicidad o transición epitelial-mesénquima. Algunos reportes indican que los fibroblastos son resistentes a la hipoxia, logrando aumentar incluso su tasa proliferativa. Objetivo: Evaluar la viabilidad de dos líneas celulares de pulmón (A549 y fibroblastos N-04) bajo condiciones de hipoxia. Metodología: En forma separada, de ambos tipos celulares (A549 y fibroblastos N-04), se sembraron 15,000 células por pozo en placas de 48 pozos, se incubaron a $37{ }^{\circ} \mathrm{C}$ en cámaras de hipoxia (Billups-Rothenberg MIC-101, California, EUA) al 1\% de oxígeno (nitrógeno $95 \%$ y $\mathrm{CO}_{2} 5 \%$ ), Se empleó medio DMEM y Ham F-12n respectivamente, enriquecidos con suero fetal bovino (10\%), $200 \mathrm{U} / \mathrm{mL}$ de penicilina y $200 \mathrm{U} / \mathrm{mL}$ de estreptomicina. Se incubaron a las 3, 6, $9,12,24,48$ y 72 horas comparándose la viabilidad celular contra células cultivadas en normoxia (5\% de $\mathrm{CO}_{2}$ y $95 \%$ de aire). Después de incubar, las células fueron contadas por el método de exclusión de la eritrosina B. Resultados: Hubo diferencias significativas en la viabilidad de las células A549 cultivadas al 1\% de oxígeno respecto a las células cultivadas en condiciones de normoxia a las 48 horas ( $\mathrm{p}=$ $0.027)$ y a las 72 horas ( $p=0.009)$. Se observó una disminución progresiva $(30 \%)$ de la viabilidad de las A549 en hipoxia a las 72 horas. Los fibroblastos pulmonares en hipoxia disminuyeron su viabilidad a las 3 horas; a las $24 \mathrm{~h}$ la viabilidad no se afectó e incrementó por arriba del $100 \%$ a las $48 \mathrm{~h}$, por lo que en los fibroblastos pulmonares no se vio afectada la viabilidad celular, observándose que incluso crecen más que los fibroblastos que se cultivan en condiciones de normoxia. Conclusión: Las células A549 son más sensibles a la hipoxia que los fibroblastos de pulmón.

11 Proteína Nef como
promotora de hipertensión
arterial pulmonar
asociada al virus de
inmunodeficiencia humana

Sandoval GJL, Rodríguez S, Rivera RM, Sevilla RE, Flores MF, Reyes TG

INER Ismael Cosío Villegas

Descripción: En años recientes se ha observado el papel patogénico del virus de inmunodeficiencia humana (VIH) en las manifestaciones clínicas de la hipertensión arterial pulmonar (HAP), que ocurre en cualquier estadio de la enfermedad. HAP-VIH tienen manifestaciones histológicas que son indistinguibles a las encontradas en la hipertensión 5 arterial pulmonar idiopática. El papel pleiotrópico de las proteínas virales como Nef en el desarrollo de lesiones plexiformes en la HAP-VIH aún no se ha explorado. Hipótesis: La proteína Nef se encuentra presente en el endotelio vascular de los pacientes con HAP/VIH y provoca severidad en el grado de presentación de la HAP/VIH. Objetivo: Identificar la presencia de proteína Nef en células de endotelio vascular de pacientes fallecidos con HAP/VIH. Métodos: Se analizaron tejidos de arteria pulmonar obtenidos de necropsia de 30 pacientes fallecidos por VIH que tenían HAP mediante inmunohistoquímica de proteína Nef y medición por quimioluminescencia de la misma, mediante el procesador de imágenes proporcionado por los institutos nacionales de salud de Estados Unidos (imagej: http://rsbweb.nih.gov/ij/), se utilizaron necropsias de 5 pacientes con EPOC-HAP- no VIH como grupo control. Resultados: Se encontraron grados variables de HAP en las muestras de tejido de arteria pulmonar analizadas por detección de proteína Nef en el endotelio de arteria pulmonar, en todas ellas se observó mayor quimioluminiescencia en los cortes de mayor grado de severidad de la HAP. Conclusiones: La proteína Nef se encuentra en las células endoteliales de complejos vasculares de pacientes con HAP-VIH, la concentración está asociada con la severidad del cuadro de HAP.

12

\section{$\mathrm{N}$-acetilcistina como tratamiento adyuvante de la neumonitis por hipersensibilidad}

\section{Buendía I, Vicens Z, Vargas D, Estrada G, Mejía Á.}

INER Ismael Cosío Villegas

Introducción: La N-acetilcisteína (NAC) ha sido utilizada como parte del tratamiento de la fibrosis pulmonar, el mecanismo de acción propuesto es que desintoxica sustancias mediante la oxidación de glutatión, retrasa el deterioro de la capacidad vital y mantiene los valores de difusión de monóxido de carbono, además, aminora los efectos mielotóxicos de la azatioprina. En un estudio preliminar reportado por este grupo se encontró una tendencia hacia una mejoría en la evolución de la FVC y la saturación de oxígeno en pacientes que recibían triple terapia para neumonitis por hipersensibilidad (prednisona, azatioprina y NAC). Objetivo: Determinar el efecto de NAC (600 mg cada $8 \mathrm{~h}$ ) como adyuvante en el tratamiento de neumonitis por hipersensibilidad. Métodos: Se incluyeron 90 pacientes con diagnóstico por consenso de neumonitis por hipersensibilidad subaguda corroborado con tomografía de tórax de alta resolución, descartando la posibilidad de fibrosis pulmonar idiopática. Se dividieron aleatoriamente en dos grupos: el primero recibió azatioprina+prednisona (45 pacientes) y el segundo azatioprina+prednisona+NAC (45 pacientes), su evolución fue evaluada a los seis meses con pruebas de función respiratoria. Resultados: La FVC y la saturación de oxígeno en ejercicio no mostraron diferencias significativas en los 
dos grupos; sin embargo, se encontró una tendencia a la mejoría de la saturación en reposo en el grupo de pacientes que recibió $\mathrm{NAC}(\mathrm{SatO}$, reposo $82.7 \% \pm 14.7 / 83.6 \%$ \pm 8 ). Conclusiones: La evolución de las pruebas de función respiratoria en pacientes con neumonitis por hipersensibilidad subaguda, no presenta mejoría significativa al agregar como adyuvante NAC.

\section{3}

\section{Utilidad del ultrasonido pulmonar en pacientes con enfermedad pulmonar intersticial difusa secundaria a enfermedades reumáticas}

Navarro GMC, Mejía Á, Buendía R, Gaxiola G, Pineda V, Selman L

INER Ismael Cosío Villegas

Descripción: La enfermedad pulmonar intersticial difusa (EPID) es una manifestación frecuente y mortal en enfermedades reumáticas generalizadas (ERG). La tomografía axial computarizada de alta resolución (TACAR) es considerado el «Gold Standard» para el diagnóstico y seguimiento de padecimientos fibrosantes del pulmón; aunque, no siempre es accesible a cierta población. Se ha reportado que el ultrasonido de tórax puede ser útil para documentar y cuantificar el daño pulmonar ocasionado por edema o fibrosis, sin embargo, ha sido poco explorado. Hipótesis: El ultrasonido pulmonar puede ayudar en el diagnóstico de EPID en pacientes con ERG. Objetivo: Comparar los hallazgos del ultrasonido pulmonar con los datos de TACAR en pacientes con EPID. Material y métodos: Se incluyeron 28 pacientes con EPID. A todos se les realizó espirometría, prueba de caminata de 6 min y ultrasonido pulmonar con método simplificado, se realizó cuantificación del número de imágenes «en cometa» apreciados por USG, se reportó un puntaje arbitrario de cometas y éste se comparó con los hallazgos del grado de fibrosis e inflamación reportados por TACAR o en el estudio histopatológico. Resultados: Se estudiaron 7 pacientes con síndrome de Sjögren (6 $q$ con 55 años pro- medio), 7 pacientes con artritis reumatoide ( $7 q$ con 58.7 años promedio), 5 pacientes con neumonitis por hipersensibilidad $(5 \circ$ con 56.4 años promedio) y 9 pacientes con fibrosis pulmonar idiopática ( 9 $ぇ$ con 61.4 años promedio). Diez pacientes del grupo total tenían biopsia pulmonar. La correlación del grado de fibrosis e inflamación fue el siguiente: Fibrosis TACAR/USG 0.7999; Inflamación TACAR/USG -0.090; Fibrosis biopsia/USG 0.481; Inflamación biopsia/ USG -0.481; Fibrosis biopsia/TACAR

0.31; Inflamación biopsia/TACAR 0.51. Conclusiones: Existe correlación entre la presencia de cometas pulmonares detectados por USG y los datos de fibrosis reportados en TACAR y/o biopsia pulmonar. Este procedimiento podría ser útil para el seguimiento de pacientes con EPID-ERG.

\section{5}

\section{Valoración de peso corporal de pacientes con enfermedades intersticiales}

Buendía I, Escobar S, Mateos T, Estrada G, Vargas D, Barreto R, Mejía Á

INER Ismael Cosío Villegas

Descripción: Las enfermedades pulmonares intersticiales (EPID) representan un grupo amplio y heterogéneo de padecimientos no neoplásicos ni infecciosos que afectan al parénquima pulmonar, con grados variables de inflamación y fibrosis. En pacientes con este padecimiento, los estudios del estado nutricional son escasos, se ha reportado que cuando las EPID progresan es común la pérdida de apetito y peso, por lo que la desnutrición en estadios avanzados ocurre con frecuencia. Objetivo: Determinar el estado del peso corporal de pacientes con EPID. Material y métodos: Estudio observacional en las cohortes de neumonitis por hipersensibilidad(NH), fibrosis pulmonar idiopática (FPI) y neumonitis secundaria a enfermedades colágeno-vasculares (NECV) del INER, período 2007-2011, evaluando el peso corporal a través del índice de masa corporal (IMC), utilizando la clasificación de sobrepeso y obesidad propuesta por la OMS. Resultados: Se estudiaron 99 pacientes con diagnóstico de NH (87), 127 con FPI y 101 pacientes con N-ECV, en los
3 grupos predominaron: peso normal (NH $36 \%$, FPI $45 \%$ y N-ECV 35\%) y sobrepeso (NH 31\%, FPI 35\%, N-ECV 35\%), seguido de obesidad grado I (NH 18\%, FPI 13\%, N-ECV 19\%). El menor porcentaje en los 3 grupos fue bajo peso (NH 3\%, FPI 1\%, N-ECV 4\%). No se encontró una relación con el tiempo de evolución y el IMC. Conclusiones: De acuerdo a estos resultados, el incremento en el problema de sobrepeso y obesidad que se ha reportado en diferentes enfermedades debe ser estudiado también en enfermedades intersticiales, ya que el bajo peso reportado en otros estudios fue lo menos frecuente. Debido a las complicaciones que origina el sobrepeso y obesidad, debe realizarse como parte del protocolo de estudio la evaluación nutricional, seguimiento y modificaciones dietéticas que permitan mantener al paciente en peso ideal.

17

Síndrome de apnea compleja del sueño: Utilidad de la titulación CPAP/BPAP evaluados con registros video polisomnográficos

Pella CV, Alanis G, Vázquez R, Pérez L

Clínica de Epilepsia y Sueño, Hospital Ángeles Pedregal, México, D.F.

Descripción: El síndrome de apnea compleja del sueño (SACS) se caracteriza por la aparición de apneas centrales y/ o respiración de Cheyne Stokes, posterior a la titulación con CPAP. Actualmente se propone la utilización de la servo ventilación (ASV). El presente trabajo pretende demostrar la diferencia de respuesta demostrada con VPSG, la utilidad del CPAP vs. BPAP como la mejor alternativa de tratamiento. Material y métodos: Estudio descriptivo, retrospectivo, transversal de 195 pacientes con SAHS, 14 pacientes titulados con CPAP y 14 con BPAP, de la Clínica del Sueño, Hospital Ángeles del Pedregal, Ciudad de México. Resultados: El 89\% (n25) fueron hombres, la edad media fue 58 años, 32\% (n9) mayores de 65 años. Se utilizó protocolo AAMS (JCSM 2008), noche dividida, la presión promedio del CPAP $8 \mathrm{~cm} \mathrm{H}_{2} \mathrm{O}$, 
BPAP media IPAP 9 EPAP $6 \mathrm{~cm} \mathrm{H}_{2} 0$. La prevalencia SACS fue de $14.3 \%$. Comorbilidad: hipertensión arterial en $73 \%$ (n19), enfermedad cardíaca 30\%, DM2 en $11 \%$, IMC sobrepeso u obesidad $82 \%$ (n23); escala Mallampati con grado III-IV en $75 \%$ (n21). Sin tratamiento (ST): Eficacia del sueño $70 \%$, índice de apnea hipopnea (IAH) 69/H, grado severo $86 \%$ (n24). Síndrome de apnea hipopnea obstructiva del sueño (SAHOS) 50\%, síndrome de apnea central $45 \%$, apnea mixta $53.5 \%$ (15), arousals $94 \%$, PLMS 100\% (28). Con VPSG titulación: CPAP eficacia del sueño 88\%, IAH 26xhxs. Severa y moderada $36 \%$, apnea central (SAC) $100 \%$ (14), obstructiva (SAOS) 64\% (9), Cheyne Stokes (RCS) 57\% (8). BPAP: Eficacia del sueño $75 \%$, IAH 17xhxs, severa $14 \%$, moderada $29 \%$, SAHOS $28 \%$ (8), SAC 28\% (8), RCS 21\% (6). Conclusión: La apnea obstructiva severa desaparece con ambos tratamientos, persistiendo en grado moderado en un quinto de nuestra población con un mejor resultado a expensas de CPAP $14 \%$ vs. BPAP 21\%. La apnea severa, en general, presenta una mejoría notable con CPAP (36\%) comparado con BIPAP (50\%).

\section{8}

Estudio comparativo de pacientes con enfermedad pulmonar obstructiva crónica (EPOC) secundaria a tabaquismo vs. exposición a humo
de leña hospitalizados
en el Instituto Nacional
de Enfermedades
Respiratorias Ismael Cosío
Villegas en el período
enero 2012-junio 2013

\section{Escobar PMA}

INER Ismael Cosío Villegas

Antecedentes: La prevalencia de EPOC a nivel mundial es de 3-6\% en mayores de 50 años. En México es la 4ta. causa de morbimortalidad y va en aumento, en el 2025 será la 3ra. causa de morta- lidad, representando una mayor carga económica calculada entre el 7-15\% del gasto sanitario. El presente trabajo intenta identificar las características del paciente con EPOC secundario a las principales etiologías. Material y métodos: Pacientes hospitalizados con diagnóstico de EPOC, según la definición de GOLD secundario a tabaquismo y exposición al humo de leña corroborado por espirometría con criterios de aceptabilidad y repetibilidad por la ATS. Resultados:

\begin{tabular}{|c|c|c|}
\hline Variable & $\begin{array}{c}\text { Tabaquismo } \\
\text { N:55 }\end{array}$ & $\begin{array}{c}\text { Humo de leña } \\
\text { N:45 }\end{array}$ \\
\hline Edad & 70.56 años & 75.77 años \\
\hline $\begin{array}{l}\text { Días de } \\
\text { estancia intra- } \\
\text { hospitalaria }\end{array}$ & 10.84 días & 9.77 días \\
\hline $\mathrm{VEF}_{1}$ & $1.132(34 \%)$ & $1.27 \mathrm{~L}(43.5 \%)$ \\
\hline Leucocitos & 11,110 & 11,000 \\
\hline PCR & 2.45 & 1.84 \\
\hline $\mathrm{PO}_{2}$ & 56.21 & 52.11 \\
\hline $\mathrm{PCO}_{2}$ & 38.59 & 35.68 \\
\hline VMNI & $23 \%$ & $20 \%$ \\
\hline VMI & $6 \%$ & $3 \%$ \\
\hline $\mathrm{UCl}$ & $4 \%$ & $3 \%$ \\
\hline Exacerbación & $32 \%$ & $75 \%$ \\
\hline $\begin{array}{l}\text { Hospitaliza- } \\
\text { ción }\end{array}$ & $13 \%$ & $20 \%$ \\
\hline BODEx & 6.3 & 5 \\
\hline
\end{tabular}

El grupo de EPOC por tabaquismo presenta un promedio de 49.05 paquetes año. El grupo de EPOC por exposición al humo de leña presenta un promedio de $363 \mathrm{~h} / \mathrm{año}$.

\begin{tabular}{lcc}
\hline $\begin{array}{c}\text { Hallazgos por } \\
\text { TAC }\end{array}$ & Tabaquismo & $\begin{array}{c}\text { Humo de } \\
\text { leña }\end{array}$ \\
\hline Cáncer & $36 \%$ & $26 \%$ \\
Neumonías & $13.2 \%$ & $48 \%$ \\
Bronquiectasias & $1.8 \%$ & $26 \%$ \\
Enfisema & $49 \%$ & $0 \%$ \\
\hline
\end{tabular}

Conclusiones: El EPOC, independiente de su etiología, es un estado proinflamatorio por lo cual presenta niveles elevados de proteína $\mathrm{C}$ reactiva, siendo más marcado cuando su etiología es el tabaco. Los pacientes con EPOC, por tabaquismo y humo de leña requirieron manejo con ventilación mecánica no invasiva de manera similar (23\% vs. 20\%); sin embargo, el grupo de EPOC por tabaquismo requirió mayor asistencia de la unidad de cuidados intensivos respiratorios (UCIR) y mayor asistencia con ventilación mecánica invasiva, incrementando la morbimortalidad, así como los días de estancia intrahospitalaria y los costos de ésta.

19

\section{Creatinina sérica como marcador pronóstico en pacientes con hipertensión arterial pulmonar}

\section{Domínguez CE, Pulido Z, Sandoval Z, Ramírez $N$ \\ INC Ignacio Chávez}

Introducción: La hipertensión arterial pulmonar (HAP) es una enfermedad devastadora, afecta la circulación pulmonar y resulta en falla cardíaca derecha y muerte. Los marcadores pronósticos actuales están basados en los hallazgos del registro multicéntrico sobre HAP de los Institutos Nacionales de Salud, que utilizó datos colectados a principios de 1980; todos estos pacientes tenían HAP primaria. Con base en ello, se creó un modelo de predicción de riesgo a partir de variables hemodinámicas invasivas. En la actualidad, la identificación de nuevos predictores no invasivos será de utilidad en el manejo de pacientes de alto riesgo. Objetivo: Investigar si la creatinina sérica es un factor de riesgo independiente en pacientes con HAP. Métodos: Estudio retrospectivo de una cohorte de pacientes con HAP del grupo I de la Organización Mundial de la Salud, que fueron evaluados en el Instituto Nacional de Cardiología "Ignacio Chávez". Se analizaron variables hemodinámicas y de laboratorio al ingreso al instituto. Se realizó análisis multivariable. Resultados: Se estudiaron 74 pacientes. El $64.8 \%$ fueron casos de HAP idiopática, el resto HAP asociada a cardiopatía congénita. La supervivencia global a 5 años fue de $80 \%$. Mediante curva receptor operador se determinó un punto de corte de creatinina sérica en $0.9 \mathrm{mg} /$ $\mathrm{dL}$, con mejor predicción de mortalidad (sensibilidad $76 \%$, especificidad 67\%). Se realizó análisis de Cox, encontrando que un nivel de creatinina $>0.9 \mathrm{mg} / \mathrm{dL}$, confiere un HR de 11.9 veces (IC-95\%: 11.2-12.1). 
Conclusiones: La medición de los niveles de creatinina sérica en pacientes con HAP, constituye un factor pronóstico independiente en la supervivencia de los mismos.

\section{0}

Cáncer pulmonar de células no pequeñas: Expresión del receptor del factor de crecimiento epidérmico y su asociación con factores de riesgo

\section{Zambrano TBG}

UMAE Hospital de Cardiología No. 34, IMSS, Monterrey, N.L.

Introducción: La expresión del receptor del factor de crecimiento epidérmico (EGFR) se considera como marcador pronóstico. Se ha documentado que en tumores que expresan esta alteración y son tratados con terapias específicas, el pronóstico es más favorable al resto de la población con cáncer pulmonar de células no pequeñas (CPCNoP). Objetivo general: Evaluar la asociación de la expresión del EGFR con factores de riesgo en el CPCNoP. Material y métodos: Estudio descriptivo, retrospectivo, transversal y analítico. Se incluyeron pacientes con diagnóstico de CPCNoP en el período de 5 años (2007-2011), que tuvieron expediente clínico completo y material representativo para inmunohistoquímica. El muestreo fue no probabilístico de casos consecutivos, se recolectaron datos demográficos, estadio clínico, factores de riesgo. Se realizó análisis descriptivos con medidas de tendencia central y análisis de correlación entre las variables con Chicuadrada, utilizando el paquete estadístico SPSS 19.0. Resultados: Se analizaron 93 casos que cumplieron con los criterios de inclusión. La frecuencia anual del CPCNoP fue de 106 casos/año. Al género masculino correspondieron $64(68.8 \%)$ casos y al femenino 29 (31.2\%). La edad media fue de 63.6 ( \pm 11.6) años. La estirpe histológica más frecuente fue el adenocarcinoma con 44 (47.3\%) casos, seguido del epidermoide con $40(43.0 \%)$. El antecedente de tabaquismo estuvo en el $74.2 \%$ de los casos analizados y se relacionó a la estirpe epidermoide en
49.3\%. La exposición a combustión de biomasa se presentó en 10 (10.8\%) pacientes. La expresión global del EGFR por inmunohistoquímica fue positiva en el $66.7 \%$ de las muestras analizadas y se asoció con los adenocarcinomas, género masculino y antecedente de tabaquismo. Conclusión: El uso de la técnica de inmunohistoquímica para la detección de la expresión del EGFR puede usarse como un método de cribado y complementarse con técnicas moleculares. Palabras clave: Cáncer pulmonar, EGFR, tabaquismo, exposición a biomasa.

\section{5}

\section{Genotipos del gen ERCC1 en pacientes con cáncer pulmonar en la población mexicana}

\section{Sandoval C}

INER Ismael Cosío Villegas

Antecedentes: El objetivo del presente estudio fue identificar qué genotipos del gen ERCC1 que participan en la reparación del ADN se encuentran asociadas a la susceptibilidad a adenocarcinoma primario de pulmón (APP) en nuestra población. Material y métodos: Se obtuvo ADN de sangre de pacientes con cáncer pulmonar (132) y de sujetos sanos (131). Las secuencias genotípicas de ERCC1 se examinaron por RT-PCR usando sondas TaqMan. La asociación entre cáncer pulmonar y los genotipos de ERCC1 se analizaron por medio de la prueba de $\chi^{2}$ combinando tablas de contingencias de 2 x 2. Resultados: Se encontró que los genotipos para ERCC1 C/T rs 2589 (Arg280His) $(\mathrm{p}=0.05 ; \mathrm{OR}=1.72,95 \%$ CI: 1-3.11), C/C rs25487 (Arg399Gln) ( $\mathrm{p}=$ 0.00002); OR = 3.22, 95\% CI: $1.79-5.89) \mathrm{y}$ A/A rs11615 (Asn118Asn) A/A ( $\mathrm{p}=0.003$; $\mathrm{OR}=5.89 \mathrm{CI}: 1.56-26.11)$, están asociados a APP. Los pacientes con APP también se estudiaron de acuerdo al factor de riesgo asociado a la enfermedad. En los pacientes expuestos al humo de leña (L) el genotipo C/T rs2589 se encontró asociado a APP ( $\mathrm{p}=0.005 ;$ OR $=1.99,95 \%$ CI: 1-4.93) no observándose una asociación en los pacientes fumadores (T) ni en aquellos pacientes donde no se pudo establecer algún factor de riesgo asociado a APP (N). Contrariamente, en los pacientes de los grupos T y N el genotipo A/A rs11615 tuvo una significativa asociación que no estuvo presente en el grupo L. En los tres grupos se observó una asociación de APP con el genotipo $\mathrm{C} / \mathrm{C}$ rs25487 particularmente con el grupo L ( $\mathrm{p}=2.2$ x 10-5; OR = 4.99, 95\% CI: 2.14-11.74). Conclusión: Existen genotipos de ERCC1 en nuestra población cuya asociación con APP es diferente entre fumadores y no fumadores.

29

Factores funcionales respiratorios predictores de neumonitis por radioterapia en cáncer de pulmón localmente avanzado (etapas IIIA y IIIB) tratados con quimio y radioterapia

Martínez BD, Arrieta R, TorreBouscoulet, García- Sancho F, Suárez G, Pérez- Padilla

INER Ismael Cosío Villegas, InCAN

Introducción: Los pacientes con cáncer pulmonar localmente avanzado son candidatos a radioterapia (Rt). La neumonitis radica es una complicación frecuente y potencialmente mortal. Objetivo: Evaluar la toxicidad pulmonar por Rt en pacientes en los siguientes estadios IIIA- cT2N1-2, cT3N1-2, cT4N0, M0 IIIB: cT2N3, cT3N3, cT4N1-3, M0. También se incluyeron pacientes con enfermedad oligometastásica. Material y métodos: Criterios de inclusión: pacientes con cáncer pulmonar localmente avanzado (CPLA) atendidos en el InCAN en 2012-2013, candidatos a Rt y que dieron su consentimiento. Se realizó espirometría antes y después de la Rt en las semanas 6 y 12, y en los meses 6 y 12. La espirometría se hizo en el INER siguiendo los estándares de la Sociedad Americana del Tórax y de la Sociedad Europea Respiratoria. Se utilizó prueba de Wilcoxon. El protocolo se aprobó por los comités del INER y del InCAN. Resultados: Se realizó espirometría en 29 pacientes $(51.7 \%$ hom- 
bres); media de edad: 65.2 ( \pm 13.8) años; media del índice de masa corporal: 25.9 ( \pm 13.8). El 58.6\% reportó haber fumado. De la visita 1 a la 5 de seguimiento, la mediana (rango) de capacidad vital forzada (FVC) disminuyó de 3.17 (3.44) L a 2.62 (1.71) L ( $\mathrm{p}=0.01$ ); el volumen espiratorio forzado en el primer segundo $\left(\mathrm{FEV}_{1}\right)$ disminuyó de 2.24 (2.91) L a 1.73 (1.21) L ( p = 0.01) y expresado en \% del predicho FVC disminuyó de 105 (64) a 91(60) $(\mathrm{p}=0.1)$ y $\mathrm{FEV}_{1}$ de 95 (63) a $77(52)(\mathrm{p}=0.06)$. En la primera visita el $26 \%$ de los pacientes presentaron un patrón obstructivo $\left(\mathrm{FEV}_{1} /\right.$ FVC <70). Conclusiones: La obstrucción bronquial es frecuente en pacientes con CPLA candidatos a Rt. La función pulmonar disminuye significativamente durante el tratamiento con Rt.

\section{4}

La sobreexpresión
de CD47 inhibe
la fagocitosis de
neutrófilos y correlaciona
negativamente con la
sobrevida global en cáncer
de pulmón

Barrera RLM, Sánchez M, Morales $F$, Rodríguez R, Dorantes G, Herrera M, Arrieta $R$

INER Ismael Cosío Villegas

Antecedentes: El cáncer de pulmón es la primera causa de muerte por cáncer a nivel mundial. CD47 es una proteína asociada a integrinas, en cáncer se ha relacionado con evasión de la fagocitosis. Se ha reportado la existencia de neutrofilia en pacientes con cáncer, sin que se hayan dilucidado los mecanismos por medio de los cuales se acumulan. Objetivo: Evaluar la expresión de CD47 en neutrófilos de sangre periférica, así como su posible correlación clínica y asociación en la acumulación de este tipo celular en pacientes con cáncer de pulmón de células no pequeñas (CPCNP). Métodos: Se incluyeron 50 pacientes con CPCNP en estadio III y IV sin tratamiento previo y 25 sujetos control (C). Se realizó inmunofenotipificación por citometría de flujo multiparamétrica. Se cocultivaron neutrófilos con macrófagos y células THP1 en presencia y ausencia de anti-CD47. El porcentaje de fagocitosis se evaluó por citometría de flujo. Resultados: Se encontró un incremento significativo en pacientes con CPCNP comparados con controles en: 1) el porcentaje de neutrófilos ( $\mathrm{p}<0.0001)$; 2) la intensidad media de fluorescencia (IMF) total de CD47 ( $\mathrm{p}<$ 0.0001); 3) la IMF de CD47 en neutrófilos $(\mathrm{p}<0.0001)$. Se encontró un incremento en la fagocitosis de neutrófilos cuando se bloqueó con anti-CD47(N+Mac+antiCD47, p < 0.001; N+THP-1+anti-CD47, $\mathrm{p}<0.05)$. La IMF de CD47 correlacionó negativamente con la sobrevida global de los pacientes (sobrevida global a 2 años: 64 vs. $9.7 \%$ en pacientes con alta y baja expresión de CD47, p = 0.02). Conclusiones: $\mathrm{La}$ sobreexpresión de CD47 en neutrófilos de pacientes con CPCNP inhibe su fagocitosis y el bloqueo de este receptor la restaura. Los resultados sugieren que éste puede ser un mecanismo de acumulación de neutrófilos en esta neoplasia. La correlación del incremento de CD47 con la sobrevida global sugiere de manera relevante su utilidad pronóstica, así como su potencial como blanco terapéutico en CPCNP.

\section{8}

Impacto del Programa de Rehabilitación Pulmonar en pacientes con enfermedad difusa del parénquima pulmonar. Experiencia de dos años en el INER

Barragán MG, Toral F, Martínez de León, Hernández L, Añorve B, Galicia $A$

\section{TW. INER Ismael Cosío Villegas}

Antecedentes: Los pacientes con enfermedades difusas del parénquima pulmonar (EDPP) presentan disnea de esfuerzo, tos y fatiga, que en etapas crónicas y avanzadas limitan el ejercicio que impacta en su calidad de vida. El tratamiento incluye además del manejo médico, Programa de
Rehabilitación Pulmonar (PRP). Objetivos: Evaluar el impacto del Programa de Rehabilitación Pulmonar en pacientes con EDPP mediante distancia recorrida en caminata de seis minutos (C6M), calidad de vida por cuestionarios St. George y SF 36, ansiedad y depresión por HAD en una cohorte seguida a dos años. Material y métodos: El Departamento de Rehabilitación Pulmonar del INER desarrolló un estudio descriptivo, longitudinal y prolectivo a dos años con muestra a conveniencia; $>18$ años, sin distinción de género, diagnóstico de EDPP; estables pulmonar y cardiológicamente, uso de esteroide $\leq 10 \mathrm{mg}$ por día, sin agudización dos meses previos a PRP, carta de consentimiento informado. Se brindó fisioterapia pulmonar, programa de ejercicio de 36 sesiones en ciclo ergómetro y ergómetro de brazos, limitado por signos y síntomas. Fueron aplicados antes y después al PRP SF-36, HAD, St. George y C6M. Análisis estadístico: con promedios, desviación estándar y prueba de t-student. Resultados: Concluyeron 19 pacientes: 13 hombres; 8, fibrosis pulmonar; 4, alveolitis alérgica extrínseca; y 7, neumopatía intersticial difusa. Recorrieron en promedio $401 \pm 130 \mathrm{~m}$ y al término del PRP 464 - $1110 \mathrm{~m}(\mathrm{p}=0.01)$; St. George para síntomas $30.67 \pm 22.66$ antes y $22.68 \pm 15.98$ post $(\mathrm{p}=0.04)$; SF 36: Salud mental antes $73.88 \pm 22.32 \mathrm{y}$ $84 \pm 12.49$ post $(\mathrm{p}=0.04)$, salud general antes $54.88 \pm 17.79$ y $62.47 \pm 14.48$ post (p $=00.3)$, HAD: ansiedad antes $5.94 \pm 5.17$ y post $3.76 \pm 2.84(\mathrm{p}=0.03)$, depresión antes $3.53 \pm 3.87$ y 1.63 post $(\mathrm{p}=0.01)$. Conclusiones: Los pacientes con EDPP que concluyeron el PRP mejoraron la distancia recorrida, síntomas, salud general, salud mental, ansiedad y depresión. El grupo heterogéneo de estos enfermos es una limitante en este estudio.

39

Importancia de los criterios diagnósticos en la fibrosis pulmonar idiopática

Barreto RJO, Buendía R, Vargas D, Mateos T, Estrada G, Gaxiola G, Mejía Á

INER Ismael Cosío Villegas 
Introducción: Debido a que no todos los diagnósticos iniciales de la fibrosis pulmonar idiopática (FPI) se realizan en la clínica de enfermedades intersticiales del pulmón, se decidió revisar a través de los diagnósticos de egreso del Servicio de Bioestadística del INER las características clínicas de estos pacientes. Objetivo: Conocer la frecuencia y características de los pacientes con diagnóstico de FPI en todos los servicios clínicos del INER. Metodología: Se solicitó al Servicio de Bioestadística del INER el total de egresos con diagnóstico de FPI en el período 2008-2013, se revisaron expedientes y tomografías (TACAR) para confirmar diagnóstico de acuerdo con los criterios internacionales, se registraron las características de la cohorte. Resultados: Las enfermedades pulmonares intersticiales difusas (EPID) representan el $9 \%$ de egresos del INER, de éstos $12.6 \%$ son FPI (243 casos). Al realizar la revisión se excluyeron 36 casos $<55$ años y que no contaban con diagnóstico histológico, 25 por no tener disponible TACAR, 31 fueron reingresos. Por diagnóstico tomográfico: 97 típicas, 27 incompatibles y 27 probables, de éstos últimos 9 se excluyeron por tener enfermedad colágeno vascular, de los 18 restantes sólo 6 tenían diagnóstico histológico; por lo tanto, la cohorte se componía de 103; sin embargo, se excluyeron 35 casos ya que los expedientes tenían alguna otra posible causa, siendo la cohorte definitiva de 80 casos. De esta cohorte: edad $69 \pm 9$, relación hombre:mujer 5:1, tiempo de evolución antes del diagnóstico 2 años, comorbilidades: DM 21\%, SAOS 4\%, EPOC 16\%. Pruebas de función respiratoria al diagnóstico $\mathrm{FVC}$ $68 \pm 21 \%, \mathrm{SpO}_{2}$ reposo $85 \pm 12 \%$, caminata $241 \pm 156 \mathrm{~m}$ y DLCO $52 \pm 31 \%$, PSAP de $45 \pm 18 \mathrm{mmHg}$. Conclusiones: Aunque la FPI es la más frecuente de las EPID, en ocasiones puede sobrediagnosticarse, por lo que utilizar los criterios del consenso 2011 de ATS/ERS/EJR/ALAT, permite identificar otros tipos de EPID, en las cuales si existe un tratamiento y por ende un mejor pronóstico.

\section{1}

Validación de las reglas
de predicción clínica
para diagnóstico de

tromboembolia pulmonar en el Instituto Nacional de Enfermedades Respiratorias

Espinosa MDA, Báez SR, Carvajal G, Santillán M, Castro $P$, Juárez $H$

INER Ismael Cosío Villegas

Introducción: Actualmente existen reglas de predicción clínica (RPC) para el diagnóstico de tromboembolia pulmonar (TEP) que emiten probabilidad baja, media, alta o diagnóstico probable o improbable; sin embargo, no existe información suficiente sobre su desempeño en escenarios distintos del que derivaron como un hospital de enfermedades respiratorias (HER). Objetivo: Evaluar la validez de los criterios de Wells, Ginebra y Ginebra revisado en pacientes con sospecha clínica de TEP en un HER. Material y métodos: Diseño prospectivo, transversal de pacientes consecutivos que acudieron al Servicio de Urgencias del INER con sospecha clínica de TEP durante el período octubre 2012 a julio 2013; se calculó la probabilidad clínica de TEP de acuerdo a las RPC de Wells, Ginebra y Ginebra revisado. Se siguió el algoritmo diagnóstico propuesto en las guías internacionales vigentes. Las variables clínicas y paraclínicas se resumieron con estadística descriptiva, comparándose entre quienes tuvieron TEP y los que no; mediante tablas de contingencia 2 x 2 se calculó sensibilidad (S), especificidad (E), valores predictivos positivos (VPP), negativos (VPN), razones de verosimilitud (RV) y se determinó el ABC (área bajo la curva (ROC)) de cada RPC. Resultados: Se incluyeron 54 pacientes confirmándose TEP en $53.70 \%$. El mejor desempeño se obtuvo con un punto de corte $>5$ en Wells (ABC 0.82) con S 76\%, E 80\%, VPN 74\%; $>9$ en Ginebra (ABC 0.61), S 90\%, E $24 \%$, VPN 67\%; y para Ginebra revisado $>9$ (ABC 0.86) con S 62\%, E 88\%, VPP $86 \%$, VPN 67\%; el dímero D a un punto de corte $>1,226 \mathrm{ng} / \mathrm{mL}$ con ABC 0.86 y S 96\%, E 72\%, VPN 95\% y RV negativa 0.04. Conclusión: Las RPC de Wells y Ginebra revisado así como el dímero D a un punto de corte $>1,226 \mathrm{ng} / \mathrm{mL}$ tuvieron el mejor desempeño, siendo válidas para evaluar la probabilidad de TEP en pacientes de este escenario.

42

Hallazgos tomográficos y biomarcadores de gravedad en neumonitis aguda por adyuvantes

Guadarrama PC, Rojas S, Estrada G,
Buendía R, Flores B, Mejía Á

INER Ismael Cosío Villegas

Descripción: La aplicación de sustancias líquidas con fines cosméticas por personal no calificado es una práctica habitual, que puede producir neumonitis aguda por adyuvantes (NAA) que tiene una elevada morbimortalidad. Objetivo: Describir las características clínico-tomográficas de pacientes con NAA. Metodología: Estudio retrospectivo en el INER (20052013) en pacientes con diagnóstico confirmado de NAA, se registraron variables basales epidemiológicas, tipo y cantidad de adyuvante aplicado, laboratorio, características tomográficas que se correlacionaron con $\mathrm{paO}_{2}, \mathrm{G}(\mathrm{A}-\mathrm{a}) \mathrm{O}_{2}$ y $\mathrm{paO}_{2} / \mathrm{FiO}_{2}$. Resultados: Se estudiaron 25 pacientes, sexo masculino $96 \%$, mediana de edad 26 años (23-30), historia de adyuvantes $72 \%$, tipo de adyuvante: biopolímero líquido $60 \%$, aceite mineral $16 \%$, silicón $12 \%$, otros $12 \%$. Síntomas más frecuentes: disnea $96 \%$, tos $68 \%$, fiebre $40 \%$, diaforesis $52 \%$, hemoptoicos $20 \%$, todos se presentaron en $<24$ horas; hipoxemia $\mathrm{paO}_{2} 52$ (44-58) mmHg, G(Aa) $24 \pm 10, \mathrm{paO}_{2} / \mathrm{FIO}_{2} 245$ (209 a 276), LDH U/L 405.14 \pm 215.53 . Correlación de DHL con $\mathrm{paO}_{2}$ fue ( $\mathrm{r}-0.43$, p 0.048), con $\mathrm{paO}_{2} / \mathrm{FiO}_{2}(\mathrm{r}-0.46$, p 0.05$)$ y con G(A-a) (r 0.56, p 0.013). Correlación de lactato con $\mathrm{paO}_{2}(\mathrm{r}-0.57, \mathrm{p} 0.006), \mathrm{paO}_{2} / \mathrm{FiO}_{2}(\mathrm{r}$ -0.47, p 0.04) y G(A-a) (r 0.40, p 0.097). Características tomográficas: consolidación $61 \%$, multisegmentaria $83 \%$, vidrio despulido 94\%, índice de inflamación $2.35 \pm 0.73$. Distribución periférica $89 \%$, difusa-bilateral 100\%. Mortalidad 1 (4\%). El tratamiento en todos los casos fue con corticosteroides. Conclusiones: En la cohorte del INER la NAA es más frecuente 
por biopolímero líquido, el 100\% presentó insuficiencia respiratoria, de éstos $28 \%$ requirió $\mathrm{VMI}$, la mortalidad fue baja, la característica tomográfica predominante fue distribución periférica-subpleural con grados variables de vidrio despulido y consolidación multisegmentaria. La gravedad de los casos correlacionó sólo con DHL y lactato.

\section{3}

\section{Reacción anti-lgY especie- específica, y propuesta de un antígeno causal en neumonitis por hipersensibilidad (NH) secundaria a la exposición a palomas}

Segura A

INER Ismael Cosío Villegas

Antecedentes: Las aves se clasifican en distintos subórdenes: el Paleognathae que incluye aves terrestres no voladoras (avestruces, casuarios o kiwis), y el grupo Neornithes o aves voladoras como palomas, pericos australianos y tórtolas. En la neumonitis por hipersensibilidad (NH) causada por distintos antígenos aviarios (AgAv) es común la exposición a palomas, y la presencia de anticuerpos (Ac) comprende un tipo de proteínas séricas de $66 \mathrm{kDa}$ que tienen modificaciones postraduccionales similares; incluyen a una región de la $\mathrm{IgG} / \mathrm{IgY}$, y son distintivas de las aves del suborden Neornithes. Objetivos: Se estudiaron las características inmunoquímicas y propiedades antigénicas especie-específicas de la IgY de paloma, y se evaluó la producción de Ac contra IgY de paloma en NH. Material y métodos: Se obtuvieron/purificaron fuentes antigénicas usando plasmas/sueros totales e IgG/IgY de distintas aves (avestruz, pollo, paloma) y mamíferos (cobayo, ratón, conejo, borrego, cerdo, humano). En la fase experimental se obtuvieron/adquirieron Ac de ratones y conejos inmunizados con diferentes IgG/IgY o controles. El estudio clínico incluyó a 16 pacientes con NH por palomas y 16 contactos sanos expuestos a paloma sin la enfermedad. Se evaluó la presencia de Ac mediante ELISA y Western-Blot. Resultados: La reactividad anti-IgG/IgY usando muestras de ratón y conejo reveló que los Ac anti-IgY de paloma fueron Ag específicos, sin evidencia de reconocimiento de $\mathrm{IgG} / \mathrm{IgY}$ otras aves y mamíferos. En NH se encontraron frecuentemente Ac contra IgY de paloma, respecto a los controles $(11 / 16,68.8 \%$ vs. 2/16, $12.5 \%$ p < 0.01). Conclusiones: La reactividad de Ac anti-IgY de paloma en el estudio experimental demostró una respuesta inmune específica para este tipo de ave, no obstante que las IgG/IgY de otras aves y mamíferos presentan gran similitud estructural y fisicoquímica. En $\mathrm{NH}$ predominó la presencia de Ac contra IgY de paloma, respecto a los controles, y es una característica que permite proponerla como posible marcador de la enfermedad.

\section{4}

Asociación entre los niveles séricos de moléculas de adhesión celular solubles, citocinas proinflamatorias y escalas de gravedad en pacientes hospitalizados con neumonía adquirida en la comunidad

Sánchez HJD, Lascuarin L, Aguilar M, López E, Santillán M, Báez S

INER Ismael Cosío Villegas

Introducción: La neumonía adquirida en la comunidad (NAC) es la tercera causa de muerte en pacientes >65 años. Las moléculas de adhesión celular (MAC) se involucran en el proceso inflamatorio en pacientes con NAC y podrían ser un eslabón de importancia para el desenlace de la enfermedad. Objetivo: Evaluar la relación entre los niveles séricos de MAC solubles (E-selectina y V-CAM), citocinas proinflamatorias y escalas de gravedad en pacientes hospitalizados con NAC. Material y métodos: Estudio transversal. Se incluyeron 49 pacientes adultos con diagnóstico de NAC y 17 sujetos como grupo control. Se excluyeron aquellos con neumonía nosocomial o inmunosupresión. Se realizó evaluación clínica y medición de las escalas de gravedad para neumonía: PSI, CURB-65 y SMART-COP. Se midieron los niveles de MAC solubles, así como niveles de IL-1b, IL-6, INF- $\gamma$ y TNF- $\alpha$ séricos. Se evaluó la asociación entre estas moléculas y las escalas de gravedad mediante correlación de Spearman. Resultados: Se observó edad mediana de 53 años (p25-75, 35-69), el 55\% eran mayores de 50 años. Se obtuvo asociación débil significativa entre V-CAM y PSI (rho $=0.411)$, así como con CURB-65 (rho $=0.356)$ y con SMART-COP (rho $=0.300$ ); sin embargo, no hubo asociación de los niveles de E-selectina soluble con ninguna de estas escalas de gravedad. Por otra parte, se encontró una asociación moderada entre INF- $\gamma$ y TNF- $\alpha$ con PSI (rho= -0.544 y rho $=-0.508$, respectivamente), INF- $\gamma$ y TNF- $\alpha$ con CURB-65 (rho= -0.659 y rho $=-0.614$, respectivamente). Al comparar pacientes con NAC y sujetos control, IL-6 fue el único biomarcador que mostró diferencia significativa (126 vs. 16.4, p < 0.001). Conclusión: Las MAC no tienen una buena asociación con las escalas de gravedad; sin embargo, INF- $\gamma$ y TNF- $\alpha$ podrían tener un valor pronóstico en NAC. Aún se desconoce el papel de estas moléculas como factor pronóstico de la enfermedad.

45

Uso del sistema STRATOS STRACOS y resultado en 3 pacientes con fracturas costales por trauma contuso de tórax

\section{Estrella SJA}

Guadalajara, Jalisco

Descripción: Las grapas costales y las barras de conexión STRATOS son implantes quirúrgicos pensados en el tratamiento de deformidades torácicas y defectos de la pared torácica. Está pensado para la estabilización y fijación de fracturas, fusión y osteotomía de las costillas, reconstrucción de la pared torácica y esternón. Las 
fracturas costales se asocian con gran frecuencia a los traumatismos torácicos. La mortalidad y morbilidad aumentan en proporción al número de fracturas y con la edad de los pacientes. Los traumas torácicos comprenden del 10-15\% de todos los traumatismos y son la causa de la muerte en el $25 \%$ de todas las muertes debidas a traumatismo. El $70 \%$ de los traumatismos de tórax son contusos, más comúnmente se fracturan entre 4 y 9 arcos costales Existen múltiples ventajas potenciales de la fijación quirúrgica de la pared torácica, incluyen disminución en la duración del tiempo bajo ventilación mecánica, disminución de la estancia en la Unidad de Cuidados Intensivos, así como en el tiempo total de hospitalización y decremento en la probabilidad de una disfunción respiratoria de larga evolución y de deformidad esquelética. Las grapas costales no son de aparición reciente, pero la utilización del titanio para su construcción si lo es. Se describe el uso y colocación del sistema STRATOS STRACOS (grapas costales y barras de titanio) en tres pacientes con trauma contuso de tórax y múltiples fracturas costales, así como su evolución, observando la eficacia de dicho sistema en la pronta mejoría de los pacientes, principalmente en la disminución del dolor y la disminución de la dificultad respiratoria.

\section{5}

Proteína-D surfactante sérico (SP-D) como un biomarcador pronóstico en pacientes con influenza AH1N1 2009

\section{Delgado C, Krötzsch, Selman L, Zúñiga $R$}

INER Ismael Cosío Villegas

Introducción: La pandemia de influenza A/H1N1 de 2009 reportó una tasa de letalidad en México de $0.4 \%$. Estos virus de origen recombinante alteran la respuesta antiviral típica, lo cual se relaciona con el desarrollo de insuficiencia respiratoria aguda (IRA) y muerte. La proteína "D" del factor surfactante (SP-D) es una colectina que regula la homeostasis alveolar y posee afinidad por la hemaglutinina de los virus, permitiendo su agregación y opsonización. Se ha propuesto a SP-D como biomarcador de severidad en enfermedades pulmonares. Objetivo: Conocer la asociación entre las concentraciones de SP-D y la progresión a IRA en neumonía por influenza A/H1N1. Métodos: Estudiamos 37 pacientes con neumonía por influenza A/H1N1 en el INER. Se determinó al ingreso SP-D en suero por ELISA, las concentraciones se asociaron con IRA y mortalidad a 28 días. Se efectuaron análisis de riesgo relativo (RR), curvas ROC y estimadores de sobrevida para diferentes concentraciones séricas de SP-D. Resultados: $89.2 \%$ de los pacientes presentaron IRA, $32.4 \%$ fallecieron; de estos últimos, las concentraciones de SP-D fueron mayores $v s$. sobrevivientes ( $\mathrm{p}$ $<0.02$ ). La curva ROC para SP-D como predictor de mortalidad mostró un área bajo la curva de 0.73 (IC95\% 0.6-0.9). El RR de SP-D para mortalidad fue 6.69 (IC95\% 1.5-29.2, p < 0.013) con punto de corte $>250 \mathrm{ng} / \mathrm{mL}$. El análisis de Kaplan y Meier mostró diferencia significativa en los estimadores de sobrevida para valores de SP-D <250 ng/mL (SK-M 0.91, IC95\% 0.5-0.98) y $\geq 250 \mathrm{ng} / \mathrm{mL}$ (SK-M 0.38, IC95\% 0.2-0.6, Log rank p <0.02). SP-D no se asoció significativamente con IRA. Conclusión: En la neumonía por influenza A/H1N1 las concentraciones séricas de SP-D se asocian directamente con mortalidad a 28 días. Esta proteína es un potencial biomarcador del pronóstico. Se requiere validación de estos resultados en estudios posteriores.

\section{6}

\section{Comparación del índice FVC/DLCO entre pacientes con síndrome combinado y fibrosis pulmonar idiopática \\ Vargas DCIA, Buendía R, Mejía \\ Á, Mateos T, Barreto R, Estrada G, Selman $L$}

INER Ismael Cosío Villegas

Introducción: Recién se ha descrito la coexistencia de fibrosis pulmonar idiopática (FPI) con enfisema, en especial en hombres con historia de tabaquismo. Este síndrome combinado (SC) se caracteriza por alteraciones del intercambio gaseoso desproporcionadas a la afección de la mecánica pulmonar y con mayor frecuencia, desarrollo de hipertensión arterial pulmonar (HAP). El pronóstico del SC suele ser peor que la FPI, pero actualmente no existen índices pronósticos de morbilidad/ mortalidad confiables. El objetivo del estudio fue comparar la correlación del índice FVC/DLCO con la presión sistólica estimada de la arteria pulmonar (ePSAP) en pacientes con SC y FPI. Métodos: Es un estudio retrolectivo, transversal comparativo de una muestra por conveniencia. Se incluyeron 8 pacientes con SC y 8 con FPI a los que se les realizó espirometría simple, prueba de difusión de monóxido de carbono con los estándares ATS/ERS, y ecocardiograma transtorácico. Se evaluó calidad de vida con los cuestionarios: SF-36, Saint George, depresión y disnea. Los datos se analizaron con estadística no paramétrica. Resultados: La comparación de los grupos en estudio (FPI vs. SC, respectivamente) mostró los siguientes resultados: edad $63.6 \pm 7.1$ vs. $65.1 \pm 9.6$ ( $\mathrm{p}=0.78), \mathrm{FVC}$ (L) $2.15 \pm 0.41$ vs. $2.68 \pm$ $0.82(\mathrm{p}=0.09), \mathrm{FEV}_{1}(\mathrm{~L}): 1.77 \pm 0.48 v s$. $2.02 \pm 0.49(\mathrm{p}=0.18), \mathrm{FVC} / \mathrm{FEV}_{1}: 82 \pm 13$ vs. $77 \pm 10(\mathrm{p}=0.28)$ y ePSAP $26.25 \pm 1.5$ vs. $48.2 \pm 23(\mathrm{p}=0.05)$. Para las variables pletismográficas, de difusión y de calidad de vida no hubo diferencias estadísticamente significativas. Con respecto al índice FVC/DLco la diferencia entre FPI vs. SC fue de $1.28 \pm 0.33$ vs. $2.14 \pm 1.57$ $(\mathrm{p}=0.16)$. Las correlaciones del índice FVC/DLco con la ePSAP fueron: 0.50 (p $=0.66)$ vs. $0.82(\mathrm{p}=0.04)$. Conclusiones: Los pacientes con SC muestran un mayor grado de HAP que los de FPI. El índice FVC/DLco ha sido utilizado para predecir HAP en esclerodermia y nuestros hallazgos sugieren que puede ser útil en el SC.

\section{8}

Resultados de tratamiento en pacientes con tuberculosis resistente a fármacos: Monorresistente (MR), polirresistente (PR), 


\section{multifarmacorresistente (MDR) y con resistencia extendida a fármacos (XDR). En México, 2010 Programa Nacional de Tuberculosis}

\begin{abstract}
Martínez MD, Castellanos J, García $A$, Romero $P$, Saavedra H, Magaña $O$, Salazar $L$
\end{abstract}

INER Ismael Cosío Villegas

Antecedentes: El tratamiento de la tuberculosis resistente a fármacos (cepa de Mycobacterium tuberculosis con resistencia in vitro a la acción de algún fármaco antituberculosis) representa un reto no solamente clínico-farmacológico, sino programático; se requiere un programa efectivo de prevención y control, un sistema de gestión de fármacos, participación de expertos clínicos y acciones básicas operativas del Programa de Control de la Tuberculosis para detección, diagnóstico y seguimiento de tratamiento. Este trabajo presenta los resultados de tratamiento en estos pacientes. Material y métodos: Estudio observacional, descriptivo, prospectivo. Población de estudio: pacientes con tuberculosis pulmonar resistente a fármacos ingresados a tratamiento durante el año 2010 en todas las entidades federativas. Se analizó la base de datos del Programa Nacional de Tuberculosis (PNT). Se aplicó estadística descriptiva utilizando SPSS. Resultados: Durante el 2010 fueron ingresados a tratamiento 265 pacientes, el $65.7 \%$ (174) correspondieron a sexo masculino, la edad media fue de $43.4(\mathrm{DE} \pm 15.5)$ años. Las entidades con más casos fueron Tamaulipas, Veracruz y Coahuila con el 13.6\% (36), $11.7 \%$ (31) y $6.8 \%$ (18), respectivamente. El $83.4 \%$ (221 pacientes) tuvieron TB-MDR, el 10.2\% (27) TB-PR, el $4.2 \%$ (11) TB-MR y el $2.3 \%$ (6) TB XDR. Los resultados de tratamiento fueron curación en el $55.8 \%$ (148), término de tratamiento en el $15.8 \%$ (42), abandono en el $11.7 \%$ (31), defunción en el $10.9 \%$ (29) y fracaso en el $5.7 \%$ (15). El éxito de tratamiento (curación y término de tratamiento) se estimó en $74.6 \%$ (190), éste no tuvo diferencias estadísticamente significativas de acuerdo al tipo de TB.
Siendo el éxito de tratamiento para TB-MR de $63.6 \%$, para TB-PR de $77.8 \%$, para TBMDR de $71.5 \%$ y para TB-XDR de $66.7 \%$. Conclusiones: Se sabe que los pacientes con tuberculosis resistente a fármacos tienen menor probabilidad de curación; sin embargo, con una coordinación estratégica el PNT se demostró que independientemente del tipo de resistencia, los pacientes tienen una probabilidad de éxito de tratamiento mayor al $60 \%$.

\section{5}

Diferencias en la celularidad e identificación intracelular de IL-6 en células de esputo inducido en pacientes con EPOC secundaria a tabaquismo en comparación con EPOC secundaria a humo de leña

\section{Velázquez PLT, Falfán V, Vázquez V, Reséndiz H, Camarena O, Sansores M, Ramírez V}

INER Ismael Cosío Villegas
Antecedentes: La enfermedad pulmonar obstructiva crónica (EPOC) es una enfermedad prevenible y tratable caracterizada por limitación parcial al flujo de aire, inflamación localizada y en algunos casos sistémica. Los principales factores de riesgo son el tabaquismo y la exposición al humo de leña. Se han realizado pocos estudios empleando muestras de esputo inducido para determinar marcadores de inflamación como IL6, particularmente la forma intracitoplasmática. Materiales y métodos: Se incluyeron 40 sujetos, 10 con diagnóstico de EPOC por tabaquismo (EPT), 10 con EPOC por humo de leña (EPHL), 10 contactos expuestos al humo de leña no fumadores (NF) y 10 fumadores sin EPOC (FS); de todos se obtuvo esputo por inducción. La diferenciación celular se realizó mediante la técnica de Papanicolaou (PAP) y la expresión intracitoplasmática de IL-6 por inmunocitoquímica. El análisis estadístico fue realizado mediante las pruebas de U de Mann-Whitney y W de Wilcoxon, tomando el valor de $\mathrm{p}<$ 0.05 como significativo. Resultados: $\mathrm{Se}$ encontró una diferencia estadísticamente significativa con respecto al porcentaje de neutrófilos y macrófagos, en el grupo de EPHL con respecto al grupo EPT y con

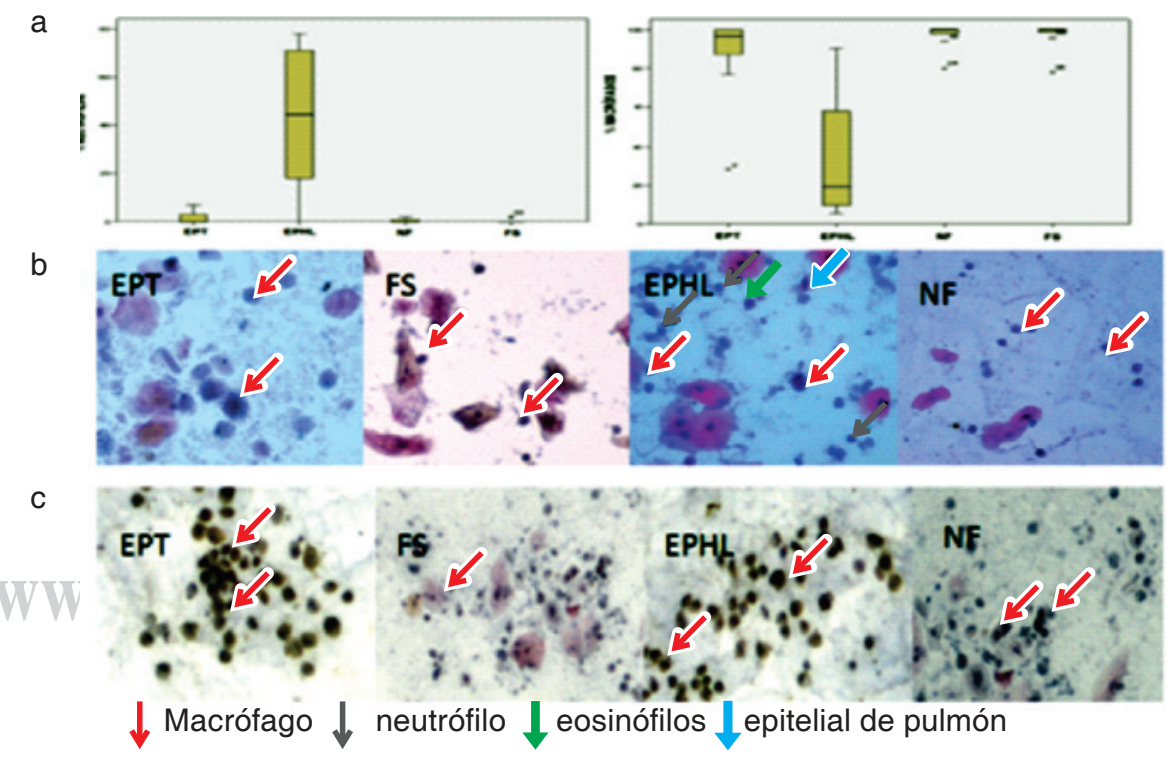

Figura 1. a) Porcentaje de neutrófilos y macrófagos encontrados por grupo; b) diferenciación celular; c) expresión intracitoplasmática. EPT: EPOC secundaria a tabaquismo, EPHL: EPOC secundaria a humo de leña, NF: contactos de humo de leña, FS: fumadores sin EPOC. 
su grupo control NF ( $p=0.006$ y 0.004$)$ (figura 1); al comparar IL-6 en los grupos EPHL y EPT con sus respectivos controles se encontró diferencia estadísticamente significativa ( $\mathrm{p} \leq$ 0.001). Conclusión: Existe diferencia en la celularidad y no así en la expresión intracitoplasmática entre los grupos EP.

\section{7}

Variantes genéticas en neurexina 1 (NRXN1) y subunidad $\beta 4$ del receptor nicotínico colinérgico (CHRNB4) como marcadores de riesgo en la adicción a la nicotina en mestizos mexicanos

Pérez RG, Falfán V, Fenández L, Sansores M, Ramírez V, Urdapilleta $H$, Camarena $O$

INER Ismael Cosío Villegas

Antecedentes: La adicción a nicotina es una enfermedad compleja, con alta predisposición genética, particularmente en genes de los receptores nicotínicos colinérgicos (CHRNs) y neurexina 1 (NRXN1). El objetivo del trabajo es conocer en población mestiza mexicana la participación de dichos genes. Metodología: Estudio observacional con mexicanos mestizos, $\geq 30$ años; divididos en 2 grupos: no fumadores (NF) 192 y 576 fumadores (F). Se diseñó un microarreglo (Illumina,

\section{Resumen 67}

Tabla 1. Análisis de asociación alélica entre el grupo de no fumadores y fumadores.

\begin{tabular}{|c|c|c|c|c|c|}
\hline GEN & $\mathrm{CHR}$ & SNP & $p$ & OR (IC 95\%) & $\mathrm{p}$ (Bonferroni) \\
\hline \multirow{7}{*}{$N R X N 1$} & \multirow{7}{*}{2} & rs17447848 & 7.46E-07 & $9.5(3.8-23.1)$ & 0.000232 \\
\hline & & rs17040885 & 8.74E-06 & $3.1(1.8-5.1)$ & 0.002718 \\
\hline & & rs2352540 & $1.00 \mathrm{E}-05$ & $6.5(2.8-14.9)$ & 0.003110 \\
\hline & & rs858956 & $3.05 E-05$ & $4.7(2.3-9.7)$ & 0.009475 \\
\hline & & rs17040958 & 4.37E-05 & $9.0(3.1-25.9)$ & 0.013590 \\
\hline & & rs17040026 & $5.84 \mathrm{E}-05$ & $8.7(3.0-25.2)$ & 0.018170 \\
\hline & & rs12995085 & 8.31E-05 & $3.4(1.8-6.3)$ & 0.025830 \\
\hline CHRNB4 & 15 & rs1481131 & 5.21E-05 & $8.8(3.0-25.4)$ & 0.016200 \\
\hline
\end{tabular}

CA, USA) con 384 polimorfismos tipo SNP en 11 genes de CHRNs y NRXN1. Se descripción de variables clínicas y ancestría poblacional, respectivamente. La asociación se evaluó con un modelo de regresión logística mediante el uso del software PLINK (covariables edad, sexo y ancestría), el análisis de haplotipos se realizó mediante HaploView. Resultados: En el análisis de asociación 8 SNPs resultaron asociados (tabla 1); el haplotipo GGA en NRXN1 se encontró asociado al riesgo a la dependencia a la nicotina $(\mathrm{p}=1.74 \mathrm{E}-09)$. Conclusiones: Existen 7 SNPs y un haplotipo formado por 3 SNPs asociados al riesgo en NRXN1, que participa en la sinapsis neuronal y señalización intracelular; así como un SNP en el gen CHRNB4. Estas variantes asociadas podrían ser marcadores de riesgo para la dependencia a la nicotina, que conduce a una gran cantidad de patologías respiratorias, entre ellas EPOC y cáncer pulmonar.

\section{0}

Asociación genética de polimorfismos tipo SNPs en MMPs con EPOC secundaria a tabaquismo Hernández MJ, Falfán $V$, Pérez $R$,
Camarena $O$

INER Ismael Cosío Villegas

Antecedentes: En la patogénesis de la EPOC, coexiste una respuesta inflamatoria anormal con el desequilibrio de emplearon SPSS y EIGENSOFT para la proteasas-antiproteasas en las vías aéreas. Las MMPs son proteasas que en procesos fisiológicos y patológicos implican remodelación y mantenimiento tisular. Las MMPs producidas por las células inflamatorias contribuyen al mantenimiento de la inflamación crónica en el tejido pulmonar y destrucción de las paredes alveolares. SNPs (polimorfismos de un solo nucleótido) en MMPs participan en el desarrollo y la progresión de EPOC en población caucásica; los genes candidato asociados a la EPOC son MMP1, MMP2, MMP9 y MMP12. Materiales y métodos: Se evaluaron 12 SNPs de MMPs en fumadores con EPOC (EP = 315) y fumadores sin EPOC (FS = 327), en los genes MMP1, MMP2, MMP9 y MMP12; la genotipificación se hizo por PCR en tiempo real. El material genético se obtuvo del biobanco de muestras de DNA del Laboratorio de HLA del Instituto Nacional de Enfermedades Respiratorias (INER). El análisis de asociación de los genotipos y alelos se hizo con el software Epi Info 7.0. Resultados: El genotipo GG del rs243864 en MMP2 y el genotipo TT del rs3918253 en MMP9 muestran "OR" que indican susceptibilidad (tabla 1). No hubo asociación con ninguno de los otros 10 SNPs evaluados. Conclusiones: Existen polimorfismos tipo SNP en MMP2/9 asociados a la susceptibilidad genética de EPOC secundaria a tabaquismo en población mexicana.

72

Determinación de polimorfismos en los genes GST-M1, GST-T1 y NQO1 en pacientes con neumonía grave secundaria a influenza $A$ / H1N1

Muñoz PC, Cruz L, Zúñiga R, Sierra V

INER Ismael Cosío Villegas

Introducción: El virus de influenza A/ H1N1 es causante de pandemias como la ocurrida en nuestro país en marzo de 2009, estudios realizados muestran que los pa- 
Resumen $\mathbf{7 0}$

Tabla 1. Resultados asociación genética.

\begin{tabular}{|c|c|c|c|c|c|}
\hline Gen/SNP & $\begin{array}{c}E P \\
n=315 \\
F G(\%)\end{array}$ & $\begin{array}{c}\mathrm{FS} \\
\mathrm{n}=327 \\
\mathrm{FG}(\%)\end{array}$ & $p$ & OR & IC 95\% \\
\hline \multicolumn{6}{|l|}{$\begin{array}{l}\text { MMP2/ } \\
\text { rs243864 }\end{array}$} \\
\hline TT & 52.7 & 61.47 & 0.0303 & 0.69 & $0.51-0.95$ \\
\hline GT & 28.89 & 35.47 & & & \\
\hline GG & 18.41 & 3.06 & $1.0 \mathrm{E}-10$ & 7.15 & $3.58-14.27$ \\
\hline $\mathrm{T}$ & 67.14 & 79.2 & 2.6E-06 & 0.53 & $0.41-0.69$ \\
\hline $\begin{array}{l}\mathrm{G} \\
\text { MMP9/ } \\
\text { rs3918253 }\end{array}$ & 32.86 & 20.8 & 2.6E-06 & 1.86 & $1.44-2.39$ \\
\hline $\mathrm{CC}$ & 46.67 & 55.96 & 0.0227 & 0.68 & $0.50-0.93$ \\
\hline CT & 41.59 & 37.61 & & & \\
\hline TT & 11.74 & 6.43 & 0.0267 & 1.93 & $1.10-3.39$ \\
\hline$C$ & 67.46 & 74.77 & 0.0046 & 0.69 & $0.54-0.89$ \\
\hline $\mathrm{T}$ & 32.54 & 25.23 & 0.0046 & 1.42 & $1.12-1.82$ \\
\hline
\end{tabular}

Resumen 73

Tabla1. Asociación de SNPs con la gravedad de la infección.

\begin{tabular}{|c|c|c|c|c|}
\hline $\begin{array}{l}\text { IL1B } \\
\text { rs16944 } \\
\text { Genotipo }\end{array}$ & $\begin{array}{c}\text { AH1N1-P } \\
n=145(\%)\end{array}$ & $\begin{array}{c}\text { ILI P } \\
\mathrm{n}=135(\%)\end{array}$ & $\mathrm{p}$ & OR (IC 95\%) \\
\hline$A A$ & 49 (34.3) & 42 (31.8) & & 1.00 \\
\hline$A G$ & $66(46.2)$ & 44 (33.3) & 0.041 & $0.52(0.28-0.97)$ \\
\hline GG & 28 (19.6) & $46(34.8)$ & 0.38 & $1.29(0.73-2.25)$ \\
\hline$A$ & 164 (57.3) & $128(48.5)$ & & 1.00 \\
\hline$G$ & $122(42.6)$ & $136(51.5)$ & 0.05 & $0.70(0.50-0.98)$ \\
\hline \multicolumn{5}{|l|}{$\begin{array}{l}\text { IL } 6 \\
\text { rs1818879 }\end{array}$} \\
\hline $\mathrm{GG}$ & $93(65.5)$ & $55(45.1)$ & & 1.00 \\
\hline GA & 49 (34.5) & $20(16.4)$ & 0.0001 & $5.94(3.05-11.56)$ \\
\hline $\mathrm{AA}$ & 0 & 47 (38.5) & 0.136 & $1.58(0.86-2.90)$ \\
\hline $\mathrm{G}$ & 235 (82.7) & $130(53.3)$ & & 1.00 \\
\hline$A$ & 49 (17.3) & $114(46.7)$ & 0.11 & $0.75(0.53-1.05)$ \\
\hline
\end{tabular}

cientes que desarrollaron la forma más grave de la enfermedad (neumonía) son adultos jóvenes y personas con comorbilidades, pero la causa de esta predisposición aún se desconoce. Las transferasas de glutatión son enzimas de fase II, y la presencia de polimorfismos en los genes que las codifican se ha relacionado con el riesgo a presentar sintomatología respiratoria y disminución de la función pulmonar. El objetivo de este estudio fue determinar la frecuencia de polimorfismos en los genes GST-M1(-/+), GST-T1(-/+) y NQO1(Pro/Pro, Ser/Pro, Ser/ Ser) en un grupo de sujetos expuestos al vi- rus de influenza A/H1N1 que desarrollaron neumonía grave comparado con un grupo de sujetos expuesto al virus, pero que no desarrollaron la forma grave de la infección. Metodología: Estudio de casos y controles. Las deleciones homocigotas de los genes GSTM1, GSTT1 y el polimorfismo de NQO1 se determinaron mediante PCR múltiple en tiempo real, en placas de 96 pozos en un equipo StepOne Plus (Applied Biosystems). Resultados: La prevalencia de GST-M1(-) fue de 54\% de los casos y $39 \%$ en los controles, mientras que para GST-M1(+) la prevalencia fue mayor en los controles $61 \%$ comparado con los casos en donde se obtuvo una frecuencia del $46 \%$ ( $\mathrm{p}<0.05$; OR 0.5, IC 95\% 0.29-0.97). Con respecto a GST-T1(-) fue más frecuente en los controles ( $93 \%$ vs. $75 \%$ ), mientras que GST-T1(+) lo fue en los casos (25\% vs. $7 \%$, $\mathrm{p}<0.001$; OR 4.0; IC 95\% 1.7-9.6). NQO1 la presencia de polimorfismo en este gen fue similar en ambos grupos. Conclusión: Los resultados obtenidos sugieren una interacción potencial entre los genes de las transferasas de glutatión y el desarrollo de neumonía grave secundaria a infección por virus de influenza A/H1N1.

73

Polimorfismos en IL6 e IL1B se asocian a cuadro clínico grave en infección por el virus de influenza AH1N1

García RRA, Falfán V, Vargas $R$, Camarena $O$

INER Ismael Cosío Villegas

Antecedentes: Una de las características más interesantes en el proceso infeccioso por influenza AH1N1 es la exacerbación de la respuesta inflamatoria, caracterizada por hipercitocinemia. Los pacientes infectados por el virus AH1N1 presentan niveles incrementados en suero de proteínas pro-inflamatorias como IL-6, IL-8, IL-1 $\beta$, TNF e IL-10. Existen polimorfismos de un solo nucleótido (SNPs) en las regiones promotoras de éstos como: IL-6 -174 e IL1B -51 asociados a cambios en la expresión de dichas citocinas. Material y métodos: Se genotipificaron 11 SNPs por PCR en tiempo real de 145 pacientes con influenza AH1N1, 360 contactos intradomiciliarios no relacionados biológicamente (CAS) y 133 pacientes con enfermedad similar a influenza negativos al virus AH1N1 (ESI). El genotipo de comparación fue el ancestral. Se correlacionaron los resultados con 27 variables clínicas de gravedad. El análisis de asociación de genotipos y alelos se realizó con EpiInfo v7.0. Resultados: El genotipo homocigoto $\mathrm{AG}$ en IL1B en el polimorfismo rs16944 fue asociado con la protección a desarrollar un 
cuadro clínico grave de influenza AH1N1 $(\mathrm{p}=0.04, \mathrm{OR}=0.52 \mathrm{IC} 95 \%$ [0.28-0.97]), respecto al genotipo homocigoto para el alelo ancestral. De forma similar, el SNP en IL6 rs1818879 GA se asoció al riesgo $(\mathrm{p}=0.0001$, OR $=5.94$ IC 95\% [3.0511.56]). No se encontraron diferencias significativas entre los pacientes y los contactos. En la tabla 1 se muestran la asociación entre la variable clínica y los SNPs. Conclusiones: Los SNPs en IL1B e IL6 desempeñan un papel importante en la susceptibilidad a desarrollar cuadros clínicos más graves causados por el virus de influenza AH1N1.

\section{4}

\section{Secuenciación del} promotor de TNF muestra perfiles genéticos asociados a la susceptibilidad y gravedad clínica de EPOC secundaria a tabaquismo

\section{Reséndiz HJM, Falfán VR, Ramírez $V A$, Sansores MR, Vargas $R$, Flores $T$, Camarena $O$}

INER Ismael Cosío Villegas

Antecedentes: La EPOC es una enfermedad caracterizada por limitación del flujo aéreo. Diferentes estudios han demostrado

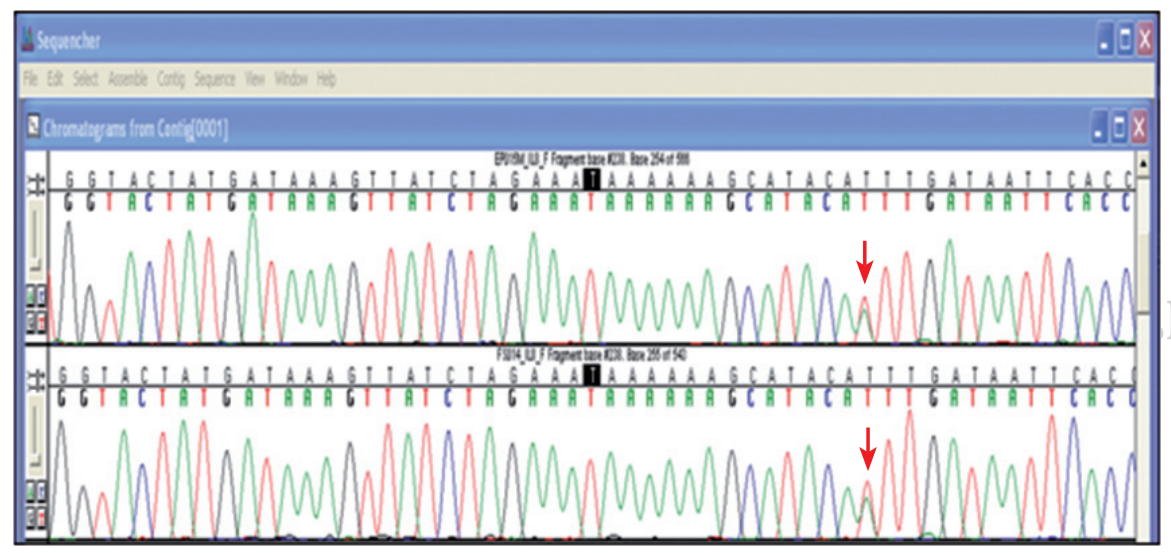

Figura 1. Se muestra una alineación comparativa de electroferogramas; las flechas indican un polimorfismo A/T. asociación de polimorfismos tipo SNP en genes involucrados en la inflamación, entre éstos IL6, TNF, e IL8. Adicionalmente la susceptibilidad genética a una enfermedad generalmente no es atribuible a un solo polimorfismo, sino a conjuntos de éstos. Material y métodos: Se incluyeron 165 personas con diagnóstico de EPOC (EP), el grupo de comparación fue integrado por 165 sujetos fumadores sin EPOC (FSE). La región génica incluida fue de la base -1 a -350 en TNF. La determinación de los perfiles genéticos fue realizada por secuenciación bidireccional, (Big Dye Terminator v3.1). Los electroferogramas fueron interpretados por medio del software sequencing analysis 5.4. La alineación comparativa de las secuencias se realizó con el software sequencher v5.1 (figura 1); el conjunto de secuencias que comparten variantes genéticas fue definido como perfil genético. El análisis estadístico fue realizado mediante la prueba de $\chi^{2}$ y valor de $\mathrm{p}$ con corrección de Yates. Resultados: Se determinaron 11 perfiles diferentes. El perfil 10 mostró una diferencia estadísticamente significativa entre en el grupo de EP vs. FSE (p $<0.001$ OR $=3.64$ IC95\% = 2.03-6.71); cuando se realizó la comparación entre los grados GOLD III+IV vs. I+II ( $\mathrm{p}=0.018$, OR = 3.6, IC 95\% = 1.19-11.53); al comparar GOLD III+IV vs. FSE los valores fueron $\mathrm{p}=0.0058 \mathrm{OR}=2.99 \mathrm{IC} 95 \%=$ 1.31-6.66, finalmente cuando se comparó el grupo GOLD I vs. II vs. FSE, el perfil 1 fue asociado $(\mathrm{p}=0.035 \mathrm{OR}=0.4 \mathrm{IC}$
95\% $=0.14-1.00)$. Conclusiones: Existen variaciones genéticas relacionadas con la regulación transcripcional, que están asociadas a la susceptibilidad y gravedad clínica de EPOC secundaria a tabaquismo.

\section{5}

Efecto de la humidificación sobre eventos adversos y cumplimiento al uso de la CPAP en pacientes con SAOS

Castorena A, Baños F, Castillo G, Carrillo A, Anaya R, López E, Galicia P

INER Ismael Cosío Villegas

Antecedentes: El dispositivo de presión positiva continua en la vía aérea (CPAP), es el tratamiento de elección para el síndrome de apnea obstructiva del sueño (SAOS); el uso de humidificación no es rutinario, pero podría ser una estrategia para incrementar el cumplimiento al tratamiento. El objetivo fue comparar los eventos adversos y el cumplimiento al CPAP con y sin humidificación térmica entre pacientes con SAOS. Materiales y métodos: Se analizó la base de datos de la Clínica de CPAP INER, se incluyeron pacientes con SAOS habitantes de la ciudad de México, al menos tres meses de tratamiento con CPAP; fueron excluidos pacientes con traqueotomía; se aplicó un cuestionario estandarizado de efectos adversos. Resultados: Se incluyeron 277 pacientes, 184 con humidificador y $93 \mathrm{sin}$ humidificador, sin diferencias en variables antropométricas, presión terapéutica y marcadores de gravedad. No se encontró diferencia en las horas/uso/promedio/día entre los pacientes con y sin humidificador $(6.3 \pm 0.4$ vs. $6.8 \pm 0.12, \mathrm{p}=0.3)$. No hubo diferencias entre los grupos al reportar algún evento adverso, sequedad de nariz/boca y cefalea matutina, aquellos que usaron humidificador reportaron más fuga $(19 \%$ vs. $36 \%$, respectivamente, $\mathrm{p}=$ 0.006). El reporte de mejoría subjetiva entre los grupos no tuvo diferencias ( $85 \%$ vs. $90 \%, \mathrm{p}=0.93$ ), pero el grupo con humidificador suspendió en menor frecuencia su tratamiento ( $19 \%$ vs. $0.05 \%$, $\mathrm{p}=0.001)$. El uso de humidificador no 
incrementó la probabilidad de reportar mejoría (OR 1.04, 0.33-3.22 IC95\%), pero si disminuyó la probabilidad de abandonar el tratamiento (OR 0.26, 0.11-0.61 IC95\%). Conclusiones: En pacientes con SAOS, un dispositivo humidificador térmico disminuye la posibilidad de abandono al tratamiento con CPAP a tres meses de uso.

\section{4}

\section{Utilidad del ensayo Xpert MTB/RIF para el diagnóstico de tuberculosis pulmonar}

Muñoz TMV, Carrillo R, Villarreal V, Flores V, Suárez L, Alonso M, Salazar L

INER Ismael Cosío Villegas

Objetivo: Determinar la exactitud diagnóstica del ensayo Xpert MTB/RIF comparada con el cultivo en muestras de expectoración y/o lavado bronquial, en pacientes con sospecha de tuberculosis pulmonar. Diseño: Se revisaron retrospectivamente los expedientes clínicos de pacientes con sospecha de tuberculosis pulmonar (TBP) en quienes se solicitó Xpert MTB/RIF y cultivo con pruebas de sensibilidad (PFS) en muestras de expectoración y/o lavado bronquial. Se estimó la sensibilidad, especificidad, valor predictivo positivo (VPP) y el valor predictivo negativo (VPN) del Xpert MTB/RIF, utilizando como estándar de oro el cultivo para micobacterias en medio sólido (Lowenstein Jensen) y medio líquido (BACTEC MIGIT). Resultados: 41 pacientes con sospecha de TBP fueron incluidos en el análisis final. En 29 pacientes se confirmó el diagnóstico de TBP por cultivo y Xpert MTB/RIF positivos para M. tuberculosis (MTB); en 8 pacientes el cultivo y el Xpert MTB/RIF fueron negativos y se egresaron con otro diagnóstico; en 4 pacientes el Xpert MTB/RIF fue positivo, pero el cultivo negativo. En esta revisión, se identificaron 15 pacientes con resistencia a rifampicina a través del ensayo Xpert MTB/RIF y se confirmó con cultivo y PFS en 14 pacientes. Utilizando como estándar de oro el cultivo, la sensibilidad y especificidad del Xpert MTB/RIF fue del $100 \%$ y del $67 \%$, respectivamente; el VPP y VPN fueron del $88 \%$ y $100 \%$. Conclusión: El ensayo Xpert MTB/RIF tiene una alta sensibilidad y especificidad para el diagnóstico de TBP y para la detección rápida de pacientes con tuberculosis resistente a rifampicina. Comparado con el cultivo tuvo una alta concordancia, por lo que en el futuro podría superar a esta prueba como estándar de oro debido a que el Xpert MTB/RIF ofrece ventajas tales como la prontitud de los resultados y la facilidad de su proceso.

\section{8 Experiencia en el manejo quirúrgico de los tumores de vía aérea central}

\section{Narváez FS, Ruiz ZJL, Miranda FA, Araiza $A$}

Hospital Regional de Alta Especialidad del Bajío, Unidad Médica de Alta Especialidad Bajío

Antecedentes: Los tumores que se localizan en el interior de la vía aérea central ofrecen un reto quirúrgico en cuanto a su manejo, ya que en ciertas ocasiones están ubicados en sitios donde es posible realizar una resección tumoral y anastomosis término terminal de los bordes. Sin embargo, en otros casos los sitios de ubicación o la destrucción pulmonar retrógrada al mismo tumor, hace que sea más seguro para el paciente ofrecer una cirugía de resección pulmonar. Material y métodos: Se presenta la experiencia de siete casos de pacientes con tumores dentro de la vía aérea central: 1 en tráquea proximal, 1 en tráquea distal, 3 en bronquio intermediario, 1 en bronquio del lóbulo superior derecho y 1 en bronquio principal izquierdo. En 3 pacientes fue posible realizar resección tumoral y anastomosis término terminal de la vía aérea, y fueron los pacientes de los tumores en tráquea y el localizado en bronquio principal izquierdo. A los 3 tumores localizados en bronquio intermediario se les realizó bilobectomía media e inferior, así como lobectomía superior derecha al localizado en bronquio de lóbulo superior derecho. Resultados: Todos los pacientes evolucionaron de manera satisfactoria. El número de días promedio en terapia fue de tres y de internamiento de siete. Todos los pacientes siguen vivos hasta el momento, teniendo un período de seguimiento mayor a cinco años. Conclusiones: Es de suma importancia conocer la experiencia de otras instituciones para poder así determinar nuestro propio accionar y tomar las mejores decisiones al momento de considerar un plan quirúrgico para nuestros pacientes. Esperamos que los resultados presentados cumplan estos objetivos.

\section{9}

Sedación profunda y superficial en pacientes con ventilación mecánica asistida VMA

\section{Villazon SS}

Hospital de Especialidades, CMN XXI

Antecedentes: La sedación de pacientes con VMA suspendida y revaluada cada 24 $h$ es una rutina reconocida en las unidades de terapia intensiva. En México, las instituciones ISSTE, IMSS, SSA mantienen la costumbre de tener una población de pacientes graves con VMA en los pisos comunes de hospitalización. La sedación en estas condiciones suele ser profunda y más prolongada, cuando se usan sistemas de ventilación asistocontrolada. Se reportan cinco meses de comparación entre sedación profunda Ram 4-5 y sedación superficial Ram 2-3, con observación en mortalidad, uso de presores y neumonía asociada a ventilador entre los dos grupos. Material y métodos: Se reporta el resultado parcial de 37 pacientes en piso común con VMA divididos en dos grupos; a) pacientes controlados por nuestro servicio en sedación continua Ram: 2`3, y pacientes sedados y controlados por sus servicios. Las variables comparadas son: mortalidad, neumonía asociada a ventilador (NAV), tiempo de ventilador y uso de pretores. Resultados: 19 pacientes en grupo 1 y 13 pacientes en grupo 2, 5 pacientes excluidos por traslado a Cuidados Intensivos. Mortalidad general: G1 47\%, G2 34\%; NAV: G1 52\% G2 46\%; tiempo de ventilador: G1 12 
\pm 8 días, G2 $15 \pm 10$ días. Uso de presores/ día: G1 8 días, G2 3 días.

\section{CARTELES}

01

\section{Neumología} Navarro VDI, Cueto RG, Yescas SG,
Barragán PG

Hospital General de México

Descripción: La hipertensión pulmonar (HP) es una complicación común de las enfermedades pulmonares intersticiales (EPIs), lo que se asocia con baja capacidad de ejercicio y pobre pronóstico. El grado de HP generalmente es leve a moderado; sin embargo, algunos pacientes desarrollan un aumento desproporcionado de la HP que no se justifica por la hipoxia y lesión parenquimatosa. Objetivo: Evaluar los parámetros hemodinámicos mediante CCD incluyendo vasorreactividad pulmonar de pacientes con HP del grupo 3 de la Unidad de Neumología del Hospital General de México (HGM). Material y métodos: Los datos se obtuvieron de un estudio prospectivo de pacientes con HP de la Unidad de Neumología del HGM desde 2010, se incluyeron pacientes con cuadro clínico, estudios de imagen y ecocardiograma sugestivos de HP, portadores de neumopatía crónica. Los resultados de datos pareados se analizaron mediante prueba t de student, con IC 95\%. Resultados: De los 12 pacientes incluidos con neumopatía crónica, en 10 pacientes se corroboró HP por CCD. De los cuales, $70 \%$ son hombres y $30 \%$ mujeres, edad promedio de 53 años, 8 con fibrosis pulmonar idiopática, 1 síndrome de sobreposición y 1 con linfangioleiomiomatosis. En el $50 \%$ se encontró HP desproporcionada (PAPm $\geq 35 \mathrm{mmHg}$ ). La PAPm promedio fue $41 \mathrm{mmHg}$, con disminución a 34.88 con la administración de iloprost (p 0.002). Se observó, además, aumento del GC (p 0.000) y disminución de la RTP (p 0.010). Conclusiones: La patogénesis de HP en estos pacientes no es del todo entendida y puede ser multifactorial. Como mecanismos implicados se mencionan obstrucción vascular o destrucción por fibrosis parenquimatosa progresiva, vasoconstricción pulmonar hipóxica y remodelamiento vascular debido a sobreexpresión de citocinas y factores de crecimiento; y disfunción endotelial, sugiriendo un fenotipo vascular anormal en el subgrupo de pacientes con HP moderada-severa; lo que podría explicar la vasorreactividad positiva encontrada en nuestro grupo de pacientes.

\section{2}

\section{Resultados de un} programa de rehabilitación respiratoria domiciliario en pacientes con enfermedades difusas del parénquima pulmonar

Toral FSC, Galicia A

INER Ismael Cosío Villegas

Descripción: Las enfermedades difusas del parénquima pulmonar (EDPP) cursan con disnea al ejercicio, intolerancia al ejercicio, fatiga y pobre calidad de vida (CV). Los síntomas ocasionados por las diferentes anormalidades estructurales en el pulmón, la disfunción musculoesquelética pueden mejorar como resultado de la participación de un programa de rehabilitación pulmonar (RP). El entrenamiento supervisado es útil para mantener o mejorar las condiciones generales de estos enfermos; sin embargo, muchos no tienen la capacidad para acudir a los pocos centros de RP que existen en el país, por lo que diseñar programas a domicilio es una buena opción. Objetivo: Valorar el impacto de un programa de RP llevado en domicilio por los propios pacientes, en la distancia recorrida en caminata de 6 minutos (C6M) y en dos cuestionarios de calidad de vida: San George y SF 36. Material y métodos: Diseño: Longitudinal, cohorte prolectiva. Pacientes con EDPP que no puedan asistir al Departamento de Rehabilitación Pulmonar del INER. Período: marzo del 2007 a diciembre 2013. Variables: Demográficas, C6M, Cuestionario San George y SF-36 al inicio y al término del programa de RP.
Enseñanza de los ejercicios que reprodujo el paciente en su casa cada tercer día por tres meses. Resultados: Cohorte de 517 pacientes, 301 terminaron el estudio. El $69 \%$ correspondió a fibrosis pulmonar, $25 \%$ a alveolitis alérgica extrínseca, el resto a otras EDPP. Los resultados en C6M mejoraron 32.5 metros con $\mathrm{p}<0.003$, el cuestionario San George tuvo mejoría de 7 puntos en total en promedio y el SF 36 mejoró en promedio en SG, RF, RE. Conclusión: La RP domiciliaria mostró beneficios en pacientes con EDPP que no pudieron acudir a nuestra institución. La CV pareció no tener gran mejoría, al menos medida por San George y SF 36. El grupo heterogéneo y sus diferentes fisiopatologías debilitan este estudio.

03

\section{Detección de} broncoespasmo inducido por ejercicio mediante oscilometría de impulso en niños asmáticos

\section{Mora RUJ \\ INER Ismael Cosío Villegas}

Descripción: La espirometría es el estándar de oro en la evaluación de los pacientes con asma. La prueba de reto bronquial con ejercicio (PRBE) evalúa el efecto del ejercicio sobre los parámetros espirométricos. La oscilometría de impulso (IOS) evalúa la mecánica pulmonar, es útil en los pacientes poco cooperadores, mide la resistencia y reactancia del sistema respiratorio. Justificación: Cuando el paciente asmático tiene síntomas y la espirometría es normal, es necesario realizar PRB para descartar broncoespasmo. La IOS evalúa la mecánica respiratoria y podría ser útil en la evaluación basal funcional de los pacientes asmáticos. Objetivos: 1) describir la proporción de pacientes con espirometría basal normal, sin respuesta al broncodilatador, y IOS basal con resistencias aumentadas o respuesta positiva al broncodilatador; 2) analizar la proporción de paciente con PRB positiva y que la IOS basal mostrara aumento en las resistencias 
o fueran positivos a broncodilatador; 3 ) conocer cuántos pacientes con PRBE positiva presentan aumento en las resistencia medidas por IOS. Método: Se invitaron a participar a pacientes asmáticos de 5 a 14 años de edad, con síntomas respiratorios cuya espirometría basal era normal y sin respuesta al broncodilatador, se les otorgó una nueva cita para la PRBE. Resultados: Se incluyeron a 21 pacientes, en condiciones basales 8 (38.1\%) presentaron aumento de las resistencias a $5 \mathrm{~Hz}$ y $11(52.3 \%)$ con respuesta positiva al broncodilatador. $\mathrm{Al}$ considerarse alguna alteración en IOS basal se observó una sensibilidad de $80 \%$ y especificidad de $42 \%$. Conclusiones: $\mathrm{La}$ IOS permite detectar alrededor del $50 \%$ de los pacientes que tendrán una PRBE positiva desde la evaluación basal. Sin embargo, se observó una baja sensibilidad y especificidad por lo que consideramos que la espirometría debe seguir siendo el estándar de oro en la evaluación de pacientes asmáticos sintomáticos.

\section{5}

\section{Serie de casos de}

\section{actinomicosis pulmonar en un centro de referencia nacional (INER-Ismael Cosío Villegas) en un lapso de 10 años 2004-2014}

Escobar PMA, Chávez M

INER Ismael Cosío Villegas

Introducción: Es una entidad clínica rara, su frecuencia e incidencia es desconocida, su importancia radica en la dificultad de su identificación oportuna, siendo confundida frecuentemente con neoplasia, acabando en muchas ocasiones en eventos quirúrgicos. Material y métodos: Revisión de base de datos del INER y expedientes de pacientes hospitalizados en el período de enero 2004 a enero 2014. Resultados: Se atendieron en un lapso de 10 años un total de 6 pacientes, 5 pacientes masculinos, 1 femenino, estudiando las siguientes variables: La edad media fue: 47.3 años. El síntoma más común fue ataque al estado general $100 \%$, seguido de dolor torácico y hemoptisis (50\%), fiebre $33 \%$. Tiempo de evolución promedio 16.66 meses. El diagnóstico de ingreso más común: neoplasia pulmonar. Broncoscopia $100 \%$ reportó hallazgos inflamatorios. Espirometría: 33\% restrictiva, $33 \%$ normal, $16 \%$ obstrucción, $16 \%$ no se realizó. Pletismografía reportó atrapamiento aéreo $33 \%$ casos. TAC afección $50 \%$ izquierda, $16 \%$ bilateral, $16 \%$ derecha, $16 \%$ sin afección. Hallazgo más común: tumoración absedada. Hallazgo odontológico más común: periodontitis generalizada. Estancia promedio: 16.25 días. Sólo se presentó una complicación fístula pleurocutánea. Conclusión: Es una entidad rara vez diagnosticada, de larga evolución en pacientes con factores predisponentes como inmunosupresión, bajo estrato social, mala higiene oral, la cual termina en desenlace quirúrgico prevenible con una identificación y tratamiento oportuno, es importante considerarlo en el diagnóstico diferencial de tumoración pulmonar.

\section{6}

Tumor fibroso solitario de la pleura. Revisión de 10 años en un centro de referencia

\section{Hernández LB, Mendoza $P$, Carrillo $R$}

INER Ismael Cosío Villegas

Antecedentes: El tumor fibroso solitario de la pleura (TFSP) es un tumor raro que ocupa el $5 \%$ de todos los tumores pleurales, y el $1 \%$ de la actividad quirúrgica torácica. Suele ser benigno. Justificación: En Latinoamérica existen pocas series de casos de esta patología y México no es la excepción. El Instituto Nacional de Enfermedades Respiratorias (INER) es un centro de referencia nacional en donde se desconoce el comportamiento clínico, las características radiológicas, de malignidad y la sobrevida de esta patología. Objetivos: Analizar la prevalencia, comportamiento clínicoradiológico y características asociadas a malignidad. Metodología: Estudio clínico restrospectivo, transversal, descriptivo en donde se incluyeron pacientes de ambos sexos mayores de edad, con diagnóstico histopatológico de TFSP del 1 de abril de 2002 al 1 de abril de 2012 en el INER. Resultados: Prevalencia $8.6 \%$, predilección por mujeres, edad media 57 años. Síntomas cardinales: tos, disnea y dolor torácico; discreta preferencia del hemotórax izquierdo; llegó a medir hasta $35 \mathrm{~cm}$ y un peso de hasta 3,500 g. El diagnóstico se da en la mayoría de los casos mediante biopsia transtorácica, con positividad en $100 \%$ para CD34, BCL2 y vicentina. Baja morbimortalidad postoperatoria. Recurrencia del 32\%. Conclusiones: El TFSP es una neoplasia infrecuente de comportamiento benigno en el $80 \%$ de las veces, de curso clínico indolente, con diagnóstico preoperatorio difícil, curable tras la resección quirúrgica. Se aconseja embolización preoperatoria. Es importante investigar criterios de malignidad y dar seguimiento hasta por 20 años dado su período de recurrencia.

09

\section{Frecuencia de linfangioleiomiomatosis en el Instituto Nacional de Enfermedades Respiratorias}

Barreto RJO, Mejía Á, Buendía R

INER Ismael Cosío Villegas

Descripción: La linfangioleiomiomatosis (LAM) en una enfermedad multisistémica, lenta y progresiva que a nivel pulmonar causa destrucción quística e insuficiencia respiratoria, es más frecuente en mujeres y dependiendo de la serie se reporta en 3.4-7.8 casos por millón de pacientes, existe una asociación con el complejo de esclerosis tuberosa de al menos el $30 \%$, el promedio de edad al diagnóstico es 35 años. La función pulmonar disminuye entre 3 a $15 \%$ por año y a los 10 años del diagnóstico, cerca de $55 \%$ de las pacientes tienen disnea con actividades diarias, $20 \%$ requieren oxígeno suplementario y 10\% han fallecido. Objetivo: Determinar la frecuencia del diagnóstico de LAM y características clínicas de los pacientes 
en el INER. Metodología: Se realizó un estudio retrospectivo, observacional de pacientes con diagnóstico de LAM a su egreso de hospitalización, en el INER del 2000-2013. Resultados: Se identificaron durante el período de estudio 4 pacientes, $100 \%$ mujeres, con promedio de edad de $30 \pm 3$ años, el tiempo de evolución al diagnóstico fue aproximadamente de 1 año en todos los casos, la presentación clínica al momento del diagnóstico fue en 3 casos neumotórax primario y en 1 caso de quilotórax, en todos los casos las pruebas de función respiratoria basales presentaron patrón obstructivo, el esquema de tratamiento fue muy variable en todos los casos de acuerdo al criterio médico al momento del diagnóstico. Conclusiones: Tal como se reporta en la literatura, la prevalencia de esta enfermedad en el instituto es baja. Al igual que en el resto de las enfermedades intersticiales, el tiempo de referencia a 3er. nivel es largo, lo que hace tardado el diagnóstico definitivo. El tratamiento en estos casos debe ser unificado de acuerdo a los estándares internacionales. A partir de este año, el INER forma parte del grupo de referencia de la LAM Foundation.

10

Epidemiología de enfermedades pulmonares intersticiales difusas en el Centro Médico ABC 20092014

Padua GJ, Baquera H, Calva A

Centro Médico ABC

Antecedentes: En virtud de las diferencias en frecuencia y causas más comunes de enfermedad pulmonar intersticial difusa (EPID) en el mundo; y particularmente, la ausencia de criterios para homogenizar el estudio y diagnóstico de las EPID en Latinoamérica, es de vital importancia para la neumología mexicana, crear una base de datos para el reporte de las EPID en el ámbito de la medicina institucional y privada con el objeto de conocer la epidemiología de esta patología en México y mejorar el diagnóstico y atención tempra- na de los pacientes. Métodos: Se realizó la búsqueda conjunta con patología e imagenología de los pacientes con diagnóstico de neumopatía intersticial del 01 de enero de 2009 al 01 de enero de 2014; y se hizo una revisión de los expedientes clínicos para hacer el primer trabajo descriptivo y epidemiológico de estas entidades en un hospital privado en México, con objeto de conocer la incidencia, prevalencia, los tipos más frecuentes y variables demográficas de los pacientes, así como los métodos diagnósticos empleados (TCAR, lavado broncoalveolar, biopsia transbronquial, biopsia guiada por videotoracoscopia), los hallazgos tomográficos y el tratamiento de las mismas, así como la morbilidad y mortalidad.

\section{4}

Estudio exploratorio para evaluar las diferencias en la presentación de enfermedad pulmonar intersticial en pacientes con síndrome de Sjögren primario versus secundario

Buendía I, Mateos T, Rojas S, Estrada G, Navarro G, Barreto R, Mejía Á

INER Ismael Cosío Villegas

Descripción: Una de las manifestaciones sistémicas más comunes en el síndrome de Sjögren primario (pSS) es el involucro pulmonar, se presenta hasta en el $42.3 \%$ de los casos en algún momento de la enfermedad. En $25.2 \%$ de los casos, la afección pulmonar puede preceder al diagnóstico, y la afección intersticial es la más común (23.2\%) siendo, además, un factor relacionado a evolución y pronóstico, se ha reportado que a mayor puntaje de fibrosis en tomografía mayor mortalidad. Se evaluó en la Clínica de Enfermedades Intersticiales del INER de enero a diciembre del 2012, los casos con enfermedad pulmonar intersticial asociada con enfermedad colágeno vascular, se formaron dos grupos: síndrome de Sjögren primario (pSS) o secundario (sSS), se identificaron 21 pacientes con
SS, 13 se clasificaron como pSS y 8 como sSS; en este último las enfermedades asociadas: 5 artritis reumatoide (AR), 2 esclerosis sistémica progresiva (ESP) y 1 lupus eritematoso sistémico (LES), el $81 \%$ correspondieron al género femenino (17/21), edad promedio en ambos grupos $58.4 \pm 10.7$ años (37-80), las pruebas de función pulmonar entre pSS y sSS no mostraron diferencia: CVF \% $61.7 \pm 11.9$ vs. $74.3 \pm 40.8, \mathrm{p}=0.39, \mathrm{SO}_{2}$ en reposo $83 \pm 9 \%$ vs. $87 \pm 5 \%, \mathrm{p}=\mathrm{NS}, \mathrm{PaO}_{2} 51 \pm$ $7 \mathrm{mmHg}$ vs. $54+6 \mathrm{mmHg}$, p NS. Con relación al patrón intersticial en el pSS se identificaron: NIU 7, NIL 4 y NINE 2, mientras que en el sSS NIU 2, NIL 3, NINE 1 y $\mathrm{BO}_{2}$, el puntaje de fibrosis por TCAR en pSS fue de $1.35 \pm 0.85$ vs. 0.75 \pm 0.88 en sSS, p 0.13, mientras que inflamación fue de $1.47 \pm 0.70$ vs. $1.25 \pm 0.46$ p 0.43, respectivamente. Conclusión: Este estudio exploratorio no muestra diferencias en las pruebas respiratorias y puntajes de la TCAR entre grupos; sin embargo, una limitación es el número de muestra, por lo que se requieren estudios posteriores.

16

Relación de la apnea hipopnea obstructiva del sueño con obesidad e impacto de la titulación con CPAP evaluados con video de polisomnografía

Pella CV, Alanis G, Vázquez R, Pérez L

Clínica Epilepsia y Sueño, Hospital Ángeles Pedregal, México, D.F.

Descripción: El síndrome de apnea hipoapnea obstructiva del sueño (SAHOS) es un trastorno crónico, progresivo, frecuentemente asociado a enfermedades metabólicas, cardiovasculares y cerebrovasculares, con elevado riesgo laboral y accidentes de tránsito, mala calidad de vida, sueño, deterioro cognitivo y una mortalidad elevada. Afecta al 5\% de la población adulta y al $2 \%$ de niños. Ocasionada por una disminución del calibre de la vía aérea respiratoria superior que ocasiona eventos recurrentes de colapso 
de las paredes faríngeas durante el sueño, provocando episodios de hipoxemia, evidenciados por ronquidos y despertares. El diagnóstico se basa en la sospecha clínica y en la realización de polisomnografía completa. El tratamiento consiste en el uso de CPAP. Pacientes y métodos: Estudio descriptivo, retrospectivo, transversal de 100 pacientes, enviados por sospecha de apnea del sueño, roncopatía e hipersomnolencia, a la Clínica del Sueño del Hospital Ángeles del Pedregal, Ciudad de México, para efectuarles estudio de video-polisomnográfico (VPSG) nocturno, entre junio 2010 a junio 2013, población adulta, enviados por médicos otorrinolaringólogos, neumólogos, cardiólogos, internistas y neurólogos. Resultados: El 82\% de pacientes fueron masculinos, edad promedio 53 años con un rango de 21 a 86 años, mayores de 65 años $21 \%$. El motivo de envío fue por ronquido en $37 \%$, apnea en $39 \%$. El tiempo promedio del padecimiento fue de 9.5 años con un predominio mayor a 30 años en el $83 \%$ de casos. La comorbilidad se encontraba asociada a hipertensión arterial en el 57\%, síndrome metabólico 64\%, enfermedad cardíaca $16 \%$ y diabetes en $13 \%$, sobrepeso y obesidad $90 \%$, con un índice de masa corporal (IMC), escala de Mallampati grado III y IV en el 75\%. La VPSG demostró apnea obstructiva en el $70 \%$, central $31 \%$ y mixta en el $26 \%$, grado severo de apnea en $82 \%$ y moderado en $15 \%$. El promedio de la fase 3-4 de sueño fue del $12 \%$ y para el REM fue del $10 \%$, valores que se duplicaron de inmediato con la aplicación del CPAP nasal a una presión media de $8 \mathrm{cmH}_{2} \mathrm{O}$ con una disminución significativa de la apnea severa al 20\%. Conclusiones: Existe un retraso en el diagnóstico y tratamiento de los pacientes con SAHOS con una media de 10 años. La obesidad estuvo presente en el 90\%. El tratamiento con CPAP mejora las fases de sueño, sueño profundo y sueño REM con un claro beneficio hemodinámico y cardiovascular por registros comparativos pre y postratamiento.

\section{1 \\ Identificación de micobacterias no}

\section{tuberculosas en adenopatías cervicales de pacientes VIH seropositivos y seronegativos}

\section{Thirion RII, Cicero S, Hernández S, Gonzáles G}

Hospital General de México

Introducción: La OMS estima que una tercera parte de la población mundial está infectada de tuberculosis y cada año se presentan 9.2 millones de nuevos casos con una mortalidad de 1.7 millones. En México hubo 15,000 nuevos casos y 2,000 muertes en 2012. La tuberculosis pulmonar es la forma más común y se registra un aumento de extrapulmonares 17 a $20 \%$ con 27 a $35 \%$ en nodos linfáticos. La mayoría por complejo M. tuberculosis. La transición epidemiológica que ocurre en México incluye las micobacterias no tuberculosas (MNTB) que pueden confundirse con las tuberculosas en las pruebas bacteriológicas rutinarias Ziehl-Neelsen (BAAR) y los cultivos en Löwenstein-Jensen y MGIT960. Las especies de MNTB deben identificarse porque no responden al tratamiento antituberculoso. Las MNTB no se adquieren por contacto directo, se encuentran en el medio ambiente y clínicamente se asemejan a la tuberculosis y deben ser tratadas de inmediato para evitar complicaciones graves. Objetivo: Identificar la frecuencia y las especies de MNTB en nodos linfáticos. Material y métodos: Estudio transversal retrospectivo y prospectivo en muestras de biopsias de nodo linfático afectado (2010-2012) para análisis histopatológico, bacteriológico y de biología molecular con amplificación de la secuencia de inserción IS6110 con PCR RFLP de cepas identificadas como complejo $M$. tuberculosis. Resultados: De 45 biopsias, 20 fueron de VIH+ y 25 VIH-, con diferencia significativa con t-Student (p-value $\leq 0.001$ ) para muestras independientes sin diferencia significativa en $\chi^{2}$ de Pearson para $95 \%$ IC. En los VIH+ se encontraron dos $M$. intracellulare y una M. gordonae, en los
VIH- una M. fortuitum. Conclusión: La mayor causa de micobacteriosis linfógena es M. tuberculosis. Las cepas de MNTB deben ser identificadas para indicar el tratamiento adecuado.

\section{2 \\ Salud respiratoria en niños con sobrepeso y obesidad}

Ramírez AJ, Gochicoa R, Mora RUJ

Estudio multicéntrico, D.F. (INER), Mérida, Tepic, Monterrey, Toluca, Texcoco

Descripción: La obesidad, incluyendo al sobrepeso como un estado premórbido, predispone a la presentación de trastornos que deterioran el estado de salud. En México, es considerada el principal problema de salud pública. La prevalencia nacional combinada de sobrepeso y obesidad en 2012, en la población de 5 a 11 años utilizando los criterios de la OMS fue de $34.4 \%$. Representan alrededor de $5,664,870$ niños con sobrepeso y obesidad. Las cifras en escolares no han aumentado en los últimos seis años. Material y métodos: Estudio prospectivo, transversal. Se estudiaron niños que acuden a escuelas preprimarias, primarias y secundarias de las siguientes ciudades de la República Mexicana: Mérida, Tepic, Monterrey, Toluca, Texcoco y Distrito Federal, entre 3 y 15 años, con peso normal, sobrepeso y obesidad determinado por valores- $Z$ para índice de masa corporal (IMC). Se aplicó un cuestionario de salud y midió la estatura, el peso y oximetría de pulso. Resultados: Se recabaron 2,315 cuestionarios, de los cuales 1,213 (52.4\%) fueron hombres, la edad promedio de la población fue de 8.9 años (+3 DE), estatura de $130.4 \mathrm{~cm}(+18.7 \mathrm{DE})$, peso $32.5 \mathrm{~kg}(+14.4 \mathrm{DE})$, IMC de $18.2(+3.6) \mathrm{y}$ oximetría de pulso de $95.4 \%$ (+5.3 DE). Para el análisis se incluyeron 1,702 niños, de éstos el $41 \%$ presentaron sobrepeso u obesidad, el género masculino predominó en los niños con obesidad. Los resultados muestran que en niños mexicanos, existe una mayor asociación entre tener más asma, otitis, alergias y roncar al dormir y el estado antropométrico; es decir, tener peso normal, sobrepeso u obesidad. Estos 
resultados apoyan la asociación descrita entre obesidad e inflamación, así como la asociación entre obesidad y roncar.

\section{3}

\section{Desempeño de la biopsia pleural cerrada para el diagnóstico de cáncer de pulmón o mesotelioma en pacientes con derrame pleural}

\section{Báez SR, Rumbo N, Castillo G Aguirre $P$, León $D$, Vázquez $M$}

INER Ismael Cosío Villegas

Antecedentes: Recién, ha despertado controversia el valor de la biopsia pleural cerrada como procedimiento de diagnóstico para neoplasia pulmonar o pleural en pacientes con derrame pleural. Objetivo: Evaluar la exactitud de la biopsia pleural cerrada para establecer el diagnóstico de cáncer de pulmón o mesotelioma en pacientes con derrame pleural. Métodos: Se realizó un estudio ambispectivo en todos los individuos con derrame pleural, y que se sometieron a la realización de biopsia pleural cerrada para establecer la etiología del derrame durante un período de 8 años en un hospital de referencia de enfermedades respiratorias. La información de cada paciente se tomó de los registros de anatomopatología y expediente clínico. Cuando el resultado de la biopsia pleural cerrada demostró malignidad o tuberculosis se tomó como biopsia diagnóstica y quedó éste como diagnóstico definitivo. En casos en que el resultado del estudio histopatológico de la biopsia resultó inespecífica, el diagnóstico definitivo se estableció con base en otros procedimientos diagnósticos, como prueba/s estándar de oro, y fueron: toracoscopia, toracotomía para biopsia pulmonar/pleural, fibrobroncoscopia, características bioquímicas y celulares del líquido pleural y/o pruebas microbiológicas. Mediante una tabla de contingencia de 2 × 2 se midieron: sensibilidad, especificidad, valores predictivos positivo y negativo e índices de probabilidad. Resultados: Se estudiaron 1,034 biopsias de pacientes, se excluyeron 169
(16.34\%) por muestra inadecuada o información clínica insuficiente. El desempeño para cáncer de pulmón o mesotelioma fue: sensibilidad 77\% (IC95\% 74\%-79\%), especificidad 98\% (IC 95\% 97-99\%), valor predictivo positivo 99\% (IC95\% 98\%$100 \%$ ), valor predictivo negativo $66 \%$ (IC95\% 63\%-70\%), razón de verosimilitud positiva 38.5 , razón de verosimilitud negativa 0.23 , prevalencia $68 \%$. Conclusión: La biopsia pleural cerrada en el sitio de estudio es útil en nuestra práctica, debido a que produce un cambio importante de la probabilidad antes de la prueba a la probabilidad después de la prueba.

\section{6}

\section{Respuesta inmune innata en pacientes con tuberculosis pulmonar $\mathrm{y}$ diabetes mellitus tipo 2}

\section{Arango GE \\ INER Ismael Cosío Villegas}

Introducción: Diversos aspectos de la inmunidad se encuentran alterados en los pacientes con DM tipo 2. La inmunidad celular innata parece ser la más afectada, la inmunidad celular adaptativa se ve afectada con una disminución de la respuesta proliferativa linfocítica a estímulos y a algunos patógenos. Objetivos: Comparar los niveles de biomarcadores de inflamación como PCR, VSG, albúmina, DHL y la producción de citocinas intracelulares (TNF $\alpha$, IFN $\gamma$, IL-12, IL-10) en pacientes con tuberculosis pulmonar (TBP) comprobada bacteriológicamente y diabetes con TBP sin diabetes. Material y métodos: Estudio prospectivo transversal de pacientes consecutivos con diagnóstico de TBP y diabetes mellitus tipo 2 y pacientes con TBP sin diabetes. Los pacientes fueron reclutados de la Clínica de Tuberculosis (hospitalización, consulta externa). Todos recibieron el tratamiento antituberculosis de acuerdo a la NOM006-SSA2-1993. Los biomarcadores de inflamación fueron determinados por el Laboratorio Clínico del INER. La medición de las interleucinas en células de sangre periférica. Las comparaciones entre dos grupos se realizaron con prueba de T o U-Mann Whitney de acuerdo a la distribución de las variables. Para la comparación de frecuencias se utilizó $\chi^{2}$. Se realizó correlación de Spearman entre los niveles de los biomarcadores y los niveles de glucemia. Resultados: Se encontró una tendencia hacia niveles más altos de INFg en el grupo de pacientes con DM y TB. Los niveles de IL-10, IL12 e TNF- $\alpha$ fueron más bajos en el grupo de pacientes con TB y DM. Conclusión: Existe una compleja interrelación entre DM y TB, se demuestra que el perfil de citocinas es variable, en especial el INF- $\gamma$ resultó estar elevado en los pacientes con TB y DM. Estos datos proporcionan la base para otros estudios centrados en vías específicas y tener una mejor comprensión de los eventos celulares y moleculares que subyacen a la asociación entre estas dos patologías.

\section{7}

Poligrafía respiratoria en médicos residentes del hospital de especialidades CMNO-UMAE

\section{Santoyo $A R$}

Hospital de Especialidades CMNO-UMAE

Descripción: El ronquido es un problema común en todas las edades y en ambos sexos. Afecta aproximadamente a 90 millones en Estados Unidos en adultos, 37 millones roncan regularmente, la prevalencia del ronquido es de un 25-50\% en edades medias, el roncar se puede presentar cada noche intermitentemente, las personas con mayor riesgo son aquellas con sobrepeso, anormalidades anatómicas de la garganta, pólipos nasales, desviación del tabique nasal. Afecta a ambos sexos, aunque la mujer no lo presenta tan frecuente como el hombre; el ronquido se hace más frecuente con la edad, puede causar incomodidad del paciente y despertar con su propio ronquido o causar un problema con su compañero de cuarto. Esto puede causar un sueño fragmentado, lo que puede generar un pobre desempeño durante el día, como cansancio y somnolencia. Material y métodos: Se invitó a 
todos los médicos residentes del Hospital de Especialidades del CMNO-UMAE que presentaran somnolencia diurna y ronquido, se utilizó un equipo de poligrafía embleta nivel III con bandas pletismográficas y el estudio se realizó en la casa del residente. Se realizaron 170 estudios de poligrafía respiratoria, participando 128 del sexo masculino y 42 del sexo femenino. Encontrando que 117 estudios fueron negativos para apnea del sueño, 46 estudios con apnea leve, 4 con apnea moderada y 3 con apnea severa. En cuanto al IMC, 51 residentes con peso ideal, 69 con sobrepeso y 50 con obesidad; además, la mayoría de los residentes roncó en forma intermitente durante el estudio. También se observó que el IAH, en los leves, el más alto fue de 11. Conclusiones: El presente estudio tenía la finalidad de ver sí la somnolencia de los médico residentes era debido a las guardias frecuentes y al cansancio, o si había pacientes con apnea del sueño.

\section{8}

\section{Biomarcadores de riesgo cardiovascular en pacientes con apnea obstructiva del sueño}

\section{Díaz RMA, Bautista H, Mares G, Septién $S$}

Hospital General de México

Descripción: El síndrome de apnea obstructiva del sueño (SAOS) se caracteriza por la oclusión intermitente de la vía aérea durante el sueño, apneas, hipoxemia intermitente y somnolencia diurna. La gravedad de la enfermedad se estima mediante el número de apneas/hipopneas por hora de sueño, conocido como el índice de apnea/ hipopnea (IAH). El SAOS se asocia a daño endotelial y a incremento en el riesgo cardiovascular. Al presente, existen diferentes biomarcadores que se asocian a mayor morbilidad y mortalidad, entre ellos están el ancho de distribución eritrocitaria (RDW), gama glutamiltranspeptidasa (GGT) y ácido úrico (AU). Los pacientes con obesidad hipoventilación presentan mayor mortalidad y se ha observado menor saturación durante el sueño en estos pacientes. El objetivo del estudio es evaluar la asociación de estos biomarcadores y la gravedad del SAOS en población mexicana. Diseño del estudio: Observacional, descriptivo, transversal. Se incluyeron a los pacientes con apnea obstructiva de sueño y determinación de dichos biomarcadores. Los datos se presentan como medias y desviación estándar. La asociación entre variables se estudió mediante coeficiente de correlación de Pearson. Resultados: Se incluyeron 40 pacientes en el estudio. La edad promedio fue de $47.7 \pm 11.1$ años y el índice de masa corporal de $37 \pm 7.1$ $\mathrm{kg} / \mathrm{m}^{2} .33(82.5 \%)$ tenían SAOS grave, 5 $(12.5 \%)$ moderado y 2 (5\%) leve. No se observó correlación significativa entre el RDW, GGT ni el ácido úrico con el IAH; aunque sí mostraron tendencia. Se observó correlación negativa entre la saturación mínima durante el estudio de sueño $\left(\mathrm{SO}_{2} \mathrm{~min}\right)$ y el IAH $(r=0.68, p<0.01)$. Conclusiones: La $\mathrm{SO}_{2}$ min se asocia con la gravedad del SAOS. Otros biomarcadores no mostraron relación con la gravedad de la enfermedad; sin embargo, el número limitado de pacientes no permite generalizar los resultados de este estudio.

\section{0}

\section{Asociación y evaluación de los costos de los días de estancia hospitalaria entre pacientes con y sin enfermedad periodontal del INER}

Martínez BD, Guzmán B, Olmedo T, Rosas F, González C, García-Sancho F, Fernández $P$

INER Ismael Cosío Villegas, InCAN

Introducción: La enfermedad periodontal (EP) ocasiona graves problemas de salud a nivel respiratorio y sistémicas. En México, son pocos los estudios realizados sobre el tema y se desconoce hasta dónde puede afectar la EP en la recuperación de pacientes con afección respiratoria. El Instituto Nacional de Enfermedades Respiratorias (INER) cuenta con un Servicio de Estomatología que apoya con interconsultas; sin embargo, no se contaba con información sobre la estancia hospitalaria de aquellos pacientes que presentan alguna EP grave en comparación con aquellos que no la presentan. Objetivo: Evaluar los costos de los días de estancia hospitalaria entre pacientes con y sin EP grave y su asociación. Hipótesis: Los pacientes con EP grave permanecen más días hospitalizados en comparación con los que no la presentan e incrementa los costos de hospitalización. Metodología: Estudio de casos y controles. Pacientes hospitalizados del INER de enero a diciembre de 2011. Se incluyó a hombres y mujeres $>17$ años, como EP se consideró a pacientes con gingivitis grave, caries, fractura o edentules total. Se excluyó a pacientes intubados. A través del área de Bioestadística se obtuvieron los días de estancia hospitalaria; y los costos de hospitalización de la Unidad de Costos del INER; se sacaron medianas y se realizaron modelos binomial negativa obteniendo razón de tasas de incidencia (RTI). Resultados: Se incluyeron 2,551 controles y 845 con EP. Se clasificó por las siguientes enfermedades con su respectiva RTI: VIH (1.6), tumores (1.5), influenza (2.0), tuberculosis (2.6), EPOC (2.6), intersticiales (1.5), pleurales (1.35), absceso del pulmón (1.8), todos significativos con valor $\mathrm{p}<.001$; la suma total de los costos por días de estancia hospitalaria adicionales por EP fue de más de 19 millones de pesos. Conclusiones: Pacientes con EP grave incrementan sus días de estancia hospitalaria, lo que genera un mayor gasto al paciente y a la institución.

31

Características clínicas de los pacientes enviados a la Clínica de Sueño del Hospital General de México

Bautista HD, Díaz R, Mares G, Septién $S$

Hospital General de México

Descripción: El síndrome de apnea obstructiva del sueño (SAOS) tiene una prevalencia estimada de 3 a $7 \%$, con predominio en el género masculino, siendo una causa 
importante de morbimortalidad. Se ha observado en diversos estudios lo heterogéneo de la población. En nuestra institución, la población tiene un bajo nivel socioeconómico y una prevalencia alta de obesidad. El objetivo es describir las características clínicas de nuestra población. Material y métodos: Estudio observacional, descriptivo, transversal. Se incluyeron a todos los pacientes referidos a la Clínica del Sueño en el período 2010-2013. Se utilizó estadística descriptiva. Resultados: Se incluyeron a 303 pacientes, el $67.4 \%$ (204) fueron mujeres. La edad promedio fue de 44.3 años \pm 12.3 y el índice de masa corporal (IMC) fue de $43.6 \pm 9 \mathrm{~kg} / \mathrm{m}^{2}$. El 60.4\% (171) presentó obesidad mórbida. Se observó somnolencia diurna excesiva en $28.6 \%$ (77). Se identificó hipoxemia en $22.2 \%$ e hipercapnia en $28.6 \%$. El $77.3 \%$ cuenta con estudio de sueño (69.4\% polisomnografía y $7.9 \%$ poligrafía respiratoria). La mayoría de los pacientes presenta SAOS grave (56.6\%). En cuanto al seguimiento de tratamiento se dispone información de 125 pacientes. De éstos, 31 pacientes cuentan con CPAP (dispositivo de presión continua de la vía aérea), teniendo apego adecuado 93.2\%. Requieren oxígeno $>15$ h/día $40 \%$ y el $28 \%$ lo utiliza como indicado. El tiempo promedio desde la sospecha hasta el diagnóstico fue de 99.3 y hasta la compra del CPAP de 269 días. Conclusiones: La prevalencia de obesidad mórbida y alteraciones en el intercambio gaseoso es alta, el tiempo transcurrido en establecer el diagnóstico y tratamiento es mayor a lo ideal. Lo anterior incrementa la morbimortalidad en nuestra población. Es necesario replantear estrategias para optimizar el diagnóstico y tratamiento.

\section{2}

\section{Factores pronósticos} independientes asociados con mortalidad en pacientes con tuberculosis multifarmacorresistente (TB-MFR) en el estado de Tabasco

\section{Salomón MMS}

Villahermosa, Tabasco
Descripción: Robledo-Pascual Julio, Tandazo-Vega, Psaltidis-López, FloresBarrientos, Hernández-Faz, RodríguezHernández, Méndez-Morales, SalazarLezama Miguel Ángel, Castellanos-Joya Martín, Romero-Pérez Raquel. Hospital Regional de Alta Especialidad "Dr. Juan Graham Casasús", Jurisdicción Sanitaria del Centro, Secretaría de Salud, Villahermosa, Tabasco; Instituto Nacional de Enfermedades Respiratorias Ismael Cosío Villegas Ciudad de México, Programa Nacional de Tuberculosis, Secretaría de Salud. Objetivos: 1) Describir datos demográficos y curso clínico, 2) factores pronósticos en pacientes con TB-MFR y que han recibido tratamiento. Material y métodos: Estudio de cohorte. Período 2009-2012. Criterios de inclusión: Diagnóstico de farmacorresistencia muestra respiratoria enviada al InDRE NOM 006 SSA22013. El Programa Nacional de Prevención y Control de TB-MFR autorizó el abasto de fármacos previo dictamen de COEFAR. Seguimiento por primer nivel de atención hasta completar tratamiento o desenlace. Resultados: 21/44 casos TB-MFR/casos con farmacorresistencia $(47.7 \%)$ que se completó la gestión de fármacos, iniciaron Tx 16 (77\% incluidos en este análisis), 3 por iniciarlo. $\mathrm{M}$ $79 \%$, F 21\% (M:F 4:1), edad $45 \pm 10$ (25-68) años, diabetes 64\%, privados de la libertad $14 \%$, VIH 0 . Resistencia HR 20\%, HRZ 20\%. Tiempos y movimientos del proceso: Sospecha fundada al Dx confirmado InDRE $0.24 \%$, dictamen COEFAR 46\%, gestión de fármacos y auditoria $10 \%$, tiempo de inicio tratamiento hasta última consulta $37 \%$, confirmación diagnóstica $86 \pm 24$ días (54-138), tiempo de seguimiento desde Dx última consulta $X=393+388$ (39-1374)d. Tratamiento estandarizado (E, Z, Lfx, Am, Pto) 29\%. D. conversión bacteriológica promedio 6 meses. RAFA grave 15\%. Abandonos 12.5\%, curación $31 . \%$, mortalidad $25 \%$. Probabilidad de supervivencia 0.61 a 338 días. Conclusiones: El tiempo de espera desde sospecha fundada a confirmación y extensión del daño pulmonar asociados, son factores pronósticos asociados a mortalidad de TB-MFR en el estado de Tabasco.
33

Efecto Macklin asociado a asma en niños: serie de casos

Hernández RJ

INER Ismael Cosío Villegas

Antecedentes: El neumomediastino (enfisema mediastínico o síndrome de Hamman) es la presencia de aire o gas dentro del mediastino. Puede ocurrir de forma primaria o secundaria En pacientes asmáticos esta complicación se considera rara, con incidencia de $0.2 \%$ a $0.3 \%$. Los síntomas incluyen disnea (71\%), dolor en cuello, sibilancias espiratorias y enfisema subcutáneo (hasta $95 \%$ de los casos). El efecto Macklin es la visualización topográfica en la tomografía axial computada de aire en las vainas perivasculares y peribronquiales, la cual se encuentra según reportes hasta en $89 \%$ de los neumomediastinos espontáneos. Puede visualizarse este mismo efecto en pacientes asmáticos y se considera que hasta el 5\% de los pacientes pediátricos ingresados por reagudizaciones asmáticas presentan neumomediastino. Material y métodos: Estudio descriptivo, retrospectivo que incluyó pacientes de 6 a 17 años de edad que acudieron al INER de enero de 2012 a enero de 2013, cuyo diagnóstico de egreso fue neumomediastino secundario a crisis asmática grave, recabándose datos demográficos, clínicos y radiológicos. Resultados: Se presentaron 3 casos con efecto Macklin demostrado por tomografía, las 3 pacientes de sexo femenino, de 12, 14 y 17 años, respectivamente, con cuadro clínico de 72 horas de evolución; los principales síntomas fueron tos disneizante, dolor en cuello y sibilancias; los hallazgos por imagen: tomografía de cuello y tórax de las 3 pacientes con enfisema subcutáneo y neumomediastino; la primer paciente no presentó neumotórax, la segunda, neumotórax bilateral y la tercera, con neumotórax izquierdo. Conclusiones: Aunque el neumomediastino es una entidad de baja incidencia en pacientes con asma, debe tenerse en cuenta en aquellos que presentan enfisema subcutánea para iniciar un abordaje de estudio e inicio 
de tratamiento inmediato, con lo que se disminuirá el riesgo de complicaciones mayores.

\section{5}

\section{Apnea obstructiva del sueño y síndrome metabólico en el Hospital General de México}

\section{Díaz RMA, Bautista H, Mares G, Septién $S$}

Hospital General de México

Descripción: El síndrome de apnea obstructiva del sueño (SAOS) es una enfermedad respiratoria crónica con una prevalencia estimada de $24 \%$ en hombres y $9 \%$ en mujeres, afectando a más de cien millones de personas alrededor del mundo. Asociada a esta enfermedad se encuentran múltiples alteraciones metabólicas, que ya sea evaluadas en conjunto como parte del síndrome metabólico (SM) o por separado (obesidad central, intolerancia a la glucosa, hipertensión arterial, hipertrigliceridemia y niveles bajos de lipoproteínas de alta densidad [HDL]), incrementan el riesgo cardiovascular, la morbilidad y mortalidad. El objetivo del estudio es describir la prevalencia del síndrome metabólico en los pacientes referidos a la Clínica de Sueño del Hospital General de México y su relación con el SAOS. Material y métodos: Estudio observacional, descriptivo, transversal. Se incluyeron a todos los pacientes referidos a nuestra unidad en el período 2010-2013. Los datos se presentan en promedio y desviación estándar. Las variables categóricas en proporciones. Se diagnóstico SM con base en los criterios actualizados de la American Heart Association y la National Cholesterol Education Program Adult Treatment Panel III (AHA/NCEP ATP III). Resultados: Se incluyeron a 303 pacientes, 99 (32.6\%) fueron hombres. La edad promedio fue de $44.3+12.3$ años, el índice de masa corporal de $43.5+9$ $\mathrm{kg} / \mathrm{m}^{2}$. El $96.8 \%$ de la población tenía diferentes grados de obesidad. El 52\% de los pacientes fueron diagnosticados con SM. La prevalencia del SM no cambió

significativamente con respecto a la gravedad de la apnea de sueño. Las diferentes variables dentro del SM (perímetro abdominal, triglicéridos, HDL y hemoglobina glucosilada) no difirieron significativamente en relación a la gravedad del SAOS. Conclusiones: La prevalencia del SM en pacientes con SAOS de nuestra institución es alta. Esto puede impactar negativamente en la sobrevida de nuestra población.

\section{6}

Estimación del perfil sociodemográfico y de funcionamiento del paciente con EPOC mediante la Clasificación Internacional del Funcionamiento, de la Discapacidad y de la Salud

\section{Martínez de León LE, Toral F, Fernández P, Hernández L, Barragán M, Galicia A}

INER Ismael Cosío Villegas

Antecedentes: La EPOC es la 4ta. causa de muerte en México. No está documentado el estado de salud y funcionamiento del enfermo con EPOC dentro las condiciones sociales y culturales de nuestro país. La Clasificación Internacional del Funcionamiento, de la Discapacidad y de la Salud (CIF), explora el estado de salud y funcionamiento. Objetivos: Determinar la deficiencia en funciones y estructuras corporales, las limitantes en actividad y participación y determinar las barreras en factores ambientales de pacientes con EPOC según el GOLD y la CIF. Material y métodos: Se aplicó por médico rehabilitador del INER el registro de identificación, servicios de salud, educación, trabajo, funciones y estructuras corporales afectadas, limitantes percibidas en actividades y participación y barreras de factores ambientales mediante la CIF y sus calificadores. Se registró el GOLD. Se aplicó estadística descriptiva. Resultados: El 44\% de 75 pacientes presentaron deficiencia grave y completa en función y estructura del sistema respiratorio y neuromusculoesquelético; además, presentaron limitación para mover objetos, caminar, desplazarse por el entorno, utilizar medios de transporte, lavarse y vestirse, adquisición de bienes y servicios, relaciones íntimas; conseguir, mantener y finalizar un trabajo para mantenerse económicamente. Fueron barreras los productos y tecnología para consumo personal en la vida diaria y movilidad, transporte personal en espacios cerrados y abiertos; productos y tecnología para el empleo y accesibilidad a áreas públicas. Esto no tuvo correlación con el estadio del GOLD. Conclusiones: Los pacientes con EPOC presentaron deficiencia en estructura y función del sistema respiratorio y neuromusculoesquelético, manifiestaron limitación en actividades de movilidad, autocuidado, vida doméstica y relaciones interpersonales. Los productos, tecnología y accesibilidad son barreras para los factores ambientales sin relacionarse con el estadio GOLD.

\section{7 \\ Coccidioidomicosis, formas inusuales de presentación}

\section{Cano Al}

IMSS, UMAE No. 34 Hospital de Cardiología Nuevo León

Descripción: La coccidioidomicosis se describió como infección fúngica desde 1900, el agente causal Coccidioides imitis es endémico en el norte de México. La presentación típica es de infección de vías respiratorias bajas y síntomas sistémicos como fiebre, artralgias, tos y dolor torácico. La radiografía de tórax puede mostrar adenomegalias hiliares, enfermerdadad fibrocavitaria y ruptura de cavidad. Presentamos tres casos con coccidioidomicosis; el primer caso corresponde a un joven de 27 años que presentó una evolución de cinco meses con fiebre, derrame pleural y pérdida de $10 \mathrm{~kg}$ de peso, se realizó TC de toracoabdominal que evidenció zonas hiperdensas con múltiples regiones quísticas en su interior en región pleural derecha infiltrando caja torácica y con invasión de glándula suprarrenal derecha, se realizó biopsia aspirativa de 
lesión torácica obteniendo diagnóstico de coccidioidomicosis. También se presenta a un masculino de 37 años que inicio con lesiones cutáneas y posteriormente tos con hemoptisis, se identificó tumor pulmonar en radiografía de tórax, por lo que se realizó broncoscopia resultando diagnóstica para coccidioidomicosis. El tercer caso corresponde a una femenina de 64 años que inició con hemiparesia fasciocorporal derecha, se realizó TAC de cráneo mostrando lesiones sugestivas de metástasis cerebral de primario desconocido, se realizó radiografía de tórax identificando nódulo pulmonar, se realizó BAAF y broncoscopia obteniendo resultado de coccidioidomicosis, se le inició tratamiento con itraconazol mostrando mejoría de alteraciones neurológicas. El norte de México es una zona endémica de coccidioidomicosis y tuberculosis; por lo que esta micosis debe de estar entre los diagnósticos diferenciales en un paciente joven con fiebre y afección pulmonar o pleural que habita en estas zonas.

\section{0}

\section{Estudio exploratorio nacional para el diagnóstico y tratamiento de la fibrosis pulmonar idiopática}

\section{Barreto RJO, Buendía R, Mejía Á, Ortiz M}

INER Ismael Cosío Villegas

Introducción: La fibrosis pulmonar idiopática (FPI) es una enfermedad crónica, progresiva y letal, con elevada mortalidad (50\% a 3 años postdiagnóstico). La FPI es provocada probablemente por la convergencia de factores genéticos y ambientales, aunque éstos no se conocen con precisión. A la fecha, no se cuenta con ningún tratamiento efectivo. Metodología: Se aplicó una encuesta en septiembrenoviembre 2013 vía Internet y presencial a 419 neumólogos de México, para conocer la facilidad de realizar diagnóstico y el tratamiento que utilizan en FPI. Resultados: Respondieron 103 neumólogos de diferentes estados de la república. En 5 estados no diagnostican FPI y en el resto diagnostican 1 a 12 casos/año. Los centros de referencia que identifican son: INER 90\%, Hospital General 5\%, y CEPREP en Monterrey 5\%. El tiempo promedio de envío a centros de referencia en México fue de 2 años. La disponibilidad de tomografía de alta resolución para diagnóstico en sus sitios de atención, el $87 \%$ dispone de este estudio. Disponibilidad de radiólogo experto en enfermedades intersticiales sólo el $44 \%$ cuenta con él. En relación al tratamiento inicial 92\% de los neumólogos encuestados utiliza prednisona, $37 \%$ azatioprina, $42 \% \mathrm{~N}$-acetil-cisteína (NAC). La combinación más utilizada es de estos 3 medicamentos. Este estudio presenta algunas limitaciones, en especial la representatividad de la realidad nacional neumológica en la muestra de encuestados. Conclusiones: Existe un retraso importante en el envío de pacientes a los centros de referencia, por lo que la educación médica continua para hacer diagnóstico temprano es de vital importancia. Es necesario reforzar y unificar el conocimiento en relación con el manejo terapéutico, ya que el mayor porcentaje de neumólogos manifestó haber usado prednisona como tratamiento único o la triple combinación, lo que actualmente está contraindicado. Proponemos crear el Registro Nacional de FPI para conocer de manera confiable la incidencia de la enfermedad.

\section{6}

\section{Somnolencia diurna} excesiva y su relación con la apnea obstructiva del

\section{sueño}

Díaz RMA, Mares G, Bautista H, Septién $S$ Hospital General de México "Dr. Eduardo
Liceaga"

Descripción: La apnea obstructiva del sueño (AOS) es un problema de salud pública en nuestro país. Un síntoma característico es la somnolencia diurna excesiva (SDE). Una de las escalas más utilizadas a nivel mundial para medir somnolencia es la escala de somnolencia de Epworth (ESE). Se define como SDE a un puntaje en la ESE $>12$. A menudo se confunde esta escala como predictor clínico del síndrome de apnea obstructiva del sueño (SAOS). El objetivo del estudio es evaluar la asociación entre SDE y la gravedad del SAOS, así como describir su impacto en dicha población. Material y métodos: Estudio observacional, descriptivo, transversal. Se incluyeron a todos los pacientes con diagnóstico de AOS valorados en la Clínica de Sueño durante el período 2010-2013. Se aplicó un cuestionario evaluando los hábitos de sueño, mismo que contenía la ESE. Se utilizó estadística descriptiva. La relación entre variables cuantitativas se evaluó mediante coeficiente de correlación de Pearson. Se consideró significancia estadística a un valor de $\mathrm{p}<0.05$. Resultados: Se incluyeron a 220 pacientes en el estudio, $67.3 \%$ del género femenino. El $60.5 \%$ presentó AOS grave, $18.2 \%$ moderado, $14.5 \%$ leve y $6.8 \%$ ronquido habitual. El $28.6 \%$ presentó SDE por ESE. E1 79.3\% de los pacientes con SDE tenía SAOS grave. En SAOS grave, la mediana de ESE fue de 9 (rangos 0-24). Se encontró asociación estadísticamente significativa entre la ESE y el índice de apnea/hipopnea $(r=0.31)$ y correlación negativa con la saturación mínima durante el estudio de sueño $(\mathrm{r}=0.35)$ y la saturación por oximetría de pulso $(r=0.19)$. Se registraron 3 accidentes a causa de somnolencia. Conclusiones: La SDE es común en la AOS grave; sin embargo, su correlación con la gravedad de la enfermedad es débil. Un bajo nivel o alto en la ESE no es predictor de la enfermedad.

\section{7}

Hipoplasia pulmonar: serie de tres casos

\section{Hernández ZJA}

INER Ismael Cosío Villegas

Descripción: Se presenta una serie de tres casos de pacientes pediátricos con diagnóstico de hipoplasia pulmonar en el Instituto Nacional de Enfermedades Respiratorias (INER) del 2011 al 2013. 
En todos los casos se presentó una radiografía de tórax anormal y clínicamente con antecedentes respiratorios como dificultad respiratoria o infecciones de vías aéreas inferiores. Se presentan los casos para describir las diferentes presentaciones clínicas que puede tener esta patología y las distintas sospechas diagnósticas previas al diagnóstico final. Antecedentes: Se define como hipoplasia pulmonar a la presencia de bronquios poco desarrollados con una variable cantidad de parénquima pulmonar, presenta arteria pulmonar hipoplásica. Existe una disminución del número y del tamaño de los alvéolos. Esta anomalía puede ser unilateral o bilateral y primaria o secundaria (la más frecuente). En función de la cantidad de parénquima pulmonar, un recién nacido puede presentar dificultad respiratoria desde el nacimiento o no. Material y métodos: Se hizo una revisión en el Servicio de Neumología Pediátrica del INER del 2011 al 2013 de pacientes que fueron ingresados al servicio con sospecha de malformación congénita broncopulmonar y se haya llegado al diagnóstico de hipoplasia pulmonar. Resultados: Caso más representativo (Caso 1): Paciente de 10 meses de edad, permaneció internado al nacimiento por 72 horas por problemas respiratorios no especificados. Contaba con dos internamientos más: 15 días después del primero, durante 48 horas, por cianosis generalizada desencadenada por llanto y episodios de regurgitación. Se diagnosticó ERGE. Siguiente a los 4 meses de edad, durante 24 horas, debido a dificultad respiratoria. Refirió polipnea desde los tres meses de edad, exacerbada con llanto y a la alimentación, así como cianosis. Conclusiones: En la hipoplasia pulmonar secundaria (la más frecuente) se han descrito un amplio espectro de anomalías asociadas que posiblemente están implicadas en su patogenia, tales como un espacio torácico insuficiente (hernia diafragmática, oligohidramnios), enfermedades neuromusculares, malformaciones esqueléticas, neurológicas, o a nivel de la vascularización broncopulmonar. Esto, además de la diversidad de manifestaciones clínicas hace importante conocer más sobre esta patología.
48

Presentación de casos confirmados de influenza H1N1 en el Servicio de Neumopediatría del Instituto Nacional de Enfermedades Respiratorias

Chapela LSI

INER Ismael Cosío Villegas

Antecedentes: En los últimos meses la actividad por influenza se ha incrementado en México. El virus prediminante en esta temporada hasta ahora, es la influenza $\mathrm{A}(\mathrm{H} 1 \mathrm{~N} 1)$, el causante de la pendemia del 2009. Adultos jóvenes y de mediana edad, mujeres embarazadas, niños menores de dos años y personas con comorbilidades como obesidad, pueden encontrarse en riesgo de presentar complicaciones severas y muerte. Material y métodos: Se realizó un estudio descriptivo, retrospectivo, incluyó pacientes de hasta 15 años hospitalizados en el Servicio de Neumología Pediátrica desde octubre de 2013 hasta enero de 2014, en los cuales se confirmó mediante PCR en exudado nasofaríngeo la infección por influenza AH1N1, se recabaron datos demográficos, clínicos y radiológicos. Resultados: Se presentan 6 casos. 2 mujeres y 4 hombres, con edades de 2 a 14 años (promedio de 6.5 años), con síntomas de 2 a 7 días de evolución, caracterizado por síntomas gripales, malestar general, fiebre de $38.6-40{ }^{\circ} \mathrm{C}$ y dificultad respiratoria. Un caso presentó síntomas gastrointestinales y 2 casos cefalea. Ninguno de los pacientes estaba vacunado contra influenza. Un caso presentó CPK elevada. 2 pacientes tuvieron leucocitosis y uno leucopenia. Todos presentaron neutrofilia. En dos casos se encontró patrón radiológico de llenado alveolar con focos múltiples, en el resto se encontró patrón reticular y de llenado alveolar. Como comorbilidades, 3 pacientes tenían obesidad, 2 desnutrición, 2 reflujo gastroesofáfico, 1 hipotiroidismo congénito, 2 retraso global en el neurode- sarrollo y 4 neumopatía crónica. Ninguno presentó neumonía complicada. No se reportaron defunciones. Dos pacientes ameritaron estancia en terapia intensiva y ventilación mecánica no invasiva. Todos los casos fueron tratados con oseltamivir. El promedio de estancia hospitalaria fue de 8.6 días. Conclusiones: En el Servicio de Neumología Pediátrica del INER se ha observado un incremento en el diagnóstico de neumonía por influenza AH1N1 durante esta temporada. La propagación de este virus sugiere que, a pesar de que se encuentra presente desde 2009, la inmunidad de la población no es suficiente y muchas personas continúan siendo susceptibles, probablemente por tratarse de personas previamente sanas no vacunadas o por disminución de la inmunidad adquirida por una infección previa. A pesar de las recomendaciones, gran parte de esta población no cuenta con vacunación anual contra la influenza, por lo que es importante hacer énfasis en la vacunación de la población en riesgo, con atención especial en las personas con comorbilidades.

\section{0 \\ Valores gasométricos en población adulta en una altitud de 1570 MSNM}

Hernández GD, Fernández-Figueroa NF, Loeza-Irigoyen J, Sánchez-Llamas $F$, Mendoza-Topete $L A$

Centro Médico Nacional de Occidente, Guadalajara, Jalisco

Descripción: Aunque se conocen los valores $\mathrm{paCO}_{2}$ y $\mathrm{paO}_{2}$ a diferentes altitudes por trabajos en los que se realizó el cálculo de éstos a partir de modelos teóricos, es deseable la medición arterial directa en sujetos a diversas altitudes. Se presentan los valores obtenidos en el Laboratorio de Fisiología Pulmonar ubicado en la Ciudad de Guadalajara, Jalisco, a 1,570 MSNM. Resultados: Se incluyeron un total de 287 pacientes que acudieron al Servicio de Fisiología Pulmonar del período del 1 enero al 31 de diciembre de 2012. 47\% hombres con una media de edad de 66 años (53-80), la 
mediana encontrada para el valor de $\mathrm{pH}$ fue de 7.42 DE 0.003 (IC 7.41-7.43), para $\mathrm{pCO}_{2} 35.4$ mmHg DE .55 (IC 33.4-36.5); para $\mathrm{pO}_{2} 69.35 \mathrm{mmHg}$ DE 1.34 (IC 66.7072.00), $\mathrm{HCO}_{3} 22.59 \mathrm{mEq} \mathrm{DE} .26$ (IC 22.07-23.11), exceso de base $2.6 \mathrm{mEq} \mathrm{DE}$ 4.2 (IC 0-5), saturación de oxígeno 95.2\% DE 7.08 (IC 89.3-99.2), con una media de fracción de carboxihemoglobina de 1.3 DE 0.9 (IC 0.3-2.5), una fracción de metahemoglobina de 0.27 DE 0.7 (IC $0.1-0.4)$ y un contenido arterial de $\mathrm{O} 2$ 18.7 DE 3.12 (IC 12.7 -23.1).

\section{1}

\section{Extracción broncoscópica} de cuerpos extraños: 23

\section{casos}

\section{Hernández GD, Sánchez-Llamas $F$, Fernández- Figueroa F, Mendoza- Topete LA, Santoyo-Ayala R, Loeza- Irigoyen $J$}

Centro Médico Nacional de Occidente, Guadalajara, Jalisco

Descripción: Los factores de riesgo para la aspiración de cuerpo extraño son alteraciones en el estado neurológico, en el reflejo de la deglución, traumatismos, uso de sedantes y alcohol. Los síntomas pueden variar en relación con la obstrucción parcial o completa del árbol bronquial, tos intratable con o sin vómito, disnea, fiebre, sibilancias. El éxito ha sido informado de 61-96\%. Se presenta la experiencia del 2003 al 2013. Se retiraron 22 de 23 cuerpos extraños, $60 \%$ hombres, media de edad 47.9 años, los síntomas más frecuentes fueron tos, neumonías de repetición, sibilancias. El $21 \%$ aspiración accidental, $13 \%$ tenían enfermedad neurológica, $13 \%$ por intubación endotraqueal y el resto causas varias. En el 8.6\% se realizó más de un procedimiento y la máxima fue 4 broncoscopias, 8.6\% fueron extraídos por broncoscopia rígida. El retraso en el diagnóstico va de 10 h hasta 15 años. Los cuerpos con más frecuencia extraídos fueron: $34 \%$ material dental, $17 \%$ material orgánico. La localización en el $65 \%$ fue BPD. Las cánulas de plata habían sido colocadas dos años previos.
52

Principales comorbilidades de los pacientes enviados a la Clínica de Sueño del Hospital General de México

\section{Bautista HD, Mares G, Septién S, Díaz $R$}

Hospital General de México

Descripción: Se ha descrito en la literatura la relación del síndrome de apnea obstructiva del sueño (SAOS) con otras enfermedades que pueden incrementar el riesgo cardiovascular, tales como la obesidad, dislipidemia y diabetes. Esto es de gran importancia porque dichas comorbilidades impactan en la calidad de vida de los pacientes, uso de recursos de salud, respuesta al tratamiento y en la mortalidad. Objetivo: Describir las principales comorbilidades de los pacientes enviados a la Clínica del Sueño del Hospital General de México (HGM). Material y métodos: Estudio observacional, descriptivo, transversal. Se incluyeron a todos los pacientes referidos a la Clínica de Sueño del HGM en el período 2010-2013. Se utilizó media y desviación estándar, proporciones para variables categóricas. Resultados: Se incluyeron en el estudio 303 pacientes, con descripción de 22 comorbilidades. La edad promedio fue de $44.3+12.3$ años, 99 (32.6\%) fueron hombres. Cada paciente tuvo en promedio $3.3+2$ comorbilidades, con un máximo de 10 y mínimo de 1 . Las principales comorbilidades por frecuencia fueron: obesidad 96\% (291 casos, $69 \%$ del género femenino), dislipidemia $43.9 \%$ (133), hipertensión arterial sistémica $32 \%$ (97) y prediabetes $23.4 \%$ (71). Se observó somnolencia diurna excesiva en 77 (28.6\%) de los pacientes. El $20.8 \%$ (63) se diagnosticó con hipertensión pulmonar, aunque sólo 52 de ellos fue por ecocardiograma transtorácico. Conclusiones: Se encontró mayor prevalencia de las condiciones que incrementan el riesgo cardiovascular, entidades que caracterizan al síndrome metabólico, lo cual se asocia a una mayor morbimortalidad. Esto tiene como consecuencia incremento en los costos de la enfermedad para diagnóstico y tratamiento. Conocer la prevalencia de estas condiciones resulta crítico para anticipar las necesidades de la población y establecer mejores estrategias en el abordaje diagnóstico y terapéutico, sobre todo en nuestro medio.

53

Tumor primario de tráquea

Hernández GD, Loeza-Irigoyen J, Morfín-Plascencia LM, MendozaTopete LA, Fernández-Figueroa NF, Sánchez-Llamas $F$

Centro Médico Nacional de Occidente, Guadalajara, Jalisco

Descripción: Hombre de 16 años, dos años con sibilancias, tos seca, disnea y fatiga. Recibió tratamiento con esteroide inhalado y salbutamol sin mejoría. Se realizó espirometría, broncoscopia y tomografía Debido a la extensión de la enfermedad no candidato a resección quirúrgica. La biopsia informó carcinoma adenoideo quístico bien diferenciado tubular y cribiforme tipo glándula salival polipoide, CD 117 +. Comentario: La incidencia de tumores primarios de tráquea es de 0.1 por 100,000 habitantes año, por las manifestaciones pueden pasar varios años con diagnóstico de asma, y la clave del diagnóstico es la espirometría con la curva volumen tiempo típicamente aplanada y sin respuesta a broncodilatador. El crecimiento es lento y las metástasis raras, el tratamiento es quirúrgico con pronóstico a 5 años de $50 \%$ y 5 a $15 \%$ con radioterapia. El papel de quimioterapia adyuvante con imatinib cuando expresan CD117 debe estudiarse.

\section{4}

Embarazo de 33 SDG y dolor torácico súbito: Ruptura esplénica

\section{Hernández GD}

Centro Médico Nacional de Occidente, Guadalajara, Jalisco

Descripción: Mujer de 25 años de edad, primigesta, con embarazo de 32.4 SDG. 
Hace 2 años pancreatitis biliar y pseudoquiste pancreático con drenaje quirúrgico, yeyunostomía, colecistectomía y sonda endopleural. Diabetes secundaria a lesión pancreática. Con dolor súbito localizado en hemitórax izquierdo, agudizado por movimientos respiratorios e irradiación hacia brazo PA 120/70 mmHg, FC 91 lpm, FR 24 lpm. Dolor a la palpación profunda en hipocondrio derecho. Leucocitos 8200 , hemoglobina $10.3 \mathrm{~g} / \mathrm{dL}$, hematócrito $30 \%$, plaquetas 153 000, DHL 343, dímero D $4093 \mathrm{ng} / \mathrm{mL}$, fibrinógeno 507.7, troponina $\mathrm{I}<0.01$. Angiotomografía de tórax por sospecha de TEP: Colección líquida periesplénica de $6 \times 6 \mathrm{~cm}$, se realizó punción guiada por TAC, se obtuvó 160 mL de líquido hemático. Se sospechó de ruptura esplénica previa cesárea (producto único, vivo), se realizó LAPE sin encontrar colecciones. Nueva tomografía toracoabdominal contrastada con evidencia de colección en cara posterior de bazo. Es reintervenida realizando esplenectomía y drenaje sin complicaciones con evolución posquirúrgica satisfactoria. La rotura esplénica espontánea es aquella que se produce en ausencia de traumatismo mayor o enfermedad esplénica previamente diagnosticada. Su incidencia es de $0.1 \%$ a $0.5 \%$. Entre sus principales causas destacan: infecciosas, alteraciones congénitas, metabólicas o inmunitarias y neoplasias. El cuadro clínico se caracteriza por dolor abdominal súbito o insidioso en el hemiabdomen superior, acompañado de signos de irritación peritoneal e inestabilidad hemodinámica y exige un alto nivel de sospecha ante la presencia de factores de riesgo predisponentes y una clínica sugestiva. En este caso, los factores de riesgo asociados son el antecedente de cirugía abdominal en la región pancreática y sonda endopleural, incremento de la presión intrabdominal por el embarazo que predispone a traumatismos internos desapercibidos originados durante maniobras de valsalva (tos o vómito).

\section{7 \\ Evaluación de aprendizaje adquirido en el curso de educación para pacientes y familiares}

\section{en el Departamento de Rehabilitación Pulmonar del INER}

\section{Hernández LB, Toral F, Martínez de León, Barragán M, Galicia A}

INER Ismael Cosío Villegas

Antecedentes: El estilo de enseñanza usado en la rehabilitación pulmonar cambia de las lecciones docentes tradicionales a la educación en automanejo. Justificación: El proceso educativo que se recomienda actualmente es utilizar el modelo de autoconocimiento que promueve el aprendizaje. Los estudios sobre los efectos a corto y largo plazo de los programas de educación son escasos y los pocos que hay sólo se enfocan a pacientes con enfermedad pulmonar obstructiva crónica. Objetivos: Medir el aprendizaje adquirido a corto plazo, y las habilidades adquiridas a mediano plazo de pacientes y familiares que tomaron el curso de educación del Departamento de Rehabilitación Pulmonar del INER. Consensar el número de pláticas, sus contenidos y sus formatos de evaluación de cada tema. Recopilar material didáctico. Material y métodos: Se incluyeron a sujetos mayores de 18 años con diagnóstico de enfermedad respiratoria crónica y a sus familiares que concluyeron el programa de Rehabilitación Pulmonar que tomaron el curso de educación, a los cuales se les aplicó un cuestionario al inicio y al final del curso y a los tres meses; los mismos cuestionarios fueron aplicados a un grupo control. Se excluyeron sujetos con curso o cuestionarios incompletos. Resultados: El grupo con curso tuvo una mejoría del promedio inicial al final de 7.14 a 7.85 p $=0.006$, a los 3 meses, entre el examen final y la evaluación posterior promedio 8.83 con $\mathrm{p}=0.06$. El grupo control promedio 5.81,

DE 1.53 y comparado con el grupo con curso en el cuestionario final $\mathrm{p}=0.0004$. Conclusiones: El grupo que tomó el curso adquirió conocimientos y habilidades con resultados estadísticamente significativos comparados con el grupo que no lo hizo. Treinta minutos de las pláticas son un tiempo óptimo para mantener el interés de los asistentes.
59

La conversión bacteriológica de los casos con TB-MDR: una aproximación a la condición de egreso final de la cohorte 2010 en México

Salazar LMÁ, Magaña O, Romero $P$, Saavedra H, García A, Castellanos J

INER Ismael Cosío Villegas

Objetivo: Determinar la conversión bacteriológica de los casos con tuberculosis multidrogorresistente (TB-MDR) como aproximación a la condición de egreso final de la cohorte 2010 en México. Material y métodos: Se realizó un estudio descriptivo, observacional, longitudinal y retrospectivo, con los siguientes criterios de inclusión: Pacientes con diagnóstico de TB-MDR confirmado por cultivo y pruebas de susceptibilidad y que la localización anatómica fue pulmonar; todos los pacientes que iniciaron tratamiento con fármacos de segunda línea durante el 2010. Los criterios de exclusión fueron: Todos los pacientes con un diagnóstico diferente a TB-MFR; todos los pacientes que iniciaron tratamiento y que por diversas situaciones suspendieron el mismo antes del los 30 días de haber iniciado; todos los paciente con diagnóstico de TB-MDR con localización extrapulmonar. Resultados: Se estudiaron longitudinalmente a 222 pacientes con diagnóstico de TB-MDR de la forma pulmonar; de los cuales: el $7.2 \%$ (16) de los pacientes fallecieron en los primeros seis meses de tratamiento, el $3.6 \%$ (8) abandonaron el tratamiento en los primeros 6 meses y el $89.2 \%$ (198) de los casos continuaron su tratamiento. $78 \%$ (173) de casos con TB-MDR convirtieron en los primeros 6 meses de tratamiento y $13 \%$ (25) no convirtieron en este período, todos estos casos tuvieron seguimiento bacteriológico en los primeros 6 meses de tratamiento. Conclusión: El tratamiento de la TB-MDR es una intervención compleja, requiere del seguimiento bacteriológico puntal para el seguimiento y toma 
de decisiones clínico-programáticas de manera oportuna.

\section{0}

\section{Epidemiología de las} reacciones adversas a fármacos antituberculosis de segunda línea en México durante el 2010

\begin{abstract}
Salazar LMÁ, Saavedra H, Magaña O, García A, Romero P, Castellanos J
\end{abstract}

INER Ismael Cosío Villegas

Descripción: Determinar las características epidemiológicas de las reacciones adversas a fármacos antituberculosis de segunda línea, en los pacientes con tuberculosis multifarmacorresistente (TB-MFR) y extremadamente resistente (TB-XFR) durante el 2010 en México. Material y métodos: Se realizó un estudio descriptivo, observacional, transversal y retrospectivo. Se incluyeron a todos los pacientes con diagnóstico confirmado de TB-MFR y TB-XFR en México. Resultados: Se estudiaron retrospectivamente a 164 pacientes con diagnóstico de TBMDR (97\%) y de TB-XDR (3\%); de los cuales el 63\% (103) fueron del género masculino y el $37 \%$ (61) del género femenino; el promedio en edades fue de 43.2 con una DE de 15.4. Los 164 pacientes iniciaron con tratamiento estandarizado de segunda línea en un $60 \%$ y con tratamiento individualizado en un $40 \%$. Las comorbilidades más frecuentes fueron la diabetes mellitus en un $48.8 \%$, la desnutrición $28 \%$, alcoholismo $8.5 \%$, tabaquismo $3.7 \%$, usuario de drogas 3.7, insuficiencia renal crónica 2.4 y sida $1.8 \%$. El mayor porcentaje de la presencia de las RAFAs fue en los primeros 6 meses de tratamiento. Las reacciones adversas gástricas se presentaron en el $100 \%$ de los casos, depresión (31.7\%), artralgias en un $25.6 \%$ e hipoacusia en un $26.6 \%$. El $74 \%$ de las reacciones adversas se recuperaron, $26 \%$ con secuelas. Se clasificó a las RAFAs de acuerdo a la intensidad de la manifestación clínica, encontrándose que el $7 \%$ correspondían a severas, el 59\% a leves y el $34 \%$ a moderadas; de 164 pacientes incluidos en el estudio se identificaron un total de 521 RAFAS, de las cuales el promedio fue de 3.18 RAFAs por paciente. Conclusión: Es importante asegurar la prevención y tratamiento de los efectos adversos secundarios que pueden presentarse durante el tratamiento, la identificación oportuna de las RAFAs coadyuva a la adherencia terapéutica, y su mal manejo pone en riesgo la eficacia terapéutica y hasta la vida de la persona afectada por este padecimiento.

\section{1}

\section{Discinesia ciliar: Una entidad con múltiples cuadros clínicos. Reporte de casos}

\section{Villatoro ALA, Del Razo RR}

INER Ismael Cosío Villegas

Antecedentes: La discinesia ciliar primaria (DCP) es una enfermedad de la motilidad ciliar autosómica recesiva, caracterizada en su mayoría de los casos por un síndrome oto-sino-pulmonar asociado a defectos en la lateralidad en el $50 \%$ de los casos. Se estima que su incidencia es de 1:15,000 nacimientos. El cuadro clínico incluye dificultad respiratoria neonatal (80\% de los casos), pero su diagnóstico es frecuentemente retrasado pues los pacientes presentan síntomas comunes en los niños sanos como rinitis, sinusitis y tos; sin embargo, el desarrollo temprano de otitis media crónica/recurrente se da en más del $85 \%$ de los casos. Su diagnóstico se realiza mediante un análisis ultraestructural de los cilios con microscopia electrónica. Material y métodos: Se realizó un estudio descriptivo, retrospectivo, transversal incluyendo pacientes de 1 a 17 años de enero de 2012 a enero de 2014, con diagnóstico de discinesia ciliar primaria. Se recabaron datos demográficos, clínicos y radiológicos. Resultados: Se presentan 4 casos con discinesia ciliar primaria, 2 masculinos y 2 femeninos, entre los 5 y 18 años de edad. Los diagnósticos de envío fueron silbante no atópico, neumonía recurrente, sinusitis crónica y neumotórax, respectivamente; 2 pacientes mostraron en la tomografía de tórax bronquiectasias, unas cilíndricas y otras quísticas, esta última, además, con zonas de llenado alveolar bilateral, presencia de 3 bulas, engrosamiento intersticial. El paciente de 7 años con datos sólo de sinusitis. Conclusiones: La heterogeneidad de la enfermedad es dada por sus 16 mutaciones genéticas encontradas a la fecha; por lo que aunado a su baja incidencia, no se ha encontrado un tratamiento basado en evidencia, dándose hasta hoy los mismos que en la fibrosis quística. Sin embargo, consideramos que es necesario contemplar el amplio espectro clínico para orientar a su detección temprana.

62

Pacientes con tuberculosis con resistencia extendida a fármacos (TB-XDR). Serie de casos. México, 2010

Martínez MD, Castellanos J, García
A, Romero P, Saavedra H, Magaña O,
Salazar L

INER Ismael Cosío Villegas

Antecedentes: La TB-XDR es la enfermedad causada por Mycobacterium tuberculosis cuya cepa presenta resistencia simultánea in vitro al menos a la acción de isoniacida y rifampicina, adicionalmente resistencia a algún aminoglucósido y a alguna quinolona. Representa un problema de impacto potencial por su menor probabilidad de curación al estar comprometidos, tanto los fármacos antituberculosis más potentes de primera como los de segunda línea. Material y métodos: Estudio observacional, descriptivo, retrospectivo, serie de casos. Población de estudio: Pacientes con TB-XDR ingresados a tratamiento durante el año 2010. Se analizó la base de datos del Programa Nacional de Tuberculosis. Se aplicó estadística descriptiva utilizando SPSS. Resultados: Durante el 2010 fueron ingresados a tratamiento 6 pacientes con TB-XDR. El 50\% (3) de sexo masculino, la mediana de edad fue 39.5 (Rango: 17-57) años, provenientes de Colima, Distrito Federal, Hidalgo, Oaxaca, Sinaloa y Veracruz. Entre los fármacos tomados previamente, la tercera parte 
había ingerido además de fármacos de primera línea, algún aminoglucósido y la tercera parte alguna quinolona, un paciente estuvo expuesto a un solo fármaco. En las pruebas de farmacosusceptibilidad (PFS) el $83.3 \%$ (4) tuvieron resistencia a más de 7 fármacos. En los esquemas de tratamiento se indicaron más de 4 fármacos y hasta un total de 7; más del $80 \%$ de los fármacos indicados eran eficaces en más de la mitad de los pacientes, ya sea porque no los hubieran tomado previamente o porque hubieran demostrado sensibilidad en PFS. Los resultados de tratamiento: $50.0 \%$ (3) curación, $16.7 \%$ (1) término de tratamiento, $16.7 \%$ (1) abandono, $16.7 \%$ (1) fracaso. Conclusiones: Si bien, se estimó el éxito de tratamiento en $66.7 \%$ (curación mas término de tratamiento), el reto adicional es el seguimiento postratamiento hasta por cinco años para vigilar recaídas. El abandono de tratamiento debe minimizarse programáticamente y el fracaso es un riesgo latente durante y al final de tratamiento.

\section{3}

Evolución de síntomas de depresión en fumadores severos durante una intervención intensiva para dejar de fumar

\section{Urdapilleta HEC}

INER Ismael Cosío Villegas

Antecedentes: Se ha descrito que los síntomas de depresión, previos y actuales, influyen durante el proceso de dejar de fumar. Los fumadores y exfumadores tienen un $80 \%$ más de probabilidad de presentar sintomatología depresiva en comparación con no fumadores. Presentan depresión entre moderados y graves quienes tienen un alto grado de adicción a la nicotina y consumen más de 21 cigarros al día. En México, se sabe poco acerca de la influencia de los tratamientos intensivos para dejar de fumar sobre los síntomas de depresión. Esta información sería de utilidad para adecuar los tratamientos a tales padecimientos y aumentar las tasas de abstinencia y reducir el porcentaje de recaídas. Objetivo: evaluar los síntomas de depresión a corto y mediano plazo en fumadores que recibieron intervención intensiva para dejar de fumar. Instrumento: Escala de valoración para depresión de Hamilton (HAM-D). Método: Estudio de tipo experimental de series cronológicas de un solo grupo en la que participaron 78 fumadores crónicos, los cuales ingresaron a una intervención intensiva para dejar de fumar (10 sesiones grupales y 4 individuales) con seguimiento al mes a los 3 y 6 meses después de haber terminado el tratamiento. Resultados: los síntomas de depresión de los participantes disminuyeron significativamente durante la intervención intensiva y en los seguimientos respecto a la evaluación basal ( $\mathrm{p}$ $=0.027$ ). Conclusiones: La intervención intensiva sugiere ser una alternativa eficaz en el manejo de síntomas depresivos en el proceso de dejar de fumar.

\section{4 Efecto inmunorregulador
del Roflumilast} Vargas RMI

INER Ismael Cosío Villegas

Antecedentes: El roflumilast inhibe a las fosfodiesterasas 4 , produciendo un efecto antiinflamatorio y ha sido aceptado en el tratamiento de la EPOC; sin embargo, se desconoce su efecto sobre el nivel de los factores solubles que participan en la polarización de las subpoblaciones de células T CD4 y si esto podría modificar los mecanismos de inmunorregulación afectados por la enfermedad. Objetivo: Determinar si el roflumilast es capaz de modificar la concentración de citocinas y quimiocinas que participan en la polarización de células T CD4+ en pacientes con EPOC. Material y métodos: Se incluyó a 24 pacientes con diagnóstico de EPOC, según los criterios de GOLD, candidatos al tratamiento con roflumilast (bronquitis, tos y flemas, exacerbadores frecuentes). Se tomaron muestras de sangre periférica, una muestra basal y otra 8 semanas después del tratamiento. Se cuantificaron citocinas y quimiocinas en el suero por Luminex, y se cuantificaron las subpoblaciones de células TCD4 por citometría de flujo. Resultados: La edad promedio fue de $67 \pm 8$ años y todos los sujetos tuvieron una función respiratoria baja $\% \mathrm{VEF}_{1} 28$ (18-36) y \%CVF 52 (42-75). Después del tratamiento con roflumilast, los pacientes mostraron una reducción significativa de citocinas proinflamatorias (IL-1b, IL-6 e IL-17) y quimiocinas (IL-8, eotaxina, IP-10 y MCP-1). Se observó disminución de células Th17 y aumento de células Treg. Conclusiones: Con este estudio se demuestra que el roflumilast en un plazo de 8 semanas es capaz de reducir la concentración de citocinas proinflamatorias y quimiocinas (IL-8, eotaxina, IP-10 y MCP-1). Esto sugiere un cambio en el microambiente, que probablemente propicie el desarrollo de ciertos mecanismos de inmunorregulación con disminución de células Th17 y aumento de células Treg.

66

Presentación de serie de casos de tumores de tórax y mediastino más frecuentes y sus complicaciones, atendidos en el servicio de Neumología Pediátrica del Instituto Nacional de Enfermedades Respiratorias

García CER

INER Ismael Cosío Villegas

Antecedentes: En pacientes menores de 15 años los tumores pulmonares primarios son infrecuentes, generalmente los tumores son de origen mediastínico o de la pared torácica. Representan un reto diagnóstico debido a una amplia diversidad en cuanto al cuadro clínico y diagnósticos diferenciales, siendo incluso asintomáticos durante largo tiempo. Es fundamental un diagnóstico y tratamiento oportuno debido a un alto índice de mortalidad, incluso posterior al tratamiento en caso de ser de etiología maligna. Material y métodos: Se realizó un estudio descriptivo, retrospectivo, incluyó pacientes de 
1 a 15 años hospitalizados en el Servicio de Neumología Pediátrica de enero 2011 a enero 2014, cuyo diagnóstico de egreso fue tumor torácico o mediastinal (diferente estirpe histopatológica); se recabaron datos demográficos, clínicos y radiológicos. Resultados: Se presentan 5 casos de tumores torácicos o mediastinales. 3 pacientes de sexo femenino y 2 masculino; de 8 años (2), 1 año, 13 y 12 años respectivamente. Tiempo transcurrido entre el inicio de los síntomas y el diagnóstico: 10 días a 2 años; diagnósticos de referencia: secuestro pulmonar, derrame pleural paraneumónico, crisis asmática, derrame pleural, cardiomegalia. Sintomatología previa: dolor torácico, disnea, estridor. Diagnósticos finales: carcinoma epidermoide lóbulo inferior izquierdo, tumor neuroectodérmico primitivo (2), neuroblastoma, teratoma maduro. Hallazgos tomográficos: imagen hiperdensa heterogénea: posterobasal izquierda sin vaso nutricio; abarcando desde retroperitoneo involucrando mediastino y tejido óseo; abarcó $90 \%$ hemitórax derecho; ocupando hemitórax izquierdo en su totalidad; abarcó mediastino anterior, respectivamente. Se corroboró diagnóstico por patología y se enviaron al Servicio de Oncología para inicio de tratamiento. Conclusiones: Los tumores torácicos y mediastinales plantean un diagnóstico diferencial difícil, las complicaciones por un diagnóstico tardío pueden ser irreversibles, es necesaria la sensibilización del médico de primer contacto para considerarlo.

68

Identificación de micobacterias tuberculosas y no tuberculosas a partir de cultivos de serosas (pleura, peritoneo, pericardio y líquido cefalorraquídeo) por métodos bacteriológicos y de biología molecular PCR RFLP

Sánchez VT, Cicero S, Hernández S, González V

Hospital General de México
Antecedentes: La tuberculosis es un problema de salud mundial. Existe un fenómeno denominado transición epidemiológica debido al aumento de casos de tuberculosis pulmonar y extrapulmonar por micobacterias no tuberculosas (MNTB) en pacientes inmunosuprimidos. Las formas extrapulmonares son paucibacilares, por lo tanto, el diagnóstico no es fácil ni rápido, lo cual es crucial para la adopción de terapia específica. Existen diferentes métodos directos e indirectos empleados para establecer el diagnóstico de tuberculosis. Uno de ellos es la reacción en cadena de la polimerasa PCR RFLP para la identificación específica de micobacterias. Material y métodos: El objetivo fue identificar los agentes causales de casos de tuberculosis en serosas (pleural, peritoneal, pericárdica y meníngea) mediante técnicas convencionales (cultivo LJ) y método de PCR-RFLP. Se realizó un estudio observacional, prospectivo, transversal, descriptivo, incluyendo pacientes con sospecha clínica de tuberculosis en serosas con ADA mayor al límite inferior normal y con cultivo Lowestein Jensen positivo. Se realizó PCR RFLP para identificar el tipo de micobacteria. Resultados: Se realizó regresión logística encontrando que en el total de los pacientes $(n=23)$, los factores asociados a tuberculosis en serosas fueron infección por VIH y diabetes mellitus. No se encontró aumento en incidencia en tuberculosis en serosas por micobacterias no tuberculosas. Conclusiones: Hay aumento en incidencia de tuberculosis en serosas en pacientes inmunosuprimidos, no sólo por infección por VIH sino por otras patologías como diabetes mellitus o enfermedades reumatológicas. Es importante encontrar los hallazgos clínicos y bacteriológicos que nos orienten para el diagnóstico oportuno e inicio de tratamiento adecuado ante la sospecha diagnóstica. Se plantea la realización de score diagnóstico clínico para inicio de tratamiento temprano de tuberculosis en serosas.

\section{1}

Reconstrucción de la pared torácica con equipo Stracos en Chihuahua

\section{González CLF}

Descripción: La reconstrucción de la caja torácica en trauma y en procedimientos de resección de amplios segmentos de la caja torácica se ha facilitado con el advenimiento de nuevos materiales de osteosíntesis. En este estudio se describe nuestra experiencia con el sistema Stracos. Estudio descriptivo de un grupo de casos durante un año en la Ciudad de Chihuahua. Se utilizó el sistema de osteosíntesis Stracos (MedXpert GMBH). Fueron incluidos todos los pacientes atendidos por los autores en su práctica quirúrgica en hospitales privados y públicos. En los cuales se realizaron amplias resecciones de pared torácica, corrección de deformidades congénitas, así como con trauma torácico. Se recabaron los datos de expedientes médicos, los resultados se muestran en cifras de porcentaje y promedio. En el estudio se incluyó un total de 31 pacientes con una distribución de 10 mujeres y 21 hombres, con un promedio de edad de 42.3 años y una relación mujer: hombre de 3.2. Con una edad mínima de 5 años y una edad máxima de 85 años. Con un promedio de 5.3 placas por paciente. En 4 pacientes se realizaron resecciones amplias de pared torácica por padecimientos oncológicos. Un paciente con malformación esternal y 26 pacientes se sometieron a fijación costal por trauma. Con una permanencia promedio de las sondas endopleurales de 4 días (Cardia Spiral Drain). Sólo un paciente desarrolló celulitis de sitio quirúrgico sin necesidad de retiro de material de osteosíntesis. Solamente en los pacientes de hospitales privados se aplicó catéter epidural para control del dolor posquirúrgico. Conclusión: En nuestros pacientes, el sistema Stracos fue útil en los casos complejos de reconstrucción de la caja torácica y en trauma, con buenos resultados y mínimas complicaciones. Sin embargo, el costo puede ser una dificultad para su uso.

76

Alelos de HLA clase I se
asocian a susceptibilidad y
protección a la influenza A
H1N1


Falfán VR, Reséndiz H, Camarena O, Narayanankutty, Pérez $R$, Ramírez $V$, Vargas $R$

INER Ismael Cosío Villegas

Antecedentes: La influenza AH1N1/ pdm09, tuvo repercusiones globales tanto a la salud como a la economía; si bien, se consideró pandemia en comparación con la influenza «española», la tasa de mortalidad fue menor. Previamente hemos reportado la existencia de factores genéticos asociados a la gravedad de la enfermedad; sin embargo, no se han descrito aquellos relacionados al sistema HLA, que por su condición de presentación de antígenos representan un candidato obligado al evaluar su participación en términos de su extensa variabilidad. Material y métodos: Se incluyeron 138 pacientes con influenza ([INF-P] dx. positivo virus AH1N1/pdm09) y 225 contactos sanos, asintomáticos, intradomiciliarios no relacionados biológicamente. Se determinó HLA clase I, (-A, -B y -C) por secuenciación directa bidireccional. La significancia estadística fue con el cálculo de $\mathrm{p}<0.05$ utilizando Epi-Info 7.0; para el análisis de haplotipos se empleó Arlequin 3.1. Resultados: Siete alelos fueron asociados a susceptibilidad $(\mathrm{p}<0.05$; OR $=1.84$ 9.98): HLA-C*07:02:01, -B*39:06:02, $-C * 03: 02: 01,-B * 44: 03: 01,-B * 51: 01: 05$ $-C * 03: 01: 01$ y $B * 73: 01: 01$. Por otro lado, siete alelos se asocian a protección: HLA-C*03:03:01, -A*11:01:01, -B*39:01:01, -A*24:02:01, -C*03:04:01, $-\mathrm{B}^{*}$ 51:01:01, and $-\mathrm{C}^{*} 07: 01: 01$ ( $\mathrm{p}<$ $0.05 ;$ OR $=0.02-0.48)$, tabla 1 . En el análisis de haplotipos encontramos que HLA-A*68:01:02-C*07:02:01 se encuentra fuertemente asociado a la susceptibilidad a la infección ( $\mathrm{p}=$ 2.78E-05; OR = 23.99). Mientras que

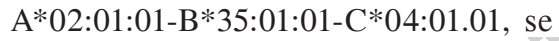
encontró significativamente disminuido en los pacientes en comparación con los contactos sanos $(\mathrm{p}=3.35 \mathrm{E}-02 ; \mathrm{OR}=$ 0.12). Conclusiones: Estos resultados sugieren la existencia de alelos y haplotipos involucrados en mecanismos de susceptibilidad y/o protección ante la infección por virus influenza AH1N1 en mestizos mexicanos (tabla 1).
Resumen 76

Tabla 1

\begin{tabular}{lcl}
\hline HLA & $p$ & OR \\
\hline$A^{*} 24: 02: 01$ & $7.69 E-05$ & 0.36 \\
$A^{*} 11: 01: 01$ & $3.35 E-02$ & 0.12 \\
$B^{\star} 39: 06: 02$ & $3.61 E-02$ & 2.53 \\
$B^{\star} 51: 01: 05$ & $3.99 E-03$ & 6.18 \\
$B^{\star} 44: 03: 01$ & $6.61 E-03$ & 5.6 \\
$B^{\star} 51: 01: 01$ & $3.39 E-02$ & 0.42 \\
$B^{\star} 73: 01: 01$ & $1.38 E-02$ & 9.98 \\
$B^{*} 39: 01: 01$ & $3.33 E-04$ & 0.17 \\
$C^{*} 07: 02: 01$ & $2.93 E-03$ & 1.84 \\
$C^{*} 07: 01: 01$ & $3.22 E-02$ & 0.48 \\
$C^{\star} 03: 04: 01$ & $4.19 E-03$ & 0.38 \\
$C^{*} 03: 02: 01$ & $4.12 E-02$ & 3.35 \\
$C^{*} 03: 01: 01$ & $3.19 E-02$ & $\mathbf{8 . 2 8}$ \\
$C^{*} 03: 03: 01$ & $8.62 E-03$ & 0.02 \\
\hline
\end{tabular}

Sólo se muestran los alelos encontrados con asociación significativa.

\section{7}

\section{Cumplimiento y efectos} adversos de CPAP

a presiones altas en pacientes con síndrome de apnea obstructiva de sueño e hipoventilaciónobesidad

Orozco GBN, Galicia P, López E, Carrillo A, Torres F, Torre-Bouscoulet, Castorena $M$

INER Ismael Cosío Villegas

Introducción: El tratamiento de la apnea obstructiva de sueño (SAOS) es la presión positiva en la vía aérea (CPAP). Las guías de la Academia Americana de Sueño recomiendan que al alcanzar $15 \mathrm{cmH}_{2} \mathrm{O}$ se cambie a bi-nivel para mejor tolerancia. En nuestra población muchos pacientes utilizan $\mathrm{CPAP} \geq 15 \mathrm{cmH}_{2} \mathrm{O}$, dado que el bi-nivel es más costoso y ellos tienen que comprarlo. El objetivo del estudio fue demostrar que las altas presiones son toleradas, con buen apego, mejoría de los síntomas y escasos efectos adversos. Material y métodos: Estudio retrospectivo, descriptivo de la base de datos de la clínica de CPAP del INER, en el que se estudiaron pacientes $>12$ años con SAOS e hipoventilación-obesidad y se compararon variables entre los pacientes que utilizan CPAP $<15$ y $\geq 15 \mathrm{cmH}_{2} \mathrm{O}$. Las diferencias entre ambos grupos se analizaron con $\chi^{2}$; y para medir las diferencias al inicio y a los 30 días de uso de CPAP se utilizó $\mathrm{T}$ student pareada. Resultados: Fueron 2,202 pacientes ( $67 \%$ hombres) con edad media de 49 años, IMC medio de 35.8 $\mathrm{kg} / \mathrm{m}^{2}$, Epworth basal de 13, con IAH medio de 60 eventos por hora y saturación promedio de $83 \%$. El $20 \%$ tenía presión prescrita $\geq 15 \mathrm{cmH}_{2} \mathrm{O}$. No hubo diferencias al comparar IMC, perímetro de cuello, IAH, saturación promedio y Epworth entre ambos grupos al inicio del tratamiento ( $\mathrm{p}<0.001)$. No hubo diferencias a los 30 días al comparar el cumplimiento en días de uso. Los pacientes con presión alta utilizaron más horas el CPAP y se quejaron de menos efectos adversos ( $p$ $<0.001$ ). Conclusión: Los pacientes que usan presión $\geq 15 \mathrm{cmH}_{2} \mathrm{O}$ mejoran sus síntomas, se quejan menos de efectos adversos, tienen buena tolerancia y apego a CPAP al compararlos con los que usan presiones menores. Por lo cual, subir la presión por $\geq 15 \mathrm{cmH}_{2} \mathrm{O}$ no debe ser una contraindicación del uso de CPAP.

78

\section{Variantes tipo SNP en genes HSP y su asociación con EPOC secundaria a tabaquismo}

Ambrocio OE, Vargas $R$, Falfán $V$, Ramírez V, Espinosa de los M, Camarena $O$

INER Ismael Cosío Villegas

Antecedentes: La EPOC se caracteriza por la obstrucción persistente del flujo de aire, usualmente es progresiva y asociada a una respuesta inflamatoria crónica alterada en las vías respiratorias y los pulmones debido a la presencia de partículas toxicas. La exposición al humo de tabaco y la presencia de SNPs en genes reguladores de la inflamación y proteínas de mantenimiento han dado pie a numerosas hipótesis sobre el desarrollo de la enfermedad, debido a que actúan como factores que alteran la susceptibilidad a padecerla. Las proteínas de choque térmico (HSP), están encargadas de regular la respuesta 
inmunológica, así como en la regulación de eventos estresantes para la célula. Métodos: Se incluyeron 376 pacientes con EPOC secundaria a tabaquismo (EPtab) y 376 fumadores sin EPOC (FSE). La discriminación alélica se realizó mediante PCR tiempo real usando sondas comerciales taqman para polimorfismos en genes HSPA1. El análisis estadístico se realizó con el programa Epi Info 6.0 Resultados: Se identificó que los genotipos CC del rs562047 y CG rs17856061 del gen HSPA1A y TT del rs2227956 del gen HSPA1L están asociados como un factor de riesgo para desarrollar EPOC. Mientras que los genotipos GG del rs562047 y GG rs17856061 del gen HSPA1A y TC del rs2227956 del gen HSPA1L están asociados como factores de protección a la enfermedad. Conclusiones: Los polimorfismos en los genes HSP pueden estar asociados al desarrollo de EPOC, algunos como factores de riesgo y otros como factores de protección para desarrollar la enfermedad.

\section{9}

Manejo del paciente con diagnóstico de VIH con presencia de SIRA severo manejado con ventilación mecánica no invasiva en el área de terapia intensiva respiratoria del INER de 1 de junio a 30 de noviembre de 2013

\section{Escobar PMA}

INER Ismael Cosío Villegas

Introducción: La atención de los pacientes con VIH en áreas de UCI van en aumento. La indicación más frecuente de ingreso son las infecciones respiratorias destacando neumonías principalmente por $P$. jirovecci, tuberculosis pulmonar, micobacterias atípicas. El paciente que desarrolla como complicación SIRA requerirá soporte con ventilación mecánica, la modalidad invasiva se ha asociado a múltiples complicaciones como neumotórax e infecciones nosocomiales por Pseudomona aeruginosa y S. aureus. Un paciente con VMI aumenta por día 4-7\% riesgo de neumonía nosocomial. Basado en lo anterior la VMNI pudiera ser una buena opción de apoyo respiratorio en el contexto del paciente con Sida y que desarrolle SIRA. Material y métodos: Pacientes que ingresaron al área de terapia respiratoria con $\mathrm{dx}$. de Sida y presencia de SIRA severo con estabilidad hemodinámica. Fueron 5 pacientes manejados con la opción de VMNI que ingresaron a UCI con presencia de SIRA severo. Resultados: El $100 \%$ de los pacientes fueron del género masculino. Se encontraban en estadio C3. Presentaban un conteo promedio de CD4 de 59.2 La conmorbilidad asociada más importante fue infección por CMV, seguida de PCP. Presentaba un score APACHE II promedio de 12.4 pts y un SOFA de 6.2 El promedio de días de uso de VM, 7.8 días. Los días de estancia en UCI promedio fue de 11.8 La mortalidad se presentó en un 20\%. Conclusión: No existen estudios de este tipo en pacientes con VIH; sin embargo, los resultados sugieren que la VMNI puede ser una herramienta importante en tratamiento de pacientes con VIH y SIRA en casos debidamente seleccionados, con estado neurológico conservado y adecuado grado de colaboración.

\section{0}

\section{Curva ROC, valor} predictivo, razones de verosimilitud y correlación de linfocitos y adenosindesaminasa (ADA) en líquido pleural para el diagnóstico de tuberculosis pleural

Manuel-Orozco M, Tandazo-Vega SG, de la Cruz-Hernández I, PsaltidisLópez A, Esquivel JF, Bañales JL, Salazar-Lezama MÁ, RobledoPascual JC

INER Ismael Cosío Villegas, Hospital Regional de Alta Especialidad "Dr. Juan Graham Casasús"
Antecedente: La tuberculosis pulmonar en Tabasco es 23.6/100,000 habitantes, la forma pleural representa un problema diagnóstico. Objetivo: 1) evaluar sensibilidad (S), especificidad (E), valores predictivos (VP), razón de verosimilitud positiva (RV), momios preprueba y posprueba de mononucleares-ADA; 2) construir curva ROC-AUC de mononucleares-ADA; 3) encontrar la correlación entre los niveles de mononucleares-ADA. Métodos: Estudio tipo utilidad de una prueba diagnóstica, período enero 2006-enero 2013. Pacientes hospitalizados, Edad $>18$ años, estudio de derrame pleural, exudado linfocítico (>30\%), para determinación de mononucleares y simultáneamente niveles de ADA por método de liberación de amonio (un solo laboratorio). Estándar de oro: constructo (datos clínicos, radiografía, cultivo, biopsia pleural y respuesta terapéutica a los dos meses con HRZE. Los evaluadores estuvieron cegados e independientes al diagnóstico. Dictamen diagnóstico: evaluador experto. Estadística: coeficiente de correlación de Pearson. Curva ROC (sensibilidad-falsos positivos), se calculó AUC. Resultados: $\mathrm{N}=40$; masculino $77.5 \%$, femenino $22.5 \%$, combe positivo 15\%. Prevalencia Tb pleural 67.5\%. Edad $41+21$ años, tiempo de inicio mediana 30 días. ADA (>70) 72.5\%, mononucleares $60+33$ mediana de 75 (0-98), ADA 82.5 +40 (12-200). ADA S = 100\%, $\mathrm{E}=84 \%$, la curva ROC ADA mostró un AUC = 0.93 IC de $95 \%$ (0.83-1.0), el punto de corte para nuestro grupo fue 78 ( $\mathrm{S}=96 \%$ y $15.4 \%$ falsos positivos). Mononucleares AUC 0.54 con IC de 95\% (0.36-0.73) el punto de corte de 75 que es para este estudio $\mathrm{S}=51 \%$ y falsos positivos de $38.5 \%, \mathrm{E}=30 \%$, no hubo cambios con cortes de 50 y 30. Se calculó RV ADA $=6.49$; probabilidad preprueba $=0.38$; momios postprueba $=2.0$, probabilidad postprueba $=0.66$. Para el conteo de linfocitos $R V=1$, con un momio postprueba de 0.38 y una probabilidad de 0.5. La correlación entre ADA y mononucleares $\mathrm{rp}=0.058, \mathrm{rs}=0.052$. Conclusión: En un estado con prevalencia alta de tuberculosis, la determinación de ADA ofrece una mayor rentabilidad que la cuenta de mononucleares en el diagnóstico de la tuberculosis pleural. 
81

\section{Registro estatal de} hipertensión pulmonar (HP) en Tabasco

\section{Manuel-Orozco M, del Prado-Piña M, Tandazo-Vega S, Reyna-Cuevas $V$, Toledo-Ocampo E, Psaltidis-López A, Robledo-Pascual J}

INER Ismael Cosío Villegas, Hospital Regional de Alta Especialidad "Dr. Juan Graham Casasús"

Introducción: No existe un registro de estos casos en Tabasco. Objetivo: Describir los tipos, clasificación, clase funcional, datos demográficos, ecocardiográficos, tipo de tratamiento de los pacientes con diagnóstico de HAP en los hospitales de referencia de Tabasco. Métodos: Cohorte. Criterios de inclusión, pacientes de todas las edades que tienen diagnóstico de HAP a través de ecocardiografía transtorácica. Variables demográficas, ecocardiográficas, tipo de fármacos utilizados, tiempo de evolución y seguimiento hasta la última consulta o desenlace. Análisis estadístico: global y estratificado por subgrupos de acuerdo a clasificación de Dana. Resultados: 105 pacientes, F: 79.2\%, M: 20.8\%; edad $47 \pm 17$ (17-83), T. evolución mediana 24 (2-132) meses. Disnea WHO clase II $66.7 \%$ y III $33.3 \%$; NYHA-HAP clase funcional II $66.7 \%$, III $25.0 \%$ y IV $8.3 \%$. Clasificación: hipertensión arterial pulmonar $50 \%$, cardíacas $20.6 \%$, pulmonares $20.6 \%$, origen tromboembólico $5.6 \%$ y multifactorial $2.9 \%$. Congénitos: pretricuspídeos $60 \%$, postricuspídeos $20 \%$, cardiopatía compleja 20\%. Clasificación anatomofuncional de los congénitos: Eisenmenger $36.4 \%$, HAP cortosistémico por defectos moderados-grandes $36.4 \%$, HAP por defectos pequeños $27.3 \%$. De causas cardíacas poscapilar: disfunción sistólica $28.6 \%$ y valvulares $71.4 \%$. El síntoma predominante: fatiga $100 \%$, síncope $8.3 \%$, angina $4.2 \%$, edema de miembros inferiores $45.8 \%$. ECG: RS $95.8 \%$, sobrecarga (VD) $75 \%$. PAPS $\mathrm{X}=$ $73.6 \pm 27$ (35-130) mmHg, dilatación del VD $62.5 \%$. Tratamiento: sildenáfilo dosis subóptimas $28.5 \%$, ACO fuera de rango $14.2 \%$, oxígeno $37.5 \%$, bosentan $4.2 \%$, diurético $4.2 \%$, digoxina $8.3 \%, 2$ pacien- tes $4.2 \%$ fueron tratados con septotomía auricular, estos casos tienen seguimiento a tres y un año sin deterioro de la clase funcional. Conclusiones: La HAP parece ser más frecuente de lo reportado, predomina grupo I en clase II y requieren tratamientos orales autorizados por FDA ya que tienen un impacto sobre la clase funcional. La septostomía auricular es una alternativa que debe considerarse en casos en donde existe deterioro funcional.

\section{2}

Comorbilidades y síntomas de sueño en pacientes con síndrome de hipoventilación, obesidad, diferencias entre hombres y mujeres

\section{Orozco GBN, Valdés $H$, Torres $F$, Reyes Z, Galicia P, Carrillo A, Castorena $M$}

INER Ismael Cosío Villegas

Antecedentes: El síndrome de hipoventilación obesidad (SHO) es un padecimiento que frecuentemente se acompaña del síndrome de apnea obstructiva del sueño (SAOS), existen diferencias en el cuadro clínico del SAOS según el género, se desconoce si en el SHO existen dichas diferencias. El objetivo es comparar las comorbilidades y síntomas entre hombres y mujeres con SHO. Materiales y métodos: Revisión de expedientes de la Clínica de Sueño del INER, enero-diciembre 2013. Se incluyeron pacientes con SHO, todos contestaron cuestionarios estandarizados de comorbilidades, síntomas de sueño, ansiedad/depresión. Resultados: Se incluyeron 28 pacientes, 14 hombres y 14 mujeres. Las comorbilidades fueron: hipertensión arterial sistémica $(\mathrm{n}=$ $23,82 \%)$, cor pulmonale $(\mathrm{n}=16,70 \%)$, insuficiencia respiratoria aguda $(\mathrm{n}=10$, $43 \%)$, dislipidemia $(n=8,34 \%)$, DM2 ( $=7,30 \%)$, hiperuricemia $(\mathrm{n}=4 ; 17 \%) \mathrm{e}$ hipotiroidismo ( $\mathrm{n}=2,8 \%$ ); la DM2 fue más común en mujeres $(\mathrm{p}=0.02)$ y accidentes automovilísticos, hiperuricemia $\mathrm{y}$ cor pulmonale en hombres $(\mathrm{p}<0.05)$. El ronquido habitual fue reportado por
27 pacientes (96\%), apneas presencias $25(90 \%)$, cansancio $23(82 \%)$, siestas 20 (71\%), cefalea matutina $23(82 \%)$, ahogo nocturno 18 (78\%), insomnio $15(65 \%)$, mediana de Epworth 19 (0-24) y SACS 54 (49-66), sin diferencias por género. Los hombres presentaron mayor nivel de ansiedad HADS 11 (6-14) vs. 7 (2-12) $\mathrm{p}=0.01$. La eficiencia de sueño y N2 fueron mayores en hombres $(p<0.05)$, sin diferencias en: latencia a sueño, N1, $\mathrm{N} 3, \mathrm{R}$, índice de apnea/hipopnea, $\mathrm{SpO}_{2}$ promedio y $\mathrm{EtCO}_{2} \max$. El tratamiento más frecuente fue CPAP $(\mathrm{n}=20,86 \%)$, la presión terapéutica fue 15 (9-20); 7 pacientes presentaron apneas resistentes a tratamiento; sin diferencias por género. Conclusiones: Los hombres con SHO tienen más comorbilidades que las mujeres, no se observaron diferencias significativas en síntomas de sueño ni terapéutica.

83

Eficacia de la biopsia aspirativa con aguja fina en tumores de mediastino anterior en la UMAE, Hospital de Cardiología No. 34

\section{Galindo GLF, Montemayor Ch, Flores $G$, Molina $R$}

IMSS, Monterrey, NL. UMAE, Hospital de Cardiología No. 34, IMSS, Monterrey, NL.

Introducción: Los tumores de mediastino anterior son la cuarta causa de ingreso a nuestro servicio, el retraso en el diagnóstico empeora el pronóstico. Material y métodos: Se analizó a 36 pacientes ( $\mathrm{n}=$ 36) que ingresaron entre 2012 y 2013; 12 (33.3\%) mujeres y 24 (66.7\%) hombres con edad promedio de $46.42 \pm 20.8$ años. En 20 (55.6\%) se evidenció síndrome de vena cava superior al ingreso. La tos en 26 (72.2\%) de los casos, edema en «escalvina» en $13(36.1 \%)$, disnea en $12(33.3 \%)$ y dolor torácico en 10 (27.8\%), fueron los síntomas más frecuentes. Tan sólo 10 (27.8\%) pacientes fueron diagnosticados tras el primer abordaje invasivo, el $72.2 \%$ restante requirió un segundo procedimien- 
to. El procedimiento invasivo inicial más frecuentemente empleado fue la biopsia aspirativa con aguja fina (BAAF) en 18 $(50 \%)$, luego la videobroncoscopia en $9(25 \%)$ y la biopsia con aguja cortante (Tru-cut) a $5(13.9 \%)$ pacientes. En 2 (5.6\%) pacientes no fue posible realizar estudios por su mal estado. El diagnóstico más frecuente fue el linfoma no Hodgkin (LNH) en 11 (30.6\%), seguido del carcinoma epidermoide pulmonar y timoma, cada uno con $3(8.3 \%)$ de los casos. Tan sólo en $3 / 18(16.7 \%)$ casos, la BAAF permitió el diagnóstico. El estudio más eficaz fue la mediastinoscopia, que obtuvo muestras para diagnóstico en los 2 casos en que se realizó de primera instancia. La videobroncoscopia permitió obtener material para diagnóstico en 3/9 (33.3\%) de los casos en que se empleó como primer estudio. Cuando se realizó BAAF inicialmente a los LNH, tan sólo en $30 \%$ de los casos se obtuvo diagnóstico. Conclusión: La biopsia aspirativa con aguja fina (BAAF) no es eficaz para obtener muestras para diagnóstico en linfoma no Hodgkin, el cual representa la primera etiología de tumores de mediastino anterior en nuestro medio, causando retraso del diagnóstico, mayor necesidad de invasión, y retraso en el inicio del tratamiento.

\section{6}

\section{Prevalencia de diabetes en} pacientes con tuberculosis multifarmacorresistente (TB-MDR) en tratamiento con fármacos de segunda línea. Cohorte México, 2010

\section{Martínez MD, Castellanos JM, García $A M A$, Romero PR, Saavedra HN, Magaña OJ, Salazar L \\ INER Ismael Cosío Villegas}

Antecedentes: La tuberculosis multifarmacorresistente (TB-MDR) definida como la resistencia in vitro de la cepa de M. tuberculosis a la acción simultánea al menos de isoniacida y rifampicina, fármacos pilares en el tratamiento de esta enfermedad, presenta entre otros desafíos en el tratamiento las comorbilidades, la más frecuente en nuestro país es la diabetes mellitus. Material y métodos: Estudio observacional, descriptivo y retrospectivo, de prevalencia. Población de estudio: pacientes que ingresaron a tratamiento antituberculosis por TB-MDR durante el año 2010. Se analizó la base de datos del Programa Nacional de Tuberculosis (PNT). Se aplicó estadística descriptiva utilizando SPSS. Resultados: Durante el 2010 fueron ingresados a tratamiento 221 pacientes con TB-MDR, correspondieron a sexo masculino $64.3 \%$ (142), la edad media fue de 43.9 $(\mathrm{DE}+15.0)$ años. Las entidades federativas con mayor frecuencia fueron Veracruz, Tamaulipas y Chiapas con $13.6 \%$ (30), $10.9 \%$ (24) y $7.7 \%$ (17), respectivamente. Entre las comorbilidades $43.9 \%$ (97) presentaron diabetes, $3.6 \%$ (8) insuficiencia renal crónica, 22.2\% (49) desnutrición, 5.9\% (13) usuario de drogas inhalantes, $5.4 \%$ (12) alcoholismo, $4.5 \%$ (10) tabaquismo y $0.9 \%$ (2) VIH. Se comparó la tasa de curación de los pacientes con y sin diabetes contra el resto de las clasificaciones de egreso (defunción, abandono, fracaso y término de tratamiento), siendo de $72.2 \%$ (70) y $58.1 \%$ (72), respectivamente, esta diferencia fue estadísticamente significativa $(\mathrm{p}<0.03)$. También se comparó el éxito de tratamiento (curación y término de tratamiento) contra el resto de las clasificaciones de egreso siendo en los diabéticos de $72.2 \%$ (70) y en los no diabéticos $71.0 \%$ (88), no hubo diferencias estadísticamente significativas. Conclusiones: Los pacientes con TBMDR y diabetes representan un desafío programático y clínico para su manejo debido a la larga duración del tratamiento y las reacciones adversas a fármacos. Este estudio demuestra que si bien, el éxito de tratamiento fue similar independientemente de esta comorbilidad, probablemente el seguimiento estrecho de ambas patologías contribuya al mejor seguimiento hasta clasificarlos como curados.

\section{7 \\ Manejo de la estenosis traqueal benigna}

\section{subglótica con láser de $\mathrm{CO}_{2}$}
Narváez FS, Domínguez EMG, López de Nava $\mathrm{CH}$, Gisel $A C$

Hospital Regional de Alta Especialidad del Bajío

Antecedentes: El estándar de oro en el manejo de la estenosis traqueal benigna es la cirugía de reconstrucción. Desafortunadamente, ésta no puede ofrecerse con cierta seguridad en pacientes con estenosis subglótica debido a la falta de espacio para realizar la anastomosis. Material y métodos: Durante los últimos 12 meses se han identificado e ingresado a este protocolo, todos aquellos pacientes con estenosis traqueal benigna, con antecedente de intubación orotraqueal y de localización subglótica, que no sean candidatos a cirugía de reconstrucción. Con la utilización de un laringoscopio de suspensión, se llevo a cabo la resección (vaporización) del tejido cicatricial de la tráquea utilizando un equipo de Láser de $\mathrm{CO}_{2}$ bajo visión directa con el microscopio. Han ingresado hasta el momento un total de 7 pacientes, cuyas edades varían desde los 3 y hasta los 36 años. Todos los pacientes contaban, además de la estenosis, con cánula de traqueostomía. Durante el procedimiento se retiró la cánula y fue sustituida por un tubo recubierto anillado LaserFlex, el cual permitió ofrecer la anestesia al paciente sin que el oxígeno entrara en contacto con el rayo láser. Resultados: En 5 de los 7 pacientes se logró restablecer una luz traqueal del $90 \%$ que permitió, después de 2 meses en promedio, decanular de manera definitiva. En los 2 restantes, cuyas estenosis eran de más de $2 \mathrm{~cm}$ de longitud, nos permitió abrir el canal para colocar una cánula en "T". Conclusiones: El número de pacientes incluidos hasta el momento, no permiten una adecuada valoración de la seguridad y eficacia del procedimiento, además de que el seguimiento más largo ha sido sólo de 12 meses. Sin embargo, creemos que se trata de una alternativa eficaz para la resolución del problema que permite al paciente poder ser decanulado como principal objetivo. 